UNIVERSIDADE DE SÃO PAULO

ESCOLA DE ENFERMAGEM DE RIBEIRÃO PRETO

GISELE BRIDES PRIETO

QUALIDADE DE VIDA DE PACIENTES SUBMETIDOS À RESSECÇÃO DE TUMORES MUSCULOESQUELÉTICOS

Ribeirão Preto 


\section{QUALIDADE DE VIDA DE PACIENTES SUBMETIDOS À RESSECÇÃO DE TUMORES MUSCULOESQUELÉTICOS}

Dissertação apresentada à Escola de Enfermagem de Ribeirão Preto da Universidade de São Paulo, para obtenção do título de Mestre em Ciências, Programa Enfermagem em Saúde Pública.

Linha de Pesquisa: Processo saúde-doença e epidemiologia

Candidato: Gisele Brides Prieto

Orientador: Profa. Dra. Marysia Mara Rodrigues do Prado De Carlo

RIBEIRÃO PRETO 
Autorizo a reprodução e divulgação total ou parcial deste trabalho, por qualquer meio convencional ou eletrônico, para fins de estudo e pesquisa, desde que citada a fonte.

Prieto, Gisele Brides

QUALIDADE DE VIDA DE PACIENTES SUBMETIDOS À RESSECÇÃO DE TUMORES MUSCULOESQUELÉTICOS. Ribeirão Preto, 2013.

94 p. : il. ; $30 \mathrm{~cm}$

Dissertação de Mestrado, apresentada à Escola de Enfermagem de Ribeirão Preto/USP. Área de concentração: Enfermagem em Saúde Pública.

Orientador: De Carlo, Marysia Mara Rodrigues do Prado.

1. qualidade de vida; 2 . funcionalidade,

3. neoplasias ósseas, 4. amputação,

5. salvamento de membro 
PRIETO, Gisele Brides

QUALIDADE DE VIDA DE PACIENTES SUBMETIDOS À RESSECÇÃO DE TUMORES MUSCULOESQUELÉTICOS

Dissertação apresentada à Escola de Enfermagem de Ribeirão Preto da Universidade de São Paulo, para obtenção do título de Mestre em Ciências, Programa Enfermagem Saúde Pública.

Aprovado em ...................................

Comissão Julgadora

Prof. Dr.

Instituição:

Prof. Dr.

Instituição:

Prof. Dr.

Instituição: 


\section{Dedicatória}

Dedico este trabalho aos amores de minha vida: meus pais, Maria Célia e Luis Antonio, por tornarem possíveis todas as minhas conquistas.

À memória da minha avó "Neguinha", aos meus irmãos Daniele e Rodrigo e ao meu grande amigo, companheiro e amor Thiago, pela dedicação e apoio sempre.

Amo demais!!! 


\section{Agradecimento Especial}

Aos meus pacientes que tornaram possíveis as reflexões acerca do tema pesquisado e que permitiram que eu fizesse parte de seu universo aprendendo e caminhando junto com eles, durante suas caminhadas. 


\section{Agradecimentos}

Agradeço a Deus, por sempre estar iluminando meu caminho nesta vida.

À minha orientadora, colega de profissão e parceira Profa. Dra. Marysia Mara Rodrigues do Prado de Carlo, por acreditar na minha capacidade e me auxiliar no desenvolvimento deste estudo com suas reflexões e contribuições.

A todos os pacientes que participaram deste estudo.

À Capes por financiar esta pesquisa.

À equipe da Onco-ortopedia do HCFMRP-USP que me recebeu e me apoiou durante essa caminhada.

Ao Prof. Dr. Edgard Eduard Engel pela suas preciosas contribuições neste estudo, auxiliando nas reflexões e questionamentos.

Agradeço à minha "segunda mãe", Rosibeth Palm, grande incentivadora que mesmo longe sempre esteve perto me mostrando o quanto é importante lutarmos e acreditarmos em nosso potencial, apesar das pedras em nosso caminho.

A Marcela Bigatão pelos diversos momentos que passamos juntas - tristes e felizes, das risadas, desabafos 
durante essa experiência de vida que foi vir morar juntas longe de nossas famílias em uma cidade desconhecida, tendo sempre o apoio uma da outra, e nisso já se foram 6 anos de vida compartilhada.

Às amizades conquistadas junto ao Grupo de Terapia Ocupacional em Contexto Hospitalar- Jana com sua alegria irradiante e dedicação à vida e a Deus, Letícia pela ajuda sempre e Leila amiga de sempre.

Agradeço às amizades conquistadas na pós-graduação, em especial à Janaína Braz (gêmea), Michele Miyauti, Andreara Almeida e Camila Abrão, pelos momentos compartilhados.

Aos meus familiares e amigos que tiveram de lidar com minhas ausências em alguns momentos, sempre com muita compreensão.

À minha sogrinha amada Rosana que é uma pessoa muito especial e querida. Aos meus cunhados, Thaiz, Thadeu e Ju. Às minhas lindas e amadas sobrinhas, Bia, Bela e Gabi.

E agradeço, enfim, a todos que direta ou indiretamente compartilharam e contribuíram para o meu amadurecimento e crescimento, durante esse processo de muito aprendizado. 
"O que vale na vida não é o ponto de partida e sim a eaminhada.

Caminhando e semeando, no fim terás o que colher"

(Cora Coralina) 


\section{RESUMO}

PRIETO, G.B. Qualidade de vida de pacientes submetidos à ressecção de tumores musculoesqueléticos. 2013. 94f. Dissertação de Mestrado - Escola de Enfermagem de Ribeirão Preto, Universidade de São Paulo, Ribeirão Preto, 2013.

Este estudo avalia a qualidade de vida de sujeitos acometidos por tumores musculoesqueléticos de membros inferiores, submetidos a cirurgias de ressecção, com salvamento de membro ou amputação. A casuística foi composta por 56 sujeitos, avaliados no período de 14 meses (agosto de 2011 a setembro de 2012), que foram divididos em três grupos: 1- 12 amputados; 2- 16 em pós-operatório de salvamento do membro (colocação de endoprótese ou reconstrução biológica); 3sujeitos saudáveis (sem diagnóstico de câncer), selecionados entre a população em geral, de forma pareada com os outros grupos, segundo sexo, idade, escolaridade e condição socioeconômica. Além do Critério de Classificação Econômica Brasil (2010), foram aplicados dois protocolos de avaliação, um de qualidade de vida (Medical Outcomes Study 36 - Item Short-Form Health Survey - SF-36) e o outro de capacidade funcional (Toronto Extremity Salvage Score - TESS), ambos adaptados culturalmente e validados no Brasil. Os dados foram estatisticamente analisados, conforme preconizado por cada protocolo. Os resultados indicaram que ambos os tipos de abordagem cirúrgica (amputação ou reconstrução) produziram prejuízos na capacidade funcional e na qualidade de vida dos sujeitos acometidos por tumores musculoesqueléticos, quando comparados à população saudável. Diferentemente do que apontaram outros trabalhos internacionais com casuística semelhante, os sujeitos submetidos a amputações apresentaram resultados melhores relacionados à sua capacidade funcional e à qualidade de vida, na maioria dos domínios do SF36 e com relevância estatística $(p=0,001)$ no escore final do TESS, do que aqueles submetidos a técnicas de salvamento de membro. Por fim, é importante analisar a percepção dos sujeitos sobre sua funcionalidade e qualidade de vida, de modo a encontrar caminhos mais adequados no processo de reabilitação desta população.

DESCRITORES: qualidade de vida; funcionalidade, neoplasias ósseas, amputação, salvamento de membro. 


\begin{abstract}
PRIETO, G.B.. Quality of life of patients undergoing resection of musculoskeletal tumors 2013. 94f. Dissertação de Mestrado - Escola de Enfermagem de Ribeirão Preto, Universidade de São Paulo, Ribeirão Preto, 2013.

This study appraises the quality of life of individuals with musculoskeletal tumors in lower extremities, undergoing resection surgeries with extremity salvage or amputation. The casuistry was composed by 56 subjects assessed in the course of 14 months (from August, 2001 to September, 2012), who were divided into 3 groups: 1- 12 amputated; 2- 16 in postsurgical extremity salvage (endoprosthesis implant or biological reconstruction); 3- healthy subjects (without cancer diagnosis), selected from the whole population, paired off with other groups, according to sex, age, schooling and socioeconomic status. Besides the Critério de Classificação Econômica Brasil (2010), two assessment protocols were applied, one about quality of life (Medical Outcomes Study 36 - Item Short-Form Health Survey - SF-36), and the other one about functional capacity (Toronto Extremity Salvage Score - TESS), both culturally adapted and validated in Brazil. The data were statistically analyzed according to what each protocol proclaims. The results revealed that both surgical approach types (amputation or reconstruction) caused harm to the functional capacity and to the quality of life of the subjects suffering from musculoskeletal tumors, when compared to the healthy population. Unlike what other international papers with similar casuistry have shown, the subjects undergoing amputation presented better results related to their functional capacity and quality of life, in the majority of the domains of SF36, with statistical relevance $(p=0.001)$, than those submitted to the techniques of extremity salvage. Finally, it is important to analyze the subjects' perception on their functionality and quality of life in order to discover the most suitable ways in the process of rehabilitating this population.
\end{abstract}

DESCRIPTORS: quality of life; functionality; bone neoplasm; amputation; extremity salvage. 


\section{RESUMEN}

PRIETO, G.B. Calidad de vida de pacientes sometidos a la resección de tumores musculoesqueléticos. 2013. 94f. Dissertação de Mestrado - Escola de Enfermagem de Ribeirão Preto, Universidade de São Paulo, Ribeirão Preto, 2013.

Este estudio evalúa la calidad de vida de sujetos acometidos de tumores musculoesqueléticos de miembros inferiores, sometidos a cirugías de resección, con salvamento de extremidad o amputación. La casuística se compuso de 56 sujetos, evaluados en el periodo de 14 meses (agosto de 2011 a septiembre de 2012), que se dividieron en 3 grupos: 1- 12 amputados; 2- 16 en posoperatorio de salvamento de extremidad (colocación de endoprótesis o reconstrucción biológica); 3- sujetos saludables (sin diagnóstico de cáncer), seleccionados entre la población en general, de forma pareada con los otros grupos, según el sexo, la edad, la escolaridad y la condición socioeconómica. Además del Critério de Classificação Econômica Brasil (2010), se aplicaron dos protocolos de evaluación, uno de calidad de vida (Medical Outcomes Study 36 - Item Short-Form Health Survey - SF-36) y otro de capacidad funcional (Toronto Extremity Salvage Score - TESS), ambos adaptados culturalmente y validados en Brasil. Los datos fueron estadísticamente analizados conforme a lo que preconiza cada protocolo. Los resultados indicaron que ambos los tipos de enfoque quirúrgico (amputación o reconstrucción) produjeron daños a la capacidad funcional y a la calidad de vida de los sujetos acometidos de tumores musculoesqueléticos cuando comparados a la población saludable. Opuesto a lo que apuntaron otros trabajos internacionales con casuística similar, los sujetos sometidos a amputaciones presentaron resultados mejores en relación a su capacidad funcional y calidad de vida, en la mayoría de los dominios del SF36 y con relevancia estadística $(p=0,001)$, que aquellos sometidos a técnicas de salvamento de extremidad. Por fin, es importante analizar la percepción de los sujetos sobre su funcionalidad y calidad de vida para que se encuentren maneras más adecuadas en el proceso de rehabilitación de esta población.

DESCRIPTORES: calidad de vida; funcionalidad; neoplasias óseas; amputación; salvamento de extremidad. 
LISTA DE FIGURA

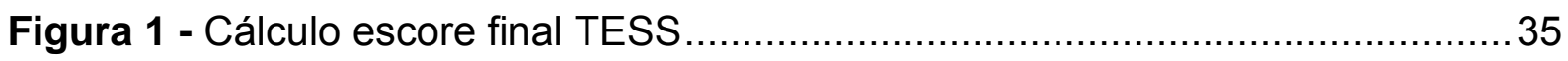




\section{LISTA DE TABELAS}

Tabela 1 - Estadiamento dos Tumores Ósseos e de Tecidos Moles de Enneking.. 21

Tabela 2 - Dados sociodemográficos da população total avaliada..................... 41

Tabela 3 - Critério de classificação econômica Brasil ..................................... 42

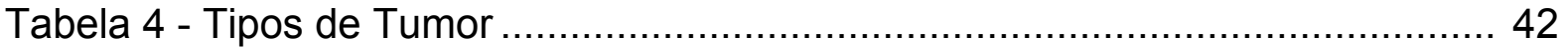

Tabela 5 - Região onde está localizado o tumor ............................................ 43

Tabela 6 - Procedimentos realizados .......................................................... 43

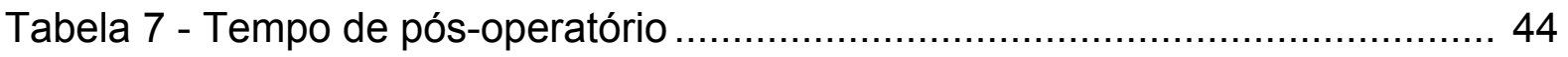

Tabela 8 - Variáveis TESS ................................................................... 45

Tabela 9 - Escore final TESS -teste de Kruskal-Wallis .................................... 46

Tabela 10 - Comparação do escore final do TESS pelo teste pos hoc DUNN ....... 46

Tabela 11 - Comparação dos dados dos grupos, referentes ao teste estatístico

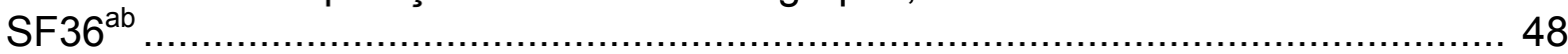

Tabela 12 - Capacidade funcional(post hoc de DUNN) ............................... 49

Tabela 13 - Aspectos fisicos (post hoc de DUNN) ......................................... 50

Tabela 14 - Aspecto emocional (post hoc de DUNN) ..................................... 50 


\section{LISTA DE ABREVIATURAS E SIGLAS}

HCFMRP Hospital das Clinicas da Faculdade de Medicina de Ribeirão Preto

FMRP Faculdade de Medicina de Ribeirão Preto

USP Universidade de São Paulo

SEE Sistema de Estadiamento de Enneking

TOB Tumores ósseos

LOP Lesões ósseas pseudotumorais

TCG Tumor de células gigantes

ENC Endoprótese não convencional

QV Qualidade de Vida

QVRS Qualidade de Vida Relacionada à Saúde

MMII Membro Inferior

MMSS Membro Superior

OMS Organização Mundial de Saúde

CIF Classificação de Funcionalidade, Incapacidade e Saúde

AONO Ambulatório de Onco-ortopedia

SF-36 Medical Outcomes Study 36 - Item Short-Form Health Survey

TESS Toronto Extremity Salvage Escore

TCLE Termo de Consentimento Livre e Esclarecido

EERP Escola de Enfermagem de Ribeirão Preto

PCS Componente Físico

MCS Componente Mental 
APRESENTAÇÃO

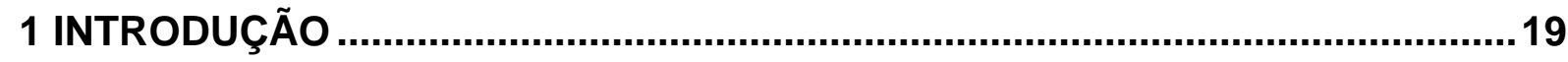

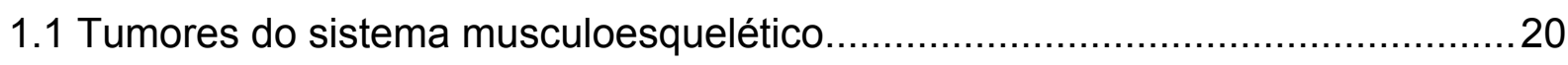

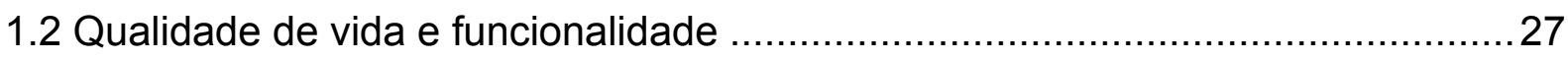

2 PROCEDIMENTOS METODOLÓGICOS...........................................................30

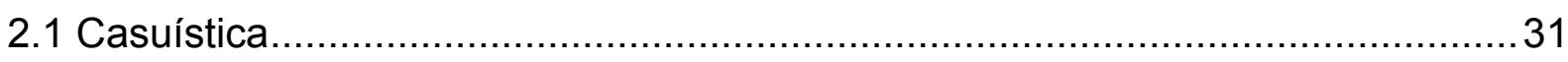

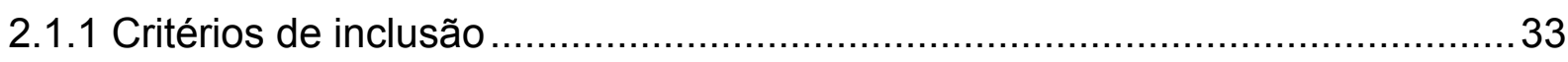

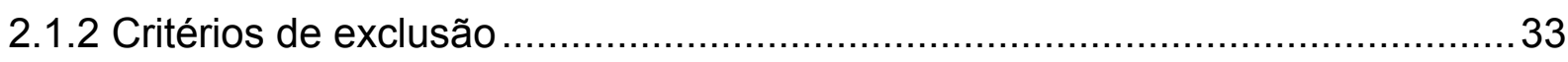

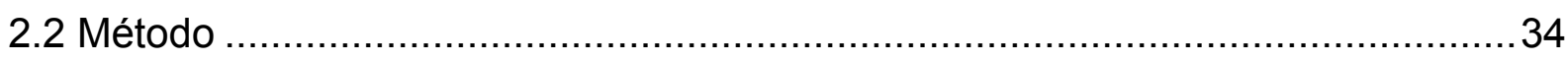

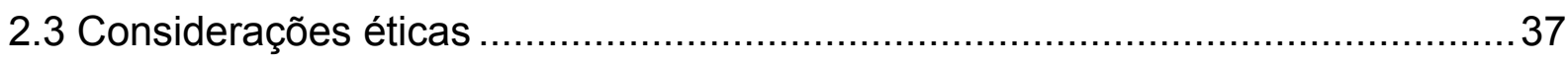

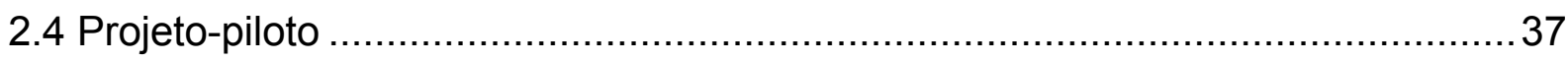

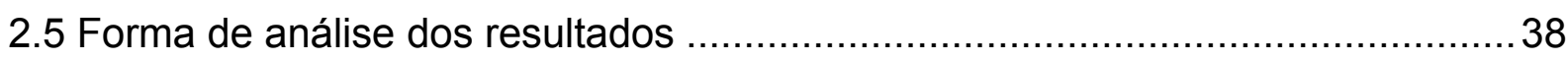

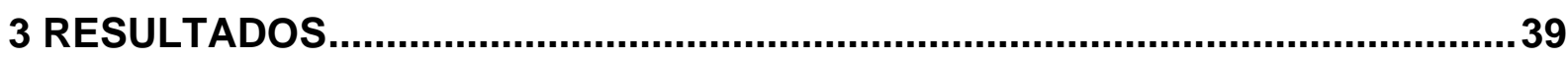

3.1 Caracterização sociodemográfica, ocupacional e clínica ....................................40

3.2 O Toronto Extremity Salvage Escore - TESS ............................................. 45

3.3 Medical Outcomes Study 36 - Item Short-Form Health Survey - SF-36 .............47

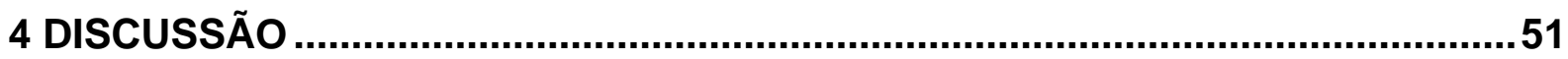

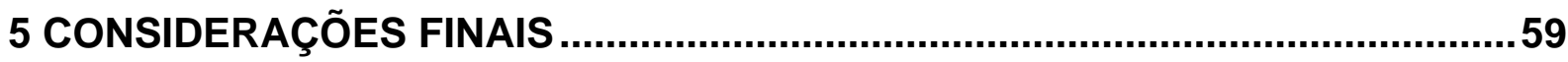

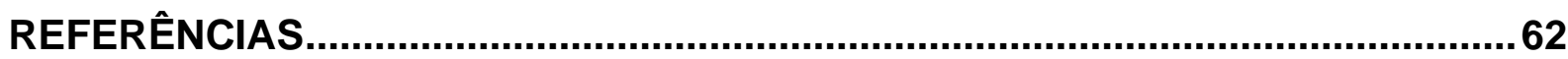

ANEXOS

ANEXO 1 - TERMO DE CONSENTIMENTO LIVRE E ESCLARECIDO …...............69

ANEXO 2 - TERMO DE CONSENTIMENTO LIVRE E ESCLARECIDO

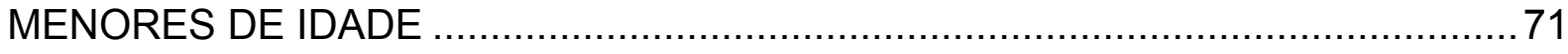

ANEXO 3 - TERMO DE CONSENTIMENTO LIVRE E ESCLARECIDO (GRUPO-

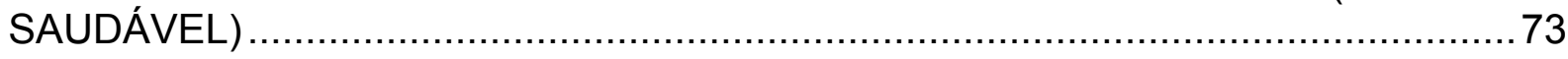

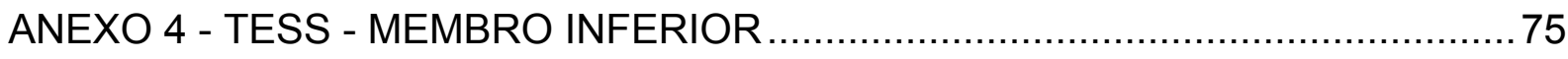


ANEXO 5 - MEDICAL OUTCOMES STUDYS 36 - ITEN SHORT FORM HEALTH SURVEY - SF-36

ANEXO 6 - QUESTIONÁRIO SOCIODEMOGRÁFICO 84

ANEXO 7 - APROVAÇÃO DO COMITÊ DE ÉTICA EM PESQUISA... 85

ANEXO 8 - ESCORE SF36 87

ANEXO 9 - DOMÍNIOS TESS 89

ANEXO 10 - ESCORE TESS 93 


\section{APRESENTAÇÃO}

Ingressei no curso de graduação em Terapia Ocupacional da Pontifícia Universidade Católica de Campinas em 2001, concluindo-o em dezembro de 2004. Durante a graduação, fui descobrindo o papel profissional do terapeuta ocupacional e a importância da sua atuação no campo da saúde, no qual estou inserida até hoje, atuando profissionalmente em contextos hospitalares.

Durante o Programa de Aprimoramento Profissional em Terapia Ocupacional da mesma universidade, com enfoque na área hospitalar e ambulatorial, tive o primeiro contato com pacientes acometidos por tumores musculoesqueléticos. Foi um período de muito crescimento e amadurecimento profissional e pessoal, quando iniciei também atividades de preceptoria a alunos da graduação, o que despertou meu interesse pela docência.

Em 2006, fui contratada pelo Serviço de Terapia Ocupacional do Hospital das Clínicas da Faculdade de Medicina de Ribeirão Preto-USP (HCFMRP-USP), para atuar na enfermaria de traumato-ortopedia. Em conjunto com a assistência, iniciei parceria junto à docente do curso de Terapia Ocupacional da FMRP-USP responsável pela área de Terapia Ocupacional Hospitalar e Cuidados Paliativos, auxiliando-a nas atividades de graduação e pós-graduação lato sensu (especialização) e como preceptora do Programa de Aprimoramento Profissional em "Terapia Ocupacional Hospitalar".

Durante minha prática assistencial, surgiram questionamentos e inquietações em relação à qualidade de vida de pacientes de onco-ortopedia, os quais são, em sua maioria, jovens submetidos a um tratamento longo, com procedimentos invasivos e, por vezes, mutilantes. Essas inquietações deram origem à minha pesquisa de pós-graduação, com ênfase na qualidade de vida de sujeitos submetidos à ressecção de tumores do sistema musculoesquelético e que apresentam prejuízos funcionais, com impactos na sua vida cotidiana e na sua participação social. Acredito que este é um tema relevante para o campo da Saúde Pública, e os resultados contribuirão para novas perspectivas e conhecimento acerca desse tema. 
INTRODUÇÃO 


\section{INTRODUÇÃO}

Para avaliar a qualidade de vida de sujeitos que foram acometidos por tumores musculoesqueléticos primários de membros inferiores, objeto deste estudo, faz-se necessário conhecer as características destes tumores e discorrer sobre a qualidade de vida e a funcionalidade, a partir de uma revisão de literatura.

\subsection{Tumores do sistema musculoesquelético}

Os tumores primários do sistema musculoesquelético são pouco frequentes, em comparação com a ocorrência de outros tipos de câncer. Correspondem a cerca de $3-4 \%$ dos casos oncológicos, em geral, e sua incidência é de aproximadamente 2.700 casos novos por ano (SOCIEDADE BRASILEIRA DE CANCEROLOGIA, 2012), o que demonstra a relevância do tema e justifica a investigação sobre a qualidade de vida de sujeitos acometidos por tumores musculoesqueléticos.

Existem vários tipos de tumores que acometem 0 sistema musculoesquelético, com comprometimento de ossos e partes moles, tanto em membro superior como inferior, que altera e/ou modifica a qualidade de vida e a capacidade funcional dos sujeitos de forma diferente.

Os tumores que acometem o sistema musculoesquelético podem ser classificados de acordo com sua localização, malignidade (se benigno ou maligno) grau de agressividade e tipo histológico. Pode ser utilizado o Sistema de Estadiamento de Enneking (SEE) que foi publicado na década de 1980 e introduziu uma linguagem única para avaliar e comparar os resultados de diferentes protocolos e séries de pacientes, de diversos centros de tratamento (DRUMOND, 2010). Esse mesmo autor, em seu estudo que teve como objetivo avaliar a eficácia desse sistema em determinar o prognóstico, planejar o tratamento cirúrgico e indicar a terapia adjuvante no tratamento de tumores ósseos benignos (TOB) e lesões ósseas pseudotumorais (LOP), concluiu com seus resultados que o SEE foi muito eficaz em determinar o prognóstico, planejar a cirurgia e indicar a terapia adjuvante no tratamento de TOB e LOP. Segue abaixo o SEE: 
Tabela 1 - Sistema de Estadiamento de Enneking (SEE).

\begin{tabular}{|l|l|}
\hline BENIGNOS & MALIGNOS \\
B-1 - BENIGNO LATENTE & I - BAIXO GRAU DE MALIGNIDADE \\
B-2 - BENIGNO ATIVO & II - ALTO GRAU DE MALIGNIDADE \\
B-3 - B BENIGNO & III - COM METÁSTASES (BAIXO OU ALTO \\
AGRESSIVO & GRAU) \\
\cline { 2 - 2 } & A - Intracompartimental \\
& B - Extracompartimental \\
\hline
\end{tabular}

Fonte: Enneking (1990 apud JESUS-GARCIA, 1996, p. 24)

O câncer ósseo pode ser primitivo do osso ou metastático, isto é, proveniente de outros órgãos, mais frequentemente oriundo da próstata, mama, tireoide, pulmão e rim. Segundo estudo de Tunn et al. (2008), cuja casuística foi composta por 87 sujeitos, a prevalência histológica dos tumores primários foi de $61 \%$ de osteossarcoma, $16,1 \%$ de condrossarcoma, $10,4 \%$ de tumor de célula gigante e os demais de outros tipos de tumores (como sarcoma de Ewing, fibro-histocitoma maligno).

Dentre os tipos de tumores que acometem o sistema musculoesquelético, os que mais frequentemente acometem o membro inferior são: ósseos (osteossarcoma, sarcoma de_Ewing, condrossarcoma, tumor de célula gigante) e de partes moles (sarcoma sinovial), os quais serão descritos, a seguir:

- Osteossarcoma: segundo Jesus Garcia (1996) implica um tumor maligno formador de osso com: 1) presença de um estroma francamente sarcomatoso e 2) a formação de osteoide neoplásico e osso pelos osteoblastos malignos. É o sarcoma primário do osso mais comum, representando aproximadamente $20 \%$ de todos os sarcomas e representa $60 \%$ de todos os tumores ósseos primários da infância e adolescência (SARAIVA, 2007). A incidência maior é entre 15 e 25 anos. Tem preferência pelo sexo masculino, podendo ocorrer em qualquer osso, mas, na maioria das vezes, acomete o fêmur distal, tíbia proximais e úmero. A dor e/ou aumento de volume local são os primeiros sintomas. O diagnóstico precoce é fator importante para o prognóstico e possibilidade de realizar cirurgias preservadoras do membro. 
- Sarcoma de Ewing: é a segunda neoplasia óssea maligna mais comum na infância e adolescência. O tumor de Ewing compreende aproximadamente $6 \%$ do total dos tumores ósseos malignos (JESUS-GARCIA, 1996). Predominante na raça branca $(96 \%)$ e no sexo masculino. Locais mais comuns de acometimento - pelve, fêmur, fíbula, tíbia, úmero, costelas e vértebras (nesta ordem do maior para o menor). Na maioria dos pacientes, o sintoma de apresentação é a dor. Dois terços deles apresentam tumor palpável e, aproximadamente, um quinto aparece com febre; fator que, inicialmente, pode causar confusão, retardando o diagnóstico correto. Os sintomas locais mais comuns são: dor e aumento de volume. Os sítios mais comuns de envolvimento são os pulmões, ossos e medula óssea. O tratamento do tumor de Ewing é normalmente dividido em três etapas: quimioterapia préoperatória, cirurgia e quimioterapia ou radioterapia pós-operatória.

- Condrossarcoma: é um tumor maligno cujo tecido neoplásico fundamental é constituído por cartilagem. Esse tumor ocorre, principalmente, em adultos entre os 30 e 60 anos e se localiza com maior frequência no fêmur, tíbia, úmero, escápula, costelas e osso ilíaco. Comumente, são tumores bem diferenciados, de crescimento lento e com taxas de metástases menores que o osteossarcoma e o sarcoma de Ewing. A cirurgia é a principal forma de tratamento do condrossarcoma. O princípio básico da cirurgia é a ressecção com amplas margens de segurança, evitando-se a recidiva, um dos fatores de mau prognóstico. As margens devem sempre ser amplas porque não há resposta à radioterapia ou quimioterapia.

- Tumor de células gigantes (TCG): é um tumor benigno agressivo, caracterizado por um tecido muito vascularizado, constituído por três tipos de células e pela presença de numerosas células gigantes do tipo osteoclástico, uniformemente distribuídas por todo o tecido neoplásico. A faixa etária de acometimento é entre os 20 e 40 anos. Campanacci (1976) apresentou uma classificação para o tumor de células gigantes em três diferentes graduações: I - latente e intraósseo ; II - ativo com periósteo intacto; III - agressivo, com invasão dos tecidos moles. Esta classificação auxilia na seleção do melhor tratamento: grau I: são radiograficamente latentes e parecem ser relativamente indolentes; são lesões pequenas e inteiramente intraósseas; grau II: parecem ser mais ativas; têm uma aparência radiográfica agressiva, sendo mais extensas, mas com periósteo intacto; grau III: têm um aspecto ainda mais agressivo e estendem-se além do periósteo para os tecidos adjacentes. Devido à frequente localização do TCG junto à articulação, o 
desafio é remover todo o tumor e preservar ou restaurar a função da articulação adjacente. Infelizmente, cerca de $50 \%$ dos TCGs são localizados na região do fêmur distal e da tíbia proximal e uma ressecção obriga a uma reconstrução do tipo artrodese ou a substituição por um homoenxerto ou uma endoprótese.

- Sarcoma sinovial: são tumores raros, compreendendo aproximadamente 5 a $10 \%$ dos sarcomas de partes moles. São mais comuns em extremidades, embora possam se originar em qualquer parte do corpo, sem qualquer relação com membranas sinoviais. Acometem principalmente adultos jovens e apresentam-se como uma massa dolorosa de crescimento lento, próxima a uma grande articulação, especialmente a região do joelho. Histologicamente, podem ser de dois tipos: monofásico e bifásico, conforme a presença ou ausência de diferenciação glandular epitelial junto a células tumorais fusiformes. São tumores agressivos, recidivando localmente em torno de 12 a $31 \%$, mesmo com tratamento adequado. Metastatizam principalmente para pulmões e, em torno de 3-7\%, para linfonodos. Apresentam índices de resposta à quimioterapia mais alta do que o restante dos sarcomas em adultos e índices de sobrevida doença-específica em cinco anos de 57 a 63\% (ROSA et al., 2002).

O câncer é uma doença complexa que exige infraestrutura adequada, tanto em termos de recursos materiais, quanto humanos. O diagnóstico e o tratamento dos tumores que acometem o sistema musculoesquelético sempre representaram grandes desafios aos especialistas e à sociedade. A cada dia procuram-se formas de tratamento que sejam mais efetivas, menos mutilantes e que causem o menor prejuízo possível à qualidade de vida e à capacidade funcional destes sujeitos.

O planejamento do tipo de tratamento médico e das condutas a serem realizadas depende da biópsia e do exame anatomopatológico, da avaliação clínica, do grau histológico, do estadiamento e dos exames específicos quanto ao tipo e à localização do tumor (se apendicular ou axial). Para os tumores considerados malignos, será necessário um tratamento coadjuvante (radioterapia e/ou quimioterapia), além da ressecção cirúrgica.

Contudo, o desenvolvimento ocorrido nos últimos anos tem levantado uma série de dúvidas e questionamentos sobre qual tipo de cirurgia é mais adequado, qual o melhor método adjuvante de tratamento e quais são os melhores métodos de reconstrução nas cirurgias de preservação dos membros. 
Para Jesus-Garcia (2008), o tratamento cirúrgico (ressecção do tumor) com margem oncológica (retirada de toda a área contaminada) é a melhor opção, mas ainda são necessários estudos sobre como aumentar a sobrevida e manter e/ou melhorar a funcionalidade e qualidade de vida destes sujeitos, em relação à técnica e ao procedimento cirúrgico utilizado.

Serão apresentados, a seguir, os dois tipos principais de cirurgias realizadas com essa população acometida por tumores musculoesqueléticos: amputação ou preservação do membro.

- A amputação, segundo Robert e Heck (1998), é comumente indicada para tumores malignos sem evidência de doença avançada (metastática) e tem por objetivo remover toda a área comprometida pelo tumor, em busca da sobrevida do paciente. Essa indicação leva em consideração o acometimento de estruturas adjacentes ao osso, como a parte vascular e partes moles. Esses fatores serão definidores do nível da amputação - se será uma desarticulação quadril e/ou joelho, amputação transfemural, suprapatelar e/ou infrapatelar ou amputação tipo Charcott. A amputação é indicada também quando a cirurgia de salvamento de membro não pode garantir margens adequadas para o controle local do tumor e quando se estima que a função seria pior do que com a prótese.

O índice de amputações realizadas nos Estados Unidos, em 1980, estava em torno de $70 \%$, tendo diminuído drasticamente nos melhores centros de tratamento, para menos de $20 \%$. No Brasil, as amputações em pacientes portadores de tumores também diminuíram drasticamente, de quase $90 \%$ para os $30 \%$ atuais (JESUSGARCIA, 2008).

Além das consequências do próprio adoecimento, os pacientes submetidos a amputações vivenciam uma perda significativa, com importantes mudanças na imagem corporal e a necessidade de adaptação à prótese. Segundo estudo de Bekerring et al. (2010), que teve como objetivo comparar a qualidade de vida relacionada à saúde de crianças e adolescentes após cirurgia de ressecção de tumor ósseo maligno da perna com grupo-controle composto por sujeitos saudáveis, os pacientes indicaram a restrição das atividades físicas, participação em esportes e aspectos cosméticos como as consequências mais prejudiciais da sua doença e do seu tratamento. 
- As cirurgias de "salvamento do membro" estão substituindo as amputações e tornaram-se mais comuns com o início dos tratamentos adjuvantes e com a evolução das técnicas de cirurgia ortopédica (NAGARAJAN, 2004). A poliquimioterapia para controle sistêmico dos tumores e a radioterapia aumentaram a sobrevida dos sujeitos e têm alterado a indicação de cirurgia radical e preservação dos membros (SARAIVA, 2007). Há evidências também de que o tratamento préoperatório com quimioterapia (drogas e protocolos diversos) representa um avanço no controle local dos tumores, além do controle sistêmico, com consequente impacto na sobrevida dos pacientes.

Os tipos de reconstruções mais comumente citados na literatura e usados na prática clínica são: a utilização de endopróteses (total e/ou parcial), de ossos de banco, o uso de enxerto e de substitutos biológicos do tecido ósseo. A indicação de uma solução biológica e não protética nas reconstruções tem sido, sempre que possível, a melhor opção, devido ao melhor resultado em longo prazo.

A endoprótese não convencional (ENC) é a mais comumente utilizada quando é necessária a ressecção articular, devido à invasão tumoral (MORAES et al., 2011). Apresenta vantagens em relação aos outros métodos, uma vez que possibilita a preservação do membro e suas funções articulares e costuma haver uma rápida recuperação pós-operatória, levando a uma menor morbidade e com menos complicações a curto e médio prazo. Relata, também, que a preservação do membro não está associada com diminuição da sobrevida do paciente oncológico, o que torna possível a indicação de endopróteses não convencionais em $85 \%$ dos casos.

Os problemas mais frequentemente encontrados, decorrentes desse tipo de procedimento, são as infecções, a demora da integração óssea (nas reconstruções biológicas) e a possibilidade de soltura do material da endoprótese, exigindo um acompanhamento a longo prazo para revisões.

Alguns estudos têm feito comparações entre pacientes submetidos à cirurgia conservadora ou amputação em casos de tumores ósseos, com sua possíveis consequências funcionais e na qualidade de vida (QV). Rougraff et al. (1994) não identificaram diferenças significativas entre os grupos estudados, mas concluíram que os pacientes submetidos à cirurgia de salvamento de membro passaram por mais abordagens cirúrgicas $(p<0,0001)$ do que os amputados. Já Nagarajan et al. (2004) concluíram que as mulheres apresentaram função e qualidade de vida 
significativamente mais baixas que os homens, quando realizada a correlação das cirurgias com a variável gênero nos dois tipos de procedimento, e que os sujeitos com escolaridade baixa também apresentaram menor função e escores mais baixos de qualidade de vida.

No mesmo sentido, Daigeler et al. (2009) concluíram que as amputações proximais de MMII e MMSS interferem severamente na imagem corporal dos pacientes, impactando na sua qualidade de vida. Schereiber et al. (2006) e Marchese et al. (2006) também estudaram populações submetidas a amputações e procedimentos de salvamento de membros, mais no sentido de avaliação de força muscular e amplitude de movimento. Concluíram que estes são apenas alguns dos fatores que contribuem para caminhar e subir escadas, que devem ser consideradas outras variáveis importantes, como questões musculoesqueléticas, dor neuropática, discrepância no comprimento das pernas, força, resistência, idade, experiências pessoais, motivação, fatores ambientais e circunstâncias familiares e comprovaram a importância de manter exercícios para maior funcionalidade e manutenção de qualidade de vida.

Hinguranage et al. (2004) investigaram a qualidade de vida e função de 124 pacientes com sarcomas de extremidade após ressecção do tumor, passando por amputação ou salvamento de membro. Seus resultados apontaram que a qualidade de vida é similar nos dois grupos, mas o grupo de pacientes com salvamento de membro apresentou maior performance funcional, enquanto os pacientes do grupo de amputados tiveram limitações relacionadas à aceitação social.

Portanto, há grande discussão sobre qual tipo de cirurgia apresenta melhores resultados funcionais, na sobrevida, na imagem corporal e na qualidade de vida, propiciando uma retomada mais precoce de suas atividades e inclusão social destes pacientes e familiares. É importante a tomada de decisão compartilhada sobre qual tipo de tratamento será eleito e também a obtenção do consentimento do paciente ou responsável, a partir da compreensão e aceitação do tratamento e prognóstico (JESUS-GARCIA, 2008). 


\subsection{Qualidade de vida e funcionalidade}

A Organização Mundial de Saúde (OMS) define qualidade de vida (QV) como:

"a percepção do indivíduo de sua posição na vida, no contexto da cultura, sistemas de valores nos quais ele vive em relação aos seus objetivos, expectativas, padrões e preocupações" (SEIDL; ZANNON, 2004).

A maioria dos autores define Qualidade de Vida (QV) como um conceito multidimensional, tem dinâmica própria, depende dos valores do indivíduo e do momento de vida pelo qual está passando, influenciado pelos fatores econômicos, sociais, físicos, psicológicos e espirituais. Existe atualmente um consenso em relação às dimensões que esse conceito deve incluir: a patologia, o estado funcional, incluindo funções físicas, psicológicas e sociais e as percepções de saúde (PATRICK; ERICKSON, 1993).

Os determinantes e condicionantes do processo saúde-doença são multifatoriais e complexos, relacionados aos aspectos econômicos, socioculturais, à experiência pessoal e a estilos de vida. Consoante com essa mudança de paradigma, a melhoria da QV passou a ser um dos resultados esperados, tanto das práticas assistenciais quanto das políticas públicas para o setor, nos campos da promoção da saúde e da prevenção de doenças (SEIDL; ZANNON, 2004).

O termo qualidade de vida relacionada à saúde (QVRS) tem sido usado como sinônimo de Estado de Saúde Percebido, está centrado na avaliação subjetiva do paciente e, para além de sua condição de saúde e intervenções médicas, inclui uma variedade de condições que podem afetar a percepção do indivíduo, seus sentimentos e comportamentos relacionados com o seu funcionamento diário. Tem o objetivo principal de verificar o quanto a doença ou estado crônico, além de seus sintomas, interferem na vida diária de um indivíduo, ou seja, o quanto as manifestações da doença ou do tratamento são sentidas por ele (FAYERS; MACHIN, 2007).

Informações sobre QVRS têm sido incluídas tanto como indicadores para avaliação da eficácia, eficiência e impacto de determinados tratamentos para grupos 
de portadores de agravos diversos quanto na comparação entre procedimentos para o controle de problemas de saúde (SEIDL; ZANNON, 2004).

Os questionários de QVRS avaliam o impacto físico e psicossocial que as enfermidades, disfunções ou incapacidades podem acarretar para as pessoas acometidas, permitindo um melhor conhecimento do paciente e de sua adaptação à determinada condição. Esses podem ser genéricos ou específicos para uma determinada condição ou população.

Instrumentos genéricos que avaliam a QVRS geral podem ser usados com quaisquer populações e para quaisquer condições de saúde e podem ser utilizados para avaliar a população geral, mas não permitem comparações entre as diversas condições (BELASCO; SESSO, 2006). Os instrumentos específicos são mais sensíveis e permitem avaliar uma doença, população e uma determinada função ou sintoma.

Outro conceito importante a ser considerado é o de funcionalidade.

A "Classificação Internacional de Funcionalidade, Incapacidade e Saúde", (CIF) proposta pela Organização Mundial da Saúde (OMS, 2003), é uma classificação composta por duas partes cujos componentes interagem: a primeira refere-se à "funcionalidade e incapacidade", contendo funções e estrutura do corpo, atividades e participação; a segunda parte é de "fatores contextuais" que contêm fatores ambientais e pessoais.

Nesse modelo, o processo de saúde-doença deve ser compreendido como um continuum, relacionado aos aspectos econômicos e socioculturais, à experiência pessoal e ao estilo de vida. Assim, as condições de funcionalidade e incapacidade de uma pessoa são concebidas como uma interação dinâmica entre os estados de saúde (doenças, distúrbios, lesões, traumas, etc.) e os fatores contextuais. Os fatores ambientais interagem com a funcionalidade e incapacidade, tendo impacto, facilitador ou limitador, tanto nas atitudes como nas características do mundo físico e social no qual as pessoas vivem e conduzem sua vida.

Segundo a CIF, funcionalidade é um termo genérico que abrange todas as funções do corpo e o desempenho de tarefas ou ações. A função do corpo é definida como funções fisiológicas, inclusive funções psicológicas. Este conceito é pautado, teoricamente, no modelo biopsicossocial que se constitui como uma síntese dos modelos médico e social, compatível com o conceito ampliado de saúde, o qual 
inclui as perspectivas biológica, individual e social (CAPONI, 1997 apud MANCINI, 2007).

Schreiber et al. (2006) discutiram a relação entre qualidade de vida e funcionalidade, tendo utilizado os conceitos trazidos pela CIF. Mostraram que as restrições na participação social, nos papéis e nas situações de vida tiveram um impacto significativo sobre a QVRS, explicando 63\% das variações encontradas no estudo. Esses resultados indicam que restrições na participação social são importantes para o bem-estar funcional e devem ser incluídas na avaliação funcional, juntamente com as outras medidas funcionais para uma completa compreensão da evolução dos pacientes.

Assim, este estudo tem como questão norteadora: Como se configura a qualidade de vida relacionada à saúde dos sujeitos acometidos por tumores musculoesqueléticos de membros inferiores que foram submetidos a diferentes tipos de cirurgias, com procedimentos de salvamento do membro (endoprótese, reconstrução biológica) ou amputação?

A análise parte dos novos conceitos sobre funcionalidade estabelecidos pela "Classificação Internacional de Funcionalidade, Incapacidade e Saúde" (OMS, 2003) e poderá contribuir para a avaliação do impacto deste processo de adoecimento e de tratamento na qualidade de vida dos pacientes submetidos à cirurgia oncoortopédica.

Justifica-se pelo grande impacto que o câncer tem na qualidade de vida desses sujeitos e suas famílias e pela necessidade de compreender os acometimentos causados pelos tumores musculoesqueléticos de MMII na população brasileira e colaborar para a melhoria da assistência prestada a estes sujeitos e a seus familiares - o que tem relevância para a Saúde Pública. 
PROCEDIMENTOS METODOLÓGICOS 


\section{PROCEDIMENTOS METODOLÓGICOS}

Este é um estudo do tipo transversal, com metodologia quantitativa. Foi realizado através da aplicação de escalas internacionais de avaliação - o "Medical Outcomes Study 36 - Item Short-Form Health Survey" (SF-36) e o "Toronto Extremity Salvage Escore (TESS)" - e também do "Critério de Classificação Econômica Brasil", com uma população acometida por tumores musculoesqueléticos de membros inferiores (MMII) submetidos a diferentes tipos de procedimentos cirúrgicos (salvamento de membro ou amputação) e grupo-controle com sujeitos saudáveis, conforme será explicado a seguir.

\subsection{Casuística}

Participaram deste estudo sujeitos em diferentes fases do desenvolvimento: adolescentes, adultos jovens, adultos e idosos que fizeram acompanhamento no ambulatório de onco-ortopedia (AONO) do Hospital das Clínicas da Faculdade de Medicina de Ribeirão Preto da Universidade de São Paulo (HCFMRP-USP). A casuística do estudo foi composta pelo número máximo possível de sujeitos submetidos à cirurgia para ressecção de tumor ósseo e de partes moles com colocação de endoprótese de MMII, reconstrução biológica ou amputação do membro, no período compreendido entre janeiro de 2001 e dezembro de 2010.

Os sujeitos do grupo de estudo foram divididos em dois grupos de sujeitos com diagnóstico de tumor musculoesquelético, sendo:

- grupo 1: composto por 12 pacientes em pós-operatório de amputação do membro acometido.

- grupo 2: composto por 16 pacientes em pós-operatório para salvamento do membro, com colocação de endoprótese ou com outro tipo de reconstrução.

- grupo 3: grupo saudável, composto por 28 sujeitos não acometidos por câncer (sujeitos saudáveis), de forma pareada com os sujeitos dos grupos $1 \mathrm{e}$ 2, segundo sexo, idade, escolaridade e condição socioeconômica. 
A definição do número de sujeitos do estudo baseia-se no levantamento dos casos já atendidos no Ambulatório da Onco-Ortopedia do HCFMRP-USP. A partir desse levantamento, foram selecionados os casos de tumores musculoesqueléticos acompanhados entre os anos de 2001 a 2010, indicou um número inicial de 105 sujeitos. Após identificar e coletar os dados no sistema informatizado do hospital, foram excluídos os sujeitos já falecidos e os menores de 12 anos de idade, chegando-se a um número de 80 sujeitos elegíveis para o estudo, sendo que 35 destes passaram por amputação e 45 por cirurgia de salvamento de membro - 33 colocaram endopróteses e 12 passaram por outros tipos de reconstrução. Ao longo do período de coleta de dados desta pesquisa, ocorreu ainda uma diminuição da casuística por óbito, abandono do processo e/ou recusa em participar da pesquisa. Houve, também, dificuldade em localizar esses sujeitos devido a dados residenciais incompletos ou incorretos.

Os sujeitos foram convidados a participar do estudo através de contato telefônico e/ou no dia do seu retorno ao ambulatório, segundo os critérios de inclusão e de exclusão abaixo descritos. Os pacientes selecionados foram avaliados após manifestarem sua concordância em participar do estudo e após a assinatura do Termo de Consentimento Livre e Esclarecido (TCLE).

O grupo saudável foi composto por sujeitos provenientes da população em geral, identificados em locais de grande circulação (um parque e duas praças públicas do centro da cidade de Ribeirão Preto), tendo sido convidados a participar voluntariamente do trabalho. A coleta de dados foi realizada após a assinatura do TCLE.

Estudos internacionais sobre a população onco-ortopédica têm utilizado grupos-controle compostos por sujeitos saudáveis, como irmãos dos sujeitos dos grupos de estudo (KOOPMAN et al., 2005: ZELTER et al., 2009), comparados com populações submetidas à amputação e à endoprótese total ou parcial. Há também estudos que fizeram comparações utilizando padrões-ouro referentes à qualidade de vida da população em geral (AKNES et al., 2007; BEKKERING et al., 2010). 


\subsubsection{Critérios de inclusão}

Os sujeitos incluídos na pesquisa deverão ser pacientes:

- submetidos à cirurgia oncológica (cirurgias eletivas) no período de janeiro de 2001 a dezembro de 2010 (seleção da casuística por estudo retrospectivo), no HC-FMRP-USP Campus;

- que estejam em seguimento clínico no Ambulatório da Ortopedia Oncológica no Hospital das Clínicas de Ribeirão Preto da Faculdade de Medicina de Ribeirão Preto, da Universidade de São Paulo.

- que tenham diagnósticos de tumor do sistema musculoesquelético primário com acometimento de MMII;

- em diferentes fases do desenvolvimento, com idade igual e/ou maior de 14 anos de idade em decorrência de um dos protocolos que será ministrado.

\subsubsection{Critérios de exclusão}

Serão excluídos da pesquisa os sujeitos que:

- não fazem acompanhamento ou que tenham abandonado o acompanhamento médico no ambulatório da onco-ortopedia do Hospital das Clínicas de Ribeirão Preto da Faculdade de Medicina de Ribeirão Preto, da USP;

- que não se comunicarem verbalmente, nem com a linguagem escrita.

A coleta de dados iniciou-se após a aprovação do projeto pelo Comitê de Ética em Pesquisa da EERP-USP, em 26 de maio de 2011. Foi realizada durante 14 meses - de agosto de 2011 a setembro de 2012. Houve uma prorrogação de 2 meses nesse período de coleta em relação à periodicidade estabelecida no projeto inicial, para que fosse alcançado o número máximo possível de sujeitos em acompanhamento no AONO. 


\subsection{Método}

Os sujeitos selecionados foram convidados a participar do estudo e avaliados utilizando os critérios e questionários, descritos a seguir:

- Prontuários clínicos: serão coletados as informações clínicas (diagnóstico, localização do tumor, técnica cirúrgica), o sexo, a faixa etária, o estado conjugal, a escolaridade relevantes para caracterização clínica da casuística, através de uma revisão minuciosa dos prontuários dos pacientes.

- "Critério de Classificação Econômica Brasil": enfatiza sua função de estimar o poder de compra das pessoas e famílias urbanas, abandonando a pretensão de classificar a população em termos de "classes sociais". Os critérios utilizados foram apresentados no Anexo 6, sendo que os itens perguntados estão relacionados aos bens como televisão, geladeira, carro entre outros e ao grau de escolaridade do "chefe da família" que não necessariamente é o sujeito entrevistado.

- O Toronto Extremity Salvage Escore (TESS) é um questionário para avaliação da função, tendo sido desenvolvido e validado para pacientes entre 12 e 85 anos com tumores ósseos, em Toronto, Canadá (DAVIS et al. 1996 ). O conceito de funcionalidade usado no TESS baseia-se na Classificação Internacional de Funcionalidade de 1980, da Organização Mundial de Saúde, atualizado em 2001 e publicado no Brasil em 2003 com o título "CIF - Classificação Internacional de Funcionalidade, Incapacidade e Saúde" (OMS, 2003). O TESS foi traduzido e validado no Brasil por Saraiva (2007), em sua dissertação de mestrado, que obteve como resultado um escore final do TESS com média 89,55 pontos, apresentando variação de 56-100 pontos. O teste alfa de Cronbach obteve o resultado de 0,87, demonstrando uma boa consistência interna. É um dos instrumentos mais utilizados em estudos internacionais sobre o tema, aborda questões relacionadas às limitações nas atividades de vida diárias, bem como nas restrições dos movimentos corporais, mobilidade, autocuidado e o desempenho nas tarefas e rotinas diárias. 
Composto por cinco questões que focalizam a situação atual do paciente em relação à ocupação (empregado, desempregado, estudante etc.), breve descrição das atividades de lazer ou recreação, uso de medicações para dor e sua frequência, ajuda para se mover ou andar (uso de andador, muleta, bengala ou cadeira de rodas) e quais os fatores que podem limitar as atividades do dia a dia (dor, rigidez, fadiga, fraqueza, diminuição do movimento). Na sequência, são formuladas 30 questões fechadas nas quais o paciente possui seis possíveis alternativas: "impossível de fazer", "dificuldade extrema", "dificuldade moderada", "pouca dificuldade", "sem dificuldade" ou "este item não se aplica a mim", se o paciente não executa a atividade como parte do seu estilo de vida normal. Ao final do questionário, também há uma pergunta opcional, aberta, para o paciente registrar se existe alguma atividade em que ele sinta dificuldade e que não tenha sido abordada nas questões anteriores. Cada questão possui um escore de 0 a 5 pontos.

O escore final do TESS é feito calculando-se a soma dos itens respondidos, subtraindo-se o número de itens que apresentou como resposta "este item não se aplica a mim", dividido pelo possível escore multiplicado por 100\%, conforme demonstrado na fórmula abaixo. A pontuação máxima a ser atingida é de 150, entretanto, o escore final pode atingir, no máximo, 100 pontos; em relação ao resultado final, quanto maior o escore significa melhor função, altos escores indicam menores restrições funcionais (MALO et al., 2001 apud SARAIVA, 2007).

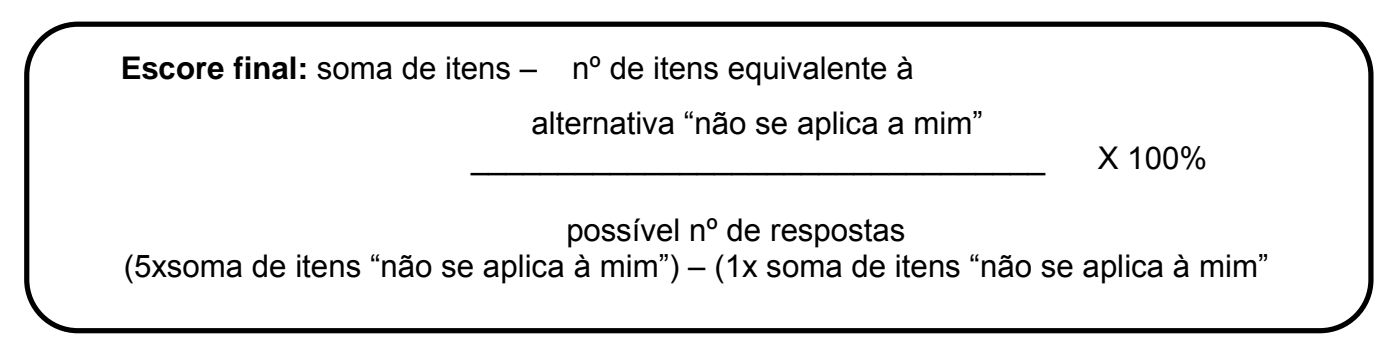

Figura 1. Cálculo escore final TESS

Segundo Saraiva (2007), autora do trabalho de validação do TESS no Brasil, este é um questionário genérico, válido, confiável, de fácil compreensão e de grande aceitabilidade.

Em geral, os pacientes tratados devido ao câncer de extremidades têm suas funções alteradas, e essas alterações têm sido documentadas, utilizando-se uma 
variedade de avaliações (ROBINSON et al., 1991 apud SARAIVA, 2007). Diversos tipos de instrumentos para avaliação física foram desenvolvidos para descobrir quais as limitações encontradas em pacientes submetidos às cirurgias conservadoras de membros e amputações.

A recuperação da independência funcional de pessoas com incapacidades é um processo complexo que envolve grande número de tarefas diárias (STINEMAN et al., 2003 apud SARAIVA, 2007).

- Medical Outcomes Study 36 - Item Short-Form Health Survey (SF-36) - É um questionário genérico multidimensional de avaliação de qualidade de vida aplicada à saúde, muito utilizado no Brasil, aplicado a diferentes populações, cuja validação e adaptação transcultural foram realizadas por Ciconelli et al. (1997).

É composto por 36 itens, distribuídos em oito domínios: capacidade funcional (dez itens), aspectos físicos (quatro itens), dor (dois itens), estado geral de saúde (cinco itens), vitalidade (quatro itens), aspectos sociais (dois itens), aspectos emocionais (três itens), saúde mental (cinco itens) e uma questão de avaliação que permite comparar a condição de saúde atual à de um ano atrás.

Segundo Ware (2004), os resultados desse instrumento são apresentados em domínios e posteriormente sumarizados em dois componentes: Componente Físico (PCS) que engloba os domínios: capacidade funcional, aspectos físicos e dor; Componente Mental (MCS) engloba os domínios: saúde mental, situação emocional e aspectos sociais; outros três domínios - Vitalidade, Saúde Geral e Aspectos Funcionais - têm correlações com ambos os componentes. Porém, neste estudo não será realizado o cálculo desses componentes, devido a restrições impostas pelos autores originais da escala.

O SF-36 é um questionário que pode ser autoadministrado pelo paciente ou ser aplicado pelo entrevistador. O cálculo dos escores das escalas tem duas fases: na primeira fase, para cada resposta atribui-se uma pontuação e é realizada a ponderação dos dados. Na segunda, é realizado o cálculo do Raw Scale de cada domínio que varia entre 0 e 100 na qual zero corresponde a um pior estado de saúde e 100 a um melhor estado, utilizando-se a forma: Domínio = (valor obtido nas questões correspondentes - limite inferior/ variação) x 100 (BRAZIER et al., 1992 apud SARAIVA, 2007). Avalia tanto aspectos negativos de saúde (doença ou 
enfermidade) como os aspectos positivos (bem-estar) (CICONELLI, 1997; VILAGUT et al., 2005).

Este instrumento é dirigido a pessoas com idade de 14 anos ou mais (VILAGUT et al., 2005). Quanto ao seu uso com a população adolescente, encontram-se diversos estudos, como o de Costa et al. (2007), Fernandes et al. (2012) e Benincasa e Custodio (2011), que avaliaram a QVRS em adolescentes com diferentes diagnósticos, utilizando o questionário SF36, e seus resultados se mostraram confiáveis mesmo com essa população.

Por ser um instrumento genérico, não se encontrarão, dentre os seus domínios, questões específicas referentes à população deste estudo, mas este vem sendo um dos mais utilizados entre os estudos internacionais que se propõem a estudar sobre essa população (AKSNES et al., 2007; BEKKRING et al., 2010; GINSBERG et al., 2007; MALEK et al., 2012; ZELTZER et al., 2009).

\subsection{Considerações éticas}

Esta pesquisa foi aprovada pelo Comitê de Ética em Pesquisa da Escola de Enfermagem de Ribeirão Preto - USP, em sua sessão de 26 de maio de 2011 Processo n 1263/2011 (Anexo 7).

\subsection{Projeto-piloto}

Foi realizado projeto-piloto do estudo com três sujeitos, com aplicação simulada dos instrumentos propostos no estudo, com duração (tempo médio) de 20 minutos. Os sujeitos, inclusive o adolescente que participou do projeto-piloto, não tiveram dificuldade em responder aos questionários. 


\subsection{Forma de análise dos resultados}

Os dados obtidos, através da aplicação dos protocolos "Medical Outcomes Study 36 - SF36", Toronto Extremity Salvage Escore - TESS e "Critérios de Classificação Econômica Brasil", foram analisados segundo critérios e procedimentos estabelecidos pelos próprios instrumentos e também foram estatisticamente analisados, para comparação entre grupos (testes pareados com análise de variância) e cálculo das correlações entre variáveis intra e intergrupos.

Para a análise estatística dos dados, foi construído banco de dados usando o programa SPSS para Windows. Como as variáveis rejeitaram a hipótese de normalidade, foram realizados testes não paramétricos - de Kruskal-Wallis que é um teste utilizado para comparar duas ou mais amostras e que demonstra se houve ou não diferença entre os grupos/amostras estudadas. Foi utilizado também o Post Hoc Tests Dunn, para a identificação de onde ocorreu essa diferença (em quais dos grupos/amostras) e foram comparados os resultados entre os grupos (PONTES; CORRENTE, 2001).

A discussão dos resultados obtidos basear-se-á nos conceitos de Qualidade de vida e o conceito de Funcionalidade, preconizado pela Classificação Internacional de Funcionalidade e Incapacidade e Saúde (CIF), proposto pela Organização Mundial de Saúde (2003). 
RESULTADOS 


\section{RESULTADOS}

Para alcançar os objetivos estabelecidos é preciso, inicialmente, apresentar a caracterização da casuística do estudo.

\subsection{Caracterização sociodemográfica, ocupacional e clínica}

Foram avaliados 56 sujeitos, divididos em três grupos: 1- sujeitos amputados e 2- sujeitos submetidos a procedimentos de salvamento de membro (ambos os grupos com diagnóstico de tumor musculoesquelético de MMII) e 3- sujeitos saudáveis sem diagnóstico de câncer. Os dados sociodemográficos referentes à população do estudo serão apresentados na Tabela 3, na página seguinte.

Observa-se que a maioria dos sujeitos do estudo é do sexo feminino, sendo $58,4 \%$ do grupo $1,68,75 \%$ do grupo 2 e $64,28 \%$ do grupo 3. Quanto ao estado civil, há prevalência de solteiros nos três grupos $(58,4 \% ; 56,25 \% ; 57,14 \%$ respectivamente). Quanto à faixa etária, prevaleceram os jovens (de 20 a 29 anos), sendo $50 \%$ do grupo $1,31,25 \%$ do grupo 2 e $39,2 \%$ do grupo 3 .

Quanto à escolaridade, observa-se que os dados caracterizam bem a população atendida neste hospital estadual público e universitário. Uma porcentagem pequena de sujeitos dos grupos 1 e 3 tem ensino superior (nenhum do grupo 2), incompleto ou completo. No ensino fundamental (incompleto e completo), identificam-se $33,4 \%$ dos sujeitos do grupo 1, 43,75\% do grupo 2 e 39,32\% do grupo 3. Destaca-se, também, um número significativo de pessoas analfabetas, particularmente no grupo 2 , com $25 \%$ dos sujeitos.

Em relação à ocupação, 41,7\% dos sujeitos do grupo 1 estão aposentados, já nos grupos 2 e 3, a maioria (37,5\% e 60,7\% respectivamente) se encontra ativa e com registro. 
Tabela 2 - Dados sociodemográficos da população total avaliada

\begin{tabular}{|c|c|c|c|c|c|c|}
\hline \multirow[t]{2}{*}{ Dados sociodemográficos } & \multicolumn{2}{|c|}{$\begin{array}{l}\text { Grupo } 1 \text { - } \\
\text { Amputação }\end{array}$} & \multicolumn{2}{|c|}{$\begin{array}{c}\text { Grupo } 2 \text { - } \\
\text { Salvamento de } \\
\text { membro }\end{array}$} & \multicolumn{2}{|c|}{$\begin{array}{l}\text { Grupo } 3 \text { - } \\
\text { População } \\
\text { saudável }\end{array}$} \\
\hline & $\mathbf{N}$ & $\%$ & $\mathbf{N}$ & $\%$ & $\mathbf{N}$ & $\%$ \\
\hline $\begin{array}{l}\text { Sexo: } \\
\text { 1- Masculino } \\
\text { 2- Feminino }\end{array}$ & $\begin{array}{l}05 \\
07 \\
\end{array}$ & $\begin{array}{l}41,6 \\
58,4 \\
\end{array}$ & $\begin{array}{l}05 \\
11 \\
\end{array}$ & $\begin{array}{l}31,25 \\
68,75 \\
\end{array}$ & $\begin{array}{l}10 \\
18 \\
\end{array}$ & $\begin{array}{l}35,72 \\
64,28\end{array}$ \\
\hline Total & 12 & 100 & 16 & 100 & 28 & 100 \\
\hline $\begin{array}{l}\text { Estado civil: } \\
\text { 1- Solteiro } \\
\text { 2- Casado } \\
\text { 3- Divorciado } \\
\text { Total }\end{array}$ & $\begin{array}{c}07 \\
05 \\
- \\
12\end{array}$ & $\begin{array}{c}58,4 \\
41,6 \\
- \\
100\end{array}$ & $\begin{array}{c}09 \\
07 \\
- \\
16\end{array}$ & $\begin{array}{c}\begin{array}{c}56,25 \% \\
43,75 \% \\
-\end{array} \\
100\end{array}$ & $\begin{array}{l}16 \\
09 \\
03 \\
28\end{array}$ & $\begin{array}{c}57,14 \\
32,14 \\
10,72 \\
100\end{array}$ \\
\hline $\begin{array}{l}\text { Idade: } \\
\text { 1- Pré adolescentes (10 a } 14 \text { anos) } \\
\text { 2- Adolescentes (15 a } 19 \text { anos) } \\
\text { 3- Jovens ( } 20 \text { a } 29 \text { anos) } \\
\text { 4- Adultos I ( } 30 \text { a } 39 \text { anos) } \\
\text { 5- Adultos II ( } 40 \text { a } 59 \text { anos) } \\
\text { 6- Idosos (60 a } 79 \text { anos ) } \\
\text { Total }\end{array}$ & $\begin{array}{l}- \\
01 \\
06 \\
01 \\
03 \\
01 \\
12\end{array}$ & $\begin{array}{l}- \\
8,3 \\
50 \\
8,3 \\
25 \\
8,3 \\
100\end{array}$ & $\begin{array}{l}01 \\
03 \\
05 \\
04 \\
02 \\
01 \\
16\end{array}$ & $\begin{array}{c}6,25 \\
18,75 \\
31,25 \\
25 \\
12,5 \\
6,25 \\
100\end{array}$ & $\begin{array}{l}01 \\
04 \\
11 \\
05 \\
05 \\
02 \\
28\end{array}$ & $\begin{array}{c}3,6 \\
14,2 \\
39,2 \\
17,9 \\
17,9 \\
7,2 \\
100\end{array}$ \\
\hline $\begin{array}{l}\text { Escolaridade: } \\
\text { 1- Analfabeto } \\
\text { 2- Fundamental incompleto } \\
\text { 3- Fundamental completo } \\
\text { 4- Médio incompleto } \\
\text { 5- Médio completo } \\
\text { 6- Superior incompleto } \\
\text { 7- Superior completo } \\
\text { Total }\end{array}$ & $\begin{array}{l}01 \\
02 \\
02 \\
03 \\
02 \\
01 \\
01 \\
12\end{array}$ & $\begin{array}{c}8.3 \\
16,7 \\
16,7 \\
25 \\
16,7 \\
8,3 \\
8,3 \\
100 \\
\end{array}$ & $\begin{array}{c}04 \\
03 \\
04 \\
03 \\
02 \\
- \\
- \\
16\end{array}$ & $\begin{array}{c}25 \\
18,75 \\
25 \\
18,75 \\
12,5 \\
- \\
- \\
100\end{array}$ & $\begin{array}{l}05 \\
05 \\
06 \\
06 \\
04 \\
01 \\
01 \\
28 \\
\end{array}$ & $\begin{array}{c}17,9 \\
17.9 \\
21,42 \\
21,42 \\
14,28 \\
3,6 \\
3,6 \\
100 \\
\end{array}$ \\
\hline $\begin{array}{l}\text { Ocupação: } \\
\text { 1- Estudante } \\
\text { 2- Do lar } \\
\text { 3- Ativo e registrado } \\
\text { 4- Ativo sem registro (autônomo) } \\
\text { 5- Afastado com benefício } \\
\text { 6- Desempregado } \\
\text { 7- Aposentado }\end{array}$ & $\begin{array}{c}01 \\
01 \\
02 \\
- \\
03 \\
- \\
05\end{array}$ & $\begin{array}{c}8,3 \\
8,3 \\
16,7 \\
- \\
25 \\
- \\
41,7\end{array}$ & $\begin{array}{l}02 \\
02 \\
06 \\
01 \\
01 \\
02 \\
02\end{array}$ & $\begin{array}{l}12,5 \\
12,5 \\
37,5 \\
6,25 \\
6,25 \\
12,5 \\
12,5\end{array}$ & $\begin{array}{c}04 \\
02 \\
17 \\
04 \\
- \\
- \\
01\end{array}$ & $\begin{array}{c}14,29 \\
7,14 \\
60,7 \\
14,29 \\
- \\
3,58 \\
-\end{array}$ \\
\hline Total & 12 & 100 & 16 & 100 & 28 & 100 \\
\hline
\end{tabular}


Segundo o "Critério de Classificação Econômica Brasil", podem ser classificados os sujeitos de acordo com a renda familiar estimada, como se apresenta na Tabela 3, a seguir

Tabela 3 - Critério de Classificação Econômica Brasil

\begin{tabular}{|c|c|c|c|c|c|c|}
\hline \multirow{2}{*}{$\begin{array}{l}\text { Critério de } \\
\text { Classificação } \\
\text { Econômica } \\
\text { Brasil }\end{array}$} & \multicolumn{2}{|c|}{$\begin{array}{l}\text { Grupo } 1 \text { - } \\
\text { Amputados }\end{array}$} & \multicolumn{2}{|c|}{$\begin{array}{c}\text { Grupo } 2 \text { - } \\
\text { Salvamento de } \\
\text { membro }\end{array}$} & \multicolumn{2}{|c|}{$\begin{array}{c}\text { Grupo } 3 \text { - } \\
\text { População saudável }\end{array}$} \\
\hline & $\mathbf{N}$ & $\%$ & $\mathbf{N}$ & $\%$ & $\mathbf{N}$ & $\%$ \\
\hline A2 & 01 & 8,3 & - & - & 01 & 3,57 \\
\hline B1 & - & - & 02 & 12.5 & 02 & 7,14 \\
\hline B2 & 03 & 25 & 06 & 37,5 & 09 & 32,14 \\
\hline C1 & 06 & 50 & 05 & 31,25 & 11 & 39,28 \\
\hline $\mathrm{C} 2$ & 01 & 8,3 & 02 & 12,5 & 03 & 10,71 \\
\hline $\mathrm{D}$ & 01 & 8,3 & 01 & 6,25 & 02 & 7,14 \\
\hline Total & \multicolumn{2}{|c|}{$12(100)$} & \multicolumn{2}{|c|}{$16(100)$} & \multicolumn{2}{|c|}{$28(100)$} \\
\hline
\end{tabular}

Quanto à classificação econômica, $50 \%$ dos sujeitos que compõem o grupo 01 e $31,25 \%$ dos sujeitos do grupo 2 pertencem à classe $\mathrm{C} 1$, com renda familiar em média de $\mathrm{R} \$ 1.390,00$ reais, e que $37,5 \%$ dos sujeitos do grupo 2 pertencem à classe B2 com renda familiar em média de $\mathrm{R} \$ 2.327,00$.

A seguir, serão apresentados os dados referentes aos diagnósticos (Tabela 4) e local anatômico da lesão (Tabela 5), considerando apenas os sujeitos dos grupos 1 e 2.

Tabela 4 - Tipos de tumor

\begin{tabular}{|c|c|c|c|c|c|}
\hline \multirow[t]{2}{*}{ Variável } & \multirow[t]{2}{*}{ Categoria } & \multicolumn{2}{|c|}{$\begin{array}{c}\text { Grupo } 1 \text { - } \\
\text { Amputados }\end{array}$} & \multicolumn{2}{|c|}{$\begin{array}{c}\text { Grupo } 2 \text { - } \\
\text { Salvamento de } \\
\text { membro }\end{array}$} \\
\hline & & $\mathbf{N}$ & $\%$ & $\mathbf{N}$ & $\%$ \\
\hline \multirow{6}{*}{$\begin{array}{l}\text { Tumor } \\
\text { maligno }\end{array}$} & Osteossarcoma & 05 & 17,86 & 06 & 21,43 \\
\hline & Fibro-histocitoma maligno & - & - & 01 & 3,58 \\
\hline & Sarcoma sinovial & 01 & 3,58 & - & - \\
\hline & Condrossarcoma & 01 & 3,58 & 01 & 3,58 \\
\hline & Sarcoma Ewing & - & - & 01 & 3,58 \\
\hline & Subtotal & 07 & 25 & 09 & 32,17 \\
\hline \multirow{5}{*}{$\begin{array}{l}\text { Tumor } \\
\text { benigno } \\
\text { agressivo }\end{array}$} & Miosite ossificante & 01 & 3,58 & - & - \\
\hline & Tumor de célula gigante & 02 & 7,14 & 07 & 25 \\
\hline & Sinovite vilonodular pigmentada & 01 & 3,58 & - & - \\
\hline & Hemangioma & 01 & 3,58 & - & - \\
\hline & Subtotal & 05 & 17,88 & 7 & 25 \\
\hline & Total & \multicolumn{4}{|c|}{$28(100)$} \\
\hline
\end{tabular}


Em relação ao diagnóstico, 12 sujeitos foram diagnosticados com tumor benigno agressivo e 16 apresentaram diagnóstico de tumor maligno, sendo que sete são do grupo 1 e nove, do grupo 2.

Tabela 5 - Região onde está localizado o tumor

\begin{tabular}{ccccc}
\hline & \multicolumn{2}{c}{$\begin{array}{c}\text { Grupos 1 - } \\
\text { Amputados }\end{array}$} & \multicolumn{2}{c}{$\begin{array}{c}\text { Grupo 2 - } \\
\text { Salvamento de } \\
\text { membro }\end{array}$} \\
\cline { 2 - 5 } & $\mathbf{N}$ & $\mathbf{\%}$ & $\mathbf{N}$ & $\%$ \\
\hline Fêmur terço distal & 06 & 21,42 & 12 & 42,86 \\
Tíbia proximal & 01 & 3.58 & 04 & 14,29 \\
Tornozelo & 03 & 10,71 & - & - \\
Pé & 02 & 7,14 & - & - \\
\hline Total & \multicolumn{4}{c}{$28(100)$} \\
\hline
\end{tabular}

Observa-se uma prevalência $(21,42 \%$ no grupo 1 e $42,86 \%$ do grupo 2$)$ da incidência dos tumores musculoesqueléticos localizados no fêmur distal (região do joelho), o que condiz com a literatura a respeito destes tumores.

Na Tabela 6, a seguir, são apresentados os resultados referentes aos tipos de procedimentos realizados.

Tabela 6 - Procedimentos realizados

\begin{tabular}{rrrcc}
\hline \multirow{2}{*}{ Procedimento } & \multicolumn{2}{c}{$\begin{array}{c}\text { Grupo 1 - } \\
\text { amputados }\end{array}$} & \multicolumn{2}{c}{$\begin{array}{c}\text { Grupo 2- } \\
\text { salvamento de } \\
\text { membro }\end{array}$} \\
\cline { 2 - 6 } & N & $\%$ & N & $\%$ \\
\hline Amputação Primária & 09 & 32,14 & - & - \\
Amputação Secundária & 03 & 10,71 & - & - \\
\hline Subtotal & 12 & 42,85 & - & - \\
\hline Endoprótese & - & - & 10 & 35,71 \\
Reconstrução biológica & - & - & 06 & 21,44 \\
\hline Subtotal & - & - & 16 & 57,15 \\
\hline Total & & \multicolumn{2}{c}{$28(100 \%)$} \\
\end{tabular}

Observa-se que, dentre aqueles pertencentes aos grupos 1 e 2 , submetidos a procedimentos cirúrgicos para ressecção dos tumores, houve prevalência de procedimentos de salvamento de membro (em $57,15 \%$ dos 28 sujeitos). 
Dentre os sujeitos que passaram pela amputação (42,85\% dos 28 sujeitos), 10,71\% tiveram amputação secundária ao procedimento de reconstrução, tendo passado por diversas intercorrências, como infecções, diversas idas ao centro cirúrgico, dor e limitação na funcionalidade.

É preciso destacar que a indicação do tipo de procedimento cirúrgico não está diretamente relacionada à malignidade do tumor, pois podem ocorrer amputações ou procedimentos de salvamento do membro, tanto em casos de tumores malignos como de tumores benignos agressivos. A definição dos procedimentos depende também do grau de comprometimento das estruturas (muscular, óssea, vascular, articular) onde se localiza o tumor.

A Tabela 7, a seguir, apresenta os dados referentes ao tempo de pósoperatório (PO).

Tabela 7 - Tempo de pós-operatório

\begin{tabular}{llcccc}
\hline \multicolumn{1}{c}{ Tempo de pós-operatório } & \multicolumn{2}{c}{$\begin{array}{c}\text { Grupo 1 - } \\
\text { Amputados }\end{array}$} & $\begin{array}{c}\text { Grupo 2 - } \\
\text { Salvamento de } \\
\text { membro }\end{array}$ \\
\hline \multicolumn{1}{c}{ Variável } & N & $\%$ & $\mathbf{N}$ & $\%$ \\
\hline $\begin{array}{l}\text { Pós-operatório recente } \\
\text { (até 1 ano e 11 meses após a cirurgia) }\end{array}$ & 02 & 7,14 & 02 & 7,14 \\
$\begin{array}{l}\text { Pós-operatório tardio } \\
\text { (mais de 2 anos após a cirurgia) }\end{array}$ & 10 & 35,72 & 14 & 50 \\
\hline & Total & \multicolumn{3}{c}{$28(100 \%)$} \\
\hline
\end{tabular}

Em relação ao tempo de pós-operatório, a partir da realização da primeira cirurgia, 24 sujeitos $(85,72 \%$ da casuística total, dentre os grupos 1 e 2$)$ estavam com mais de 2 anos PO (tardio).

Dentre os 16 sujeitos que compõem o grupo 2, 12 pessoas já passaram por mais de uma cirurgia no decorrer do tempo, em decorrência de complicações como infecções, soltura do material e rigidez articular. Esse dado indica que os sujeitos (a maioria está em PO tardio) já passaram pelo impacto inicial do diagnóstico e os primeiros meses de tratamento, sendo esperado que tenham conseguindo retomar suas atividades cotidianas, mas as complicações decorrentes dos procedimentos podem ter impactado sua funcionalidade e qualidade de vida. 


\subsection{O Toronto Extremity Salvage Escore - TESS}

O Toronto Extremity Salvage Escore (TESS) é um instrumento que, além da avaliação de funcionalidade especificamente, permite também coletar dados referentes ao uso de medicação para dor e sobre a necessidade dos sujeitos de uso de equipamentos auxiliares para deambular, como demonstrado na Tabela 8, a seguir.

Tabela 8 - Variáveis TESS

\begin{tabular}{|c|c|c|c|c|c|c|c|}
\hline \multirow[t]{2}{*}{ Variável } & \multirow[t]{2}{*}{ Categoria } & \multicolumn{2}{|c|}{$\begin{array}{l}\text { Grupo } 1 \text { - } \\
\text { Amputados }\end{array}$} & \multicolumn{2}{|c|}{$\begin{array}{c}\text { Grupo } 2 \text { - } \\
\text { Salvamento de } \\
\text { membro }\end{array}$} & \multicolumn{2}{|c|}{$\begin{array}{c}\text { Grupo } 3 \text { - } \\
\text { População } \\
\text { saudável }\end{array}$} \\
\hline & & $\mathbf{N}$ & $\%$ & $\mathbf{N}$ & $\%$ & $\mathbf{N}$ & $\%$ \\
\hline \multirow{4}{*}{$\begin{array}{c}\text { Auxílio para } \\
\text { deambular }\end{array}$} & Nenhuma & 06 & 10,71 & 12 & 21,42 & 28 & 50 \\
\hline & $\begin{array}{l}\text { Uma bengala ou } \\
\text { muleta }\end{array}$ & - & - & 02 & 3,57 & - & - \\
\hline & Duas muletas & 06 & 10,71 & 02 & 3,57 & - & - \\
\hline & Tota & \multicolumn{6}{|c|}{$56(100 \%)$} \\
\hline \multirow{3}{*}{$\begin{array}{c}\text { Uso } \\
\text { medicação } \\
\text { para dor }\end{array}$} & Sim & 03 & 5,35 & 04 & 7,14 & 8 & 14,28 \\
\hline & Não & 09 & 16,07 & 12 & 21,42 & 20 & 35,71 \\
\hline & Tota & \multicolumn{6}{|c|}{$56(100 \%)$} \\
\hline
\end{tabular}

Observa-se que 18 sujeitos dos grupos 1 e 2 não necessitam de auxílio para deambular, enquanto os outros 10 necessitam de algum tipo de apoio (bengalas ou muletas). No grupo 3, nenhum dos sujeitos (28) necessita de auxílio para deambulação. Quanto ao uso de medicação para dor, a maioria dos sujeitos da pesquisa refere não usá-la.

Os resultados de todos os sujeitos da pesquisa, obtidos através da aplicação do instrumento (TESS), podem ser consultados no Anexo 9 deste trabalho.

Quando realizado o teste de Kruskal-Wallis (Tabela 8), comparando-se os escores finais do TESS para os três grupos do estudo, observa-se que houve diferença estatisticamente significativa entre os grupos com $p<0,001$. 
Tabela 9 - Escore final TESS -teste de Kruskal-Wallis

\begin{tabular}{lcc}
\hline & $\mathbf{X}^{2}$ & $\mathbf{p}$ \\
ESCORE FINAL & 25,349 &, $000^{*}$ \\
\hline
\end{tabular}

a. Kruskal Wallis Test

b. Grouping Variable: GRUPOS

$p<0,001$

Para identificar onde mais especificamente ocorreu a diferença estatisticamente significativa, foi realizado o teste de Post Hoc de Dunn, apresentado na Tabela 10 a seguir.

Tabela 10 - Comparação do escore final do TESS pelo Teste Post Hoc DUNN

\begin{tabular}{cccc}
\hline ESCORE FINAL & $\begin{array}{c}\text { Grupo 1 - } \\
\text { Amputados }\end{array}$ & $\begin{array}{c}\text { Grupo 2 - } \\
\text { Salvamento de } \\
\text { membros }\end{array}$ & $\begin{array}{c}\text { Grupo 3 - } \\
\text { População } \\
\text { saudável }\end{array}$ \\
\hline $\mathrm{N}^{\circ}$ de indivíduos & 12 & 16 & 28 \\
\hline Média & 84,6683 & 69,2613 & 96,0479 \\
Minimum & 40,38 & 20,54 & 54,00 \\
Maximum & 100,00 & 100,00 & 100,00 \\
Mediana & 96,1200 & 64,3550 & 100,0000 \\
Desvio-padrão & 21,16892 & 21,32005 & 10,72097 \\
\hline
\end{tabular}

$p=0,10$ no Final escore - grupos $1 \times 2$

$p=0,002^{*}$ no Final escore - grupos $1 \times 3$

$p<0,001^{*}$ no Final escore - grupos $2 \times 3$

Constata-se uma grande variação entre os escores finais do TESS dos sujeitos da pesquisa. Houve diferença estatisticamente significativa entre os grupos 1 e $3\left(p=0,002^{*}\right)$ e também entre os grupos 2 e $3\left(p<0,001^{*}\right)$, sendo que os grupos 1 e 2 têm médias e medianas abaixo da população saudável (grupo 3).

Embora essa diferença estatisticamente significativa não tenha sido constatada na comparação entre os grupos 1 e $2(p=0,10)$, as médias e medianas do grupo 1 são maiores do que as do grupo 2, sugerindo que os amputados podem apresentar melhor capacidade funcional no que se refere aos itens avaliados pelo protocolo utilizado (TESS) do que aqueles submetidos a salvamento de membro. 


\subsection{Medical Outcomes Study 36 - Item Short-Form Health Survey - SF-36}

Na Tabela 10 a seguir, serão apresentados os dados referentes aos domínios do SF36 e a comparação entres os grupos.

Os resultados de todos os sujeitos da pesquisa, obtidos através da aplicação do SF-36, podem ser consultados no Anexo 8 deste trabalho. No caso das respostas dos sujeitos que não atingiram a pontuação mínima num domínio específico, de acordo com o especificado na metodologia da escala, a casela ficou como não preenchida. Entretanto, para não criar um desvio na análise estatística, a resposta foi considerada como pontuação zero, o que indica grande prejuízo no respectivo domínio. 
Tabela 11 - Comparação dos dados dos grupos, referentes ao teste estatístico: SF $36^{\text {a,b }}$

\begin{tabular}{|c|c|c|c|c|c|c|c|c|c|}
\hline & & $\begin{array}{c}\text { Capacidade } \\
\text { Funcional }\end{array}$ & $\begin{array}{l}\text { Aspectos } \\
\text { Físicos }\end{array}$ & Dor & $\begin{array}{l}\text { Estado Geral } \\
\text { de Saúde }\end{array}$ & Vitalidade & $\begin{array}{c}\text { Aspecto } \\
\text { Social }\end{array}$ & $\begin{array}{c}\text { Aspecto } \\
\text { Emocional }\end{array}$ & $\begin{array}{l}\text { Saúde } \\
\text { Mental }\end{array}$ \\
\hline & Média & 70,4167 & 72,9167 & 66,0000 & 80,8333 & 69,1667 & 73,9583 & 58,3250 & 77,3333 \\
\hline Grupo 1 & Mediana & 82,5000 & 100,0000 & 56,5000 & 84,5000 & 75,0000 & 87,5000 & 66,6500 & 78,0000 \\
\hline \multirow[t]{2}{*}{$(n=12)$} & Desvio-padrão & 30,03470 & 40,53384 & 31,32817 & 16,60139 & 19,28652 & 33,48097 & 45,23173 & $13,5735 \subseteq$ \\
\hline & Média & 52,1875 & 59,3750 & 65,4375 & 72,4375 & 64,6875 & 67,1875 & 70,8313 & 68,2500 \\
\hline Grupo 2 & Mediana & 52,5000 & 87,5000 & 72,0000 & 74,5000 & 65,0000 & 68,7500 & 100,0000 & 70,0000 \\
\hline \multirow[t]{2}{*}{$(n=16)$} & Desvio-padrão & 24,35630 & 45,52929 & 34,04501 & 18,79351 & 18,92694 & 29,53635 & 41,94728 & 19,99833 \\
\hline & Média & 88,3929 & 89,2857 & 73,5714 & 74,1786 & 56,9643 & 85,7143 & 78,5750 & 67,5714 \\
\hline Grupo 3 & Mediana & 95,0000 & 100,0000 & 72,0000 & 77,0000 & 62,5000 & 100,0000 & 100,0000 & 70,0000 \\
\hline \multirow[t]{3}{*}{$(n=28)$} & Desvio-padrão & 19,00553 & 26,72612 & 23,16515 & 20,77223 & 20,51825 & 23,98743 & 38,71731 & 21,06327 \\
\hline & Chi-Square & 16,393 & 6,223 &, 560 & 1,356 & 4,212 & 5,769 & 1,748 & 2,546 \\
\hline & $\mathbf{p}$ &, 000 * &, $045 *$ & ,756 &, 508 &, 122 &, 056 * &, 417 & ,280 \\
\hline
\end{tabular}

\footnotetext{
a. Kruskal Wallis Test

b. Grouping Variable: GRUPOS
} 
O grupo 1 (amputados) apresenta médias e medianas com valores mais elevados do que o grupo 2 (salvamento de membros) nos domínios: Capacidade Funcional, Aspectos Físicos, Dor, Estado Geral de Saúde, Vitalidade, Saúde Mental, quando comparados com o grupo 02.

No domínio estado geral de saúde, o grupo 3 (população saudável) apresenta média e medianas menores que os valores do grupo 1 e maiores do que o grupo 2 . No domínio Vitalidade, os valores do grupo 3 são menores do que os encontrados tanto no grupo 1 como no grupo 2.

O domínio Aspecto Emocional foi o único em que o grupo 2 apresenta média e mediana superiores ao grupo 1, ainda que menores do que o grupo 3.

Observe-se que, na comparação entre os grupos, houve diferenças estatisticamente significativas nos domínios Capacidade Funcional $\left(p<0,001^{*}\right)$, Aspectos Físicos $(p=0,045)$ e Aspecto Social $(p=0,056)$. Para identificar onde mais especificamente ocorreram estas diferenças, foi realizado o teste de Post Hoc de Dunn, como demonstrado nas Tabelas 12, 13 e 14, a seguir:

Tabela 12 - Capacidade funcional (post hoc de Dunn)

\begin{tabular}{|c|c|c|c|}
\hline \multicolumn{4}{|c|}{ Capacidade Funcional } \\
\hline & \multicolumn{3}{|c|}{ St } \\
\hline & $\begin{array}{c}\text { Grupo } 1 \text { - } \\
\text { Amputados }\end{array}$ & $\begin{array}{c}\text { Grupo } 2 \text { - } \\
\text { Salvamento de } \\
\text { membros }\end{array}$ & $\begin{array}{c}\text { Grupo } 3 \text { - } \\
\text { População } \\
\text { saudável }\end{array}$ \\
\hline & $\mathrm{N}=12$ & $\mathbf{N}=16$ & $N=28$ \\
\hline 3 & & & 88,3929 \\
\hline 2 & 70,4167 & & \\
\hline 1 & & 52,1875 & \\
\hline \multicolumn{4}{|c|}{ Subset for alpha $=0.05$} \\
\hline \multicolumn{4}{|c|}{ Means for groups in homogeneous subsets are displayed. } \\
\hline \\
\hline \multicolumn{4}{|c|}{$\begin{array}{l}\text { b. The group sizes are unequal. The harmonic mean of the group sizes is used. } \\
\text { Type I error levels are not guaranteed. }\end{array}$} \\
\hline
\end{tabular}

O resultado do grupo 3 foi superior ao do grupo 1 e este foi superior ao do grupo 2. O mesmo ocorreu nos domínios de Aspectos Físicos (Tabela 13) e Aspectos Sociais (Tabela 14). 
Tabela 13 - Aspectos físicos (post hoc de Dunn)

\begin{tabular}{cccc}
\hline & \multicolumn{2}{c}{ Aspectos Físicos } & \multicolumn{2}{c}{ Student-Newman-Keuls a,b $^{\mathrm{a}}$} \\
\hline & $\begin{array}{c}\text { Grupo 1 - } \\
\text { Amputados }\end{array}$ & $\begin{array}{c}\text { Grupo 2 - } \\
\text { Salvamento de } \\
\text { membros }\end{array}$ & $\begin{array}{c}\text { Grupo 3 - } \\
\text { População } \\
\text { saudável }\end{array}$ \\
\cline { 2 - 4 } & $\mathbf{N = 1 2}$ & $\mathbf{N = 1 6}$ & $\mathbf{N = \mathbf { 2 8 }}$ \\
\hline $\mathbf{3}$ & 72,9167 & & 89,2857 \\
$\mathbf{2}$ & & 59,3750 & \\
$\mathbf{1}$ & & &
\end{tabular}

Subset for alpha $=0.05$

Means for groups in homogeneous subsets are displayed.

a. Uses Harmonic Mean Sample Size $=16.525$.

b. The group sizes are unequal. The harmonic mean of the group sizes is used.

Type I error levels are not guaranteed.

A seguir (Tabela 14), os dados referentes ao domínio Aspecto Social.

Tabela 14 - Aspecto social (post hoc de Dunn)

\begin{tabular}{cccc}
\hline & \multicolumn{2}{c}{ Aspectos Sociais } & \multicolumn{2}{c}{ Student-Newman-Keuls ${ }^{\mathrm{a}, \mathrm{b}}$} \\
\hline & $\begin{array}{c}\text { Grupo 1 - } \\
\text { Amputados }\end{array}$ & $\begin{array}{c}\text { Grupo 2 - } \\
\text { Salvamento de } \\
\text { membros }\end{array}$ & $\begin{array}{c}\text { Grupo 3 - } \\
\text { População } \\
\text { saudável }\end{array}$ \\
\cline { 2 - 4 } & $\mathbf{N = 1 2}$ & $\mathbf{N = 1 6}$ & $\mathbf{N = 2 8}$ \\
\hline $\mathbf{3}$ & & & 85,7143 \\
$\mathbf{2}$ & 73,9583 & & \\
$\mathbf{1}$ & & 67,1875 & \\
\hline
\end{tabular}

Subset for alpha $=0.05$

Means for groups in homogeneous subsets are displayed.

a. Uses Harmonic Mean Sample Size $=16.525$.

b. The group sizes are unequal. The harmonic mean of the group sizes is used. Type I error levels are not guaranteed.

Constata-se que tanto no domínio da Capacidade Funcional, como nos Aspectos Físicos e Sociais, os resultados do grupo 3 (saudáveis) são superiores aos do grupo 2 (salvamento de membros), com valores intermediários para o grupo 1 (amputados). 


\section{DISCUSSÃO}

A literatura nacional e a internacional atual têm discutido os procedimentos cirúrgicos de amputação e salvamento de membros no tratamento de pacientes com tumores musculoesqueléticos e seu impacto na funcionalidade e na qualidade de vida (QVRS) dos sobreviventes. Na prática clínica, a preservação de membros tem sido a indicação preferencial, e a amputação é reservada para casos em que não é possível preservar, mas sua indicação tem decaído nas últimas décadas e hoje está por volta de 5 a $10 \%$ em países desenvolvidos.

Há diversos estudos que comparam os dados referentes a grupos submetidos à amputação com dados dos grupos submetidos a procedimentos de salvamento de membros, para avaliar se há impactos diferentes na qualidade de vida dos sujeitos (AKNES et al., 2008; GINSBERG et al., 2007; ROBERT et al., 2010; SKALICZKI et al., 2005).

Porém, há poucos estudos nacionais que ofereçam dados sobre o impacto desses diferentes procedimentos na funcionalidade e na qualidade de vida de pacientes com tumores musculoesqueléticos de membros inferiores, considerando a realidade da população brasileira, particularmente daquela atendida num hospital público universitário, dentro da realidade do Sistema Único de Saúde (SUS).

Serão apresentadas, a seguir, reflexões sobre os resultados alcançados.

Quanto aos dados sociodemográficos referentes aos sujeitos desta pesquisa, na questão de gênero houve a prevalência de mulheres nos três grupos, assim como aconteceu nos trabalhos de revisão de Zetzer et al. (2009) e Robert et al. (2010) sobre população semelhante.

Quanto à idade, a maioria é de jovens (de 20 a 29 anos) nos 3 grupos do estudo. Esse resultado condiz com outros trabalhos, como Ginsberg et al. (2007), Saraiva (2007), Malek et al. (2012) que também apontaram a ocorrência desses tumores musculoesqueléticos predominantemente na população de adolescentes e de adultos jovens. Há de se observar que esta faixa etária corresponde ao período do ensino médio e superior (escolha da carreira profissional) e também com o início da vida produtiva (trabalho) que são interrompidos para a realização do tratamento.

Embora os sujeitos do grupo 2 (de reconstrução) apresentem níveis socioeconômicos mais elevados (50\% somando-se classes B1 e B2), há predomínio 
de níveis mais baixos de escolaridade (68,75\% estão entre analfabetos e aqueles com ensino fundamental completo e incompleto). No grupo 1 (de amputados), há predomínio de sujeitos da classe C (58,3\% dos sujeitos, somando-se C1 e C2), contudo há sujeitos com maior escolaridade $(41,7 \%$ têm ensino médio completo ou incompleto e há também 16,6\% com nível superior completo ou incompleto).

Esses dados de escolaridade (maior no grupo 1) podem ter influenciado a percepção de qualidade de vida dos sujeitos da pesquisa, porém, o mais elevado nível socioeconômico do grupo 2 também deve ter influenciado nessa percepção de QV, não explicando por que os resultados da avaliação de QVRS foram, em geral, maiores no grupo de amputados do que nos de salvamento de membros.

Porém, há de se destacar que o cálculo dos níveis socioeconômicos do Critério Brasil leva em consideração o nível de escolaridade do chefe da residência, que não é, necessariamente, o sujeito da pesquisa.

Quanto à atividade profissional, destaca-se que o grupo 1, de amputados, tem um número maior de aposentados e afastados do trabalho com rendimentos $(66,75 \%)$, enquanto há mais pessoas ativas (com ou sem registro) dentre os sujeitos do grupo 2 (43,75\%), além dos $25 \%$ entre os estudantes e do lar.

O fato de manter-se ativo e produtivo deveria ser um aspecto que contribuiria para uma melhor qualidade de vida. Entretanto, não parece ser o que acontece entre os sujeitos desta pesquisa, pois há melhor percepção de QVRS no grupo 1 (amputados) que é aquele onde há predomínio de sujeitos que estão afastados do trabalho produtivo.

Quanto à prevalência histológica dos tumores primários musculoesqueléticos, foram $39,23 \%$ de osteossarcoma $(17,86 \%$ do grupo de amputados e $21,43 \%$ do grupo de salvamento de membro) e $32,14 \%$ de tumores de células gigantes $(7,14 \%$ do grupo de amputados e $25 \%$ do grupo de salvamento de membro). Esse dado é condizente com os resultados do estudo de Tunn et al. (2008), cuja casuística foi composta por 87 sujeitos, com prevalência de osteossarcomas (61\%), de condrossarcoma $(16,1 \%)$, tumor de célula gigante $(10,4 \%)$ e outros tipos de tumores (como sarcoma de Ewing, fibro-histocitoma maligno).

O estudo de Hinds et al. (2009), cuja casuística foi composta por 71 sujeitos, apontou que $65 \%$ dos tumores localizam-se na região distal do fêmur e $24 \%$, na região da tíbia proximal, o que também condiz com os resultados do presente estudo 
que constatou $64,28 \%$ dos tumores localizados na região de fêmur distal e $17,87 \%$ na região da tíbia proximal.

Neste estudo observou-se que houve prevalência de procedimentos de salvamento de membro $(57,15 \%)$ em comparação com o número de amputações realizadas. A literatura nacional e a internacional (SARAIVA 2007; MALEK et al., 2012.; AKSNES et al., 2007) têm apontado o aumento na realização de procedimentos de salvamento de membro na atualidade, para a ressecção de todos os tipos de tumores musculoesqueléticos malignos e benignos agressivos.

Os resultados do presente estudo indicam que tanto os amputados como os que foram submetidos a procedimentos de salvamento de membros apresentam alterações na sua capacidade funcional e qualidade de vida, quando comparados à população saudável (controle).

A funcionalidade foi analisada através da aplicação do Toronto Extremity Salvage Escore (TESS). O conceito de funcionalidade é aqui compreendido de acordo com o definição apresentada pela "CIF Classificação Internacional de Funcionalidade, Incapacidade e Saúde" (OMS, 2003) que não considera somente a função física específica (amplitude de movimento, força, dentre outros), mas envolve também outros aspectos importantes, como atividades, participação social e questões ambientais. Os resultados alcançados neste estudo, referentes à funcionalidade, foram comparados com outros resultados encontrados na literatura nacional e internacional.

Com a finalidade de caracterizar os grupos de pacientes submetidos aos procedimentos cirúrgicos (amputação e cirurgia conservadora), Aksnes et al. (2007) associaram diversas variáveis: sexo, região, tempo de acompanhamento pósoperatório e idade no momento da cirurgia com o procedimento cirúrgico e concluíram que não houve nenhuma diferença entre os referidos grupos. Contudo, mostraram que os sobreviventes de tumores ósseos e sarcomas musculoesqueléticos apresentam maiores taxas de comprometimento da saúde física e aumento dos relatos de dor, após tratamento cirúrgico e poliquimioterapia adjuvante, em comparação com seus irmãos saudáveis. Os autores salientam a importância das limitações no funcionamento físico e consequências estéticas como segundo aspecto importante de descontentamento do grupo de estudo comparado à população normal. 
Aksnes et al. (2008) avaliaram a função de 118 pacientes que passaram por cirurgia de salvamento de membro e amputação cinco anos após tratamento para osteossarcoma e sarcoma de Ewing, através de vários instrumentos, dentre eles o TESS. Não foi encontrada diferença estatisticamente significativa entre grupos de amputados e de salvamento de membro nos dados do TESS e na QVRS (SF36), quanto à funcionalidade, exceto no que se referiu à capacidade física que se mostrou pior no grupo de amputados. Robert et al. (2010) avaliaram 57 sujeitos comparando amputação e salvamento de membro, utilizando diferentes questionários, e tampouco encontraram diferença significativa no que diz respeito aos escores do TESS. Entretanto, referem que a função do membro inferior foi um preditor significativo de qualidade de vida.

No presente estudo, houve diferenças estatisticamente significativas entre os escores finais do TESS, quando comparados o grupo saudável e os outros dois grupos do estudo ( $p=0,002$ entre os grupos 1 e 3 e $p<0,001$ entre os grupos 2 e 3 ). Esse resultado condiz com o que vem sendo apontado na literatura (AKNES et al., 2007; BEKKERING et al., 2010; KOOPMAN et al., 2005; ZELTER et al., 2009). Quando comparados com pares saudáveis, os sujeitos que passaram pelos procedimentos de amputação e/ou salvamento de membro têm sua funcionalidade comprometida, em relação aos níveis encontrados na população em geral.

Não foram constatadas diferenças estatisticamente significativas, quando comparados os grupos 1 e $2(p=0,10)$, fato este que pode ter sido influenciado pelo número restrito de sujeitos nestes grupos do estudo. Apesar disso, nossos achados permitem indicar que a média e a mediana do grupo de amputados foram superiores às do grupo de salvamento de membro. Esses dados sugerem que os amputados podem apresentar melhor capacidade funcional no que se refere aos itens avaliados pelo protocolo utilizado (TESS) do que aqueles submetidos a procedimentos de salvamento de membros.

Nos estudos de Saraiva (2007) e Saraiva, Camargo e Davis (2008), desenvolvidos no Brasil em hospitais de grande porte para avaliação de funcionalidade, foi encontrada diferença estatisticamente significativa $(p=0,003)$ entre os escores finais do TESS. Concluíram que os que foram submetidos à amputação apresentaram-se melhor funcionalmente do que aqueles submetidos a cirurgias conservadoras. 
No estudo de Refaat et al., 2002 (apud SARAIVA, 2007), a cirurgia de amputação também apresentou melhor função do que a cirurgia conservadora, sendo que este autor refere a necessidade de considerar outros aspectos, tais como a parte social e psicológica, antes de adotar o procedimento cirúrgico que pode interferir na vida do paciente.

Em relação aos achados sobre a qualidade de vida relacionada à saúde, Aksnes et al. (2008) concluíram que os sujeitos que passaram por cirurgia de salvamento de membro apresentam melhores escores do que os amputados nos componentes capacidade física e aspectos físicos (SF36).

Outros estudos internacionais, como de Rougraff et al. (1994), Daigeler et al. (2009), Hinguranage et al. (2004), Nagarajan et al. (2004) e Tunn et al. (2008), observaram que não há diferença estatística relevante quando se compara a qualidade de vida em geral em sujeitos submetidos aos dois tipos de procedimento amputação ou colocação da endoprotese. Contudo, constataram que houve diferença entre os pacientes em relação à retomada de suas atividades diárias. Aqueles que colocaram endopróteses tiveram menos dificuldades do que os amputados, apesar da possibilidade de intercorrências.

Nas cirurgias de salvamento do membro, costumam ocorrer maiores complicações do que nas amputações, tanto a curto quanto a médio e longo prazos (NAGARAJAN et al., 2002; ROUGRAFF et al., 1994). As intercorrências podem ser de diversos tipos, como infecções, fraturas, necessidade de revisão da endoprótese, soltura do material, manipulação sob anestesia devido à rigidez articular, necessidade de liberação de cápsula articular, dor e outros tipos de comprometimentos, tendo de ficar em acompanhamento por mais tempo do que os amputados.

Neste estudo, dos 16 sujeitos submetidos a este tipo de procedimento de salvamento do membro, todos passaram por algum tipo de intercorrência. Dentre os 12 sujeitos que foram amputados, três (10,71\% dos 28 sujeitos dos grupos 1 e 2) tiveram amputação secundária ao procedimento de reconstrução, tendo passado também por diversas complicações.

Ginsberg et al. (2007) indicaram que uma das vantagens de uma amputação é que é tipicamente o último procedimento cirúrgico e permite que o paciente continue com a sua vida, sem a preocupação com a falha do dispositivo ou outros tipos de intercorrências. 
Portanto, as intercorrências clínicas decorrentes dos procedimentos de salvamento de membros podem ter impactado e comprometido sua percepção de funcionalidade e qualidade de vida mais do que no grupo de amputados, o que pode explicar maiores índices de Qualidade de vida entre os sujeitos do grupo 1.

Uma revisão sistemática recente sobre sarcomas de extremidade em adultos jovens (TANG et al., 2012) sintetizou resultados de diversos estudos sobre QVRS: Eiser et al. (2001) encontraram piores escores do TESS e imagem corporal como preditores de uma pior QVRS; Schreiber et al. (2006) apontaram que complicações na cirurgia e escores baixos no TESS são preditores de uma pior QVRS; Davidge et al. (2009) associaram uma pior QVRS com incertezas quanto às expectativas do tratamento; Thijssens et al. (2006) apontaram que a dor está associada à pior QVRS.

Com a aplicação do SF-36 e a comparação entre os três grupos neste estudo, constatou-se que houve diferenças estatisticamente significativas nos domínios Capacidade Funcional $\left(p<0,001^{*}\right)$, Aspectos Físicos $(p=0,045)$ e Aspecto Social $(p=0,56)$. Os sujeitos pertencentes ao grupo 1 (amputados) apresentaram melhores escores em sete (7) dos oito (8) domínios avaliados pelo SF-36 em relação ao grupo 2 (salvamento de membro), exceto no domínio Aspecto Emocional do SF-36. Esse fato pode ser compreendido a partir da argumentação de Nagarajan et al. (2002) que afirmam que o salvamento de membros é o mais aceito socialmente, e que os pacientes que tiveram seus membros salvos relatam menos isolamento social do que os que sofreram amputações, o que deve ter influenciado nos aspectos emocionais analisados através do SF-36.

Nos domínios de Estado Geral de Saúde e Vitalidade do SF-36, os sujeitos amputados tiveram escores mais altos do que aqueles do grupo 2, como demonstrado na Tabela 11. É possível inferir que o grupo 1 tem uma percepção de que seu estado de saúde é melhor, inclusive quando comparado com os sujeitos saudáveis, possivelmente em comparação a fases do seu tratamento anteriores à amputação, em que sua qualidade de vida estava ainda mais comprometida.

Portanto, é possível observar o quanto vasta e controversa é a discussão em relação a procedimento cirúrgico elegível e que pode promover melhor funcionalidade e qualidade de vida aos pacientes com tumores musculoesqueléticos.

Resultados relacionados à tomada de decisão e à participação do paciente na escolha do tratamento também têm sido abordados. A tomada de decisão é um 
determinante importante dos resultados do tratamento dos pacientes com osteosarcoma. Quando a escolha do tratamento é feita somente pelo cirurgião, sem a colaboração do paciente, há uma diminuição significativa do funcionamento social e mais limitações no curso do tratamento (ROBERT et al., 2010; THIJSSENS et al., 2006). Por conseguinte, constataram que quanto maior a interação entre cirurgião e o paciente na decisão do tratamento, o nível de satisfação foi significativamente maior e relacionado com um melhor funcionamento social, mais vitalidade, melhor percepção de saúde, menor tendência à fuga e menor impacto nos escores das escalas utilizadas.

Na mesma linha de pensamento, Hinds et al. (2009) avaliaram o impacto do tratamento na qualidade de vida, realizando avaliações em diferentes fases do tratamento: ao diagnóstico, período pré-cirúrgico, durante o tratamento quimioterápico e 20 semanas após a conclusão do tratamento. Os autores concluíram que a qualidade de vida melhora ao longo do tratamento, mas que a equipe deve sempre preparar pacientes e familiares para o tratamento, alertando para os sintomas que podem aparecer, como limitações funcionais, angústias, alterações de humor, sono e apetite, entre outros.

Inconsistências nos estudos com pacientes sobreviventes de tumores ósseos também têm sido discutidas (GINSBERG et al., 2007) devido à limitação do número de pacientes e aos desenhos metodológicos. Como alternativas, os autores sugerem a necessidade de desenvolver estudos multicêntricos e com seguimento maior, para chegar a conclusões mais fidedignas e que respondam aos diversos questionamentos inerentes ao tratamento, aos impactos, às decisões operatórias, à sobrevida e à qualidade de vida desses pacientes.

Portanto, os dois tipos de procedimentos cirúrgicos apresentam aspectos positivos e negativos que sugerem a necessidade de novos e detalhados estudos envolvendo maior número de pacientes. 
CONSIDERAÇÕES FINAIS 


\section{CONSIDERAÇÕES FINAIS}

A promoção da funcionalidade e da qualidade de vida relacionada à saúde tem sido um fator de grande importância nos processos de atenção à saúde por parte de todos os membros da equipe multiprofissional, particularmente para os sobreviventes de câncer.

O SF-36 tem se mostrado um instrumento útil em pesquisas de populações gerais e com condições clínicas específicas, considerando os benefícios à saúde produzidos por uma grande variedade de tratamentos. A partir da revisão de literatura realizada, observou-se que esse instrumento vem sendo largamente utilizado e associado a outros instrumentos, por exemplo, que mensurem capacidade funcional, estratégias de enfrentamento entre outros, para melhor compreender tais questões.

Sobre a avaliação de funcionalidade, o TESS é um dos instrumentos mais utilizados e foi desenvolvido especificamente para a população com tumores musculoesqueléticos e vem sendo associado a outros instrumentos de avaliação. Seu conceito de funcionalidade está baseado na CIF e aponta para a necessidade de considerar que fatores externos ao tratamento clínico e aspectos psicossociais interferem na funcionalidade, na qualidade de vida e na reabilitação.

As consequências funcionais do tratamento do câncer ósseo são relevantes, e a avaliação funcional deve merecer prioridade nas pesquisas em pacientes com câncer ósseo, juntamente com a investigação sobre a qualidade de vida relacionada à saúde. Sua mensuraçao é necessária tanto para o sucesso do procedimemnto cirúrgico como para o restabelecimento da qualidade de vida em ambas as circunstâncias.

Conclui-se que ocorreram alterações em diferentes domínios e dimensões da funcionalidade e da qualidade de vida dos sujeitos com tumores musculoesqueléticos que compuseram os grupos deste estudo, particularmente quando comparados à população saudável. Os dados foram coletados e analisados considerando a população atendida pelo Sistema Único de Saúde, num hospital público universitário, de alta complexidade, localizado no interior do Estado de São Paulo, o que ajuda a explicar alguns dos resultados encontrados, diferentes daqueles identificados em trabalhos internacionais sobre o mesmo tema. 
Uma das limitações deste estudo foi o tamanho amostral, decorrente da demanda atendida no serviço de onco-ortopedia desse hospital, com diferente número de sujeitos em cada um dos grupos estudados. São necessários outros estudos, com desenhos metodológicos diferentes, para que possam ser elucidadas as lacunas relacionadas ao tema estudado e sobre os múltiplos aspectos envolvidos na QVRS, na funcionalidade e na retomada das atividades cotidianas de pessoas com tumores musculoesqueléticos.

Por fim, e de acordo com Nagarajan et al. (2002), aponta-se a necessidade de um acompanhamento contínuo desta população, para avaliar os problemas de saúde futuros dos pacientes com tumores musculoesqueléticos. Além da necessidade de continuar o estudo sobre essa população onco-ortopédica, devem ser analisados também os procedimentos de atenção à saúde e à reabilitação oferecidos a essa população, dentro de um trabalho em equipe multiprofissional, para garantir a promoção da qualidade de vida e da funcionalidade desses sujeitos com tumores musculoesqueléticos. 
REFERÊNCIAS 


\section{REFERÊNCIAS}

AKSNES, L. H.; BAUER, H. C. F.; JEHSEN, N. L.; FOLLERÃS, G.; HAUGEN, G. S.; HALL, K. S. Limb-sparing surgery preserves more functional than amputation. Journal of Bone Joint Surgery(Br), Needham, v. 90B, p. 786-794, 2008.

AKSNES, L. H.; HALL, K. S.; JEBSEN, N.; FOSSÅ, S. D.; DAHL, A. A. Young survivors of malignant bone tumours in the extremities: a comparative study of quality of life, fatigue and mental distress. Support Care Cancer, Heidelberg, v. 15, p. 1087-1096, 2007.

BEKKERING, W. P.; VLIELAND, T. P. M. V.; KOOPMAN, H. M.; SCHAAP, G. R. H. W.; SCHREUDER, B.; BEISHUIZEN, A.; TISSING, W. J. E.; HOOGERBRUGGE, P. M.; ANNINGA, J. K.; TAMINIAU, A. H. M. Quality of life in young patients after bone tumor surgery around the knee joint and comparison with healthy controls. Pediatric Blood Cancer, Malden, v. 54, p. 738-745, 2010.

BELASCO, A. G. S.; SESSO, R. C. C. Qualidade de vida: princípios, focos de estudo e intervenções. In: DINIZ, D. P.; SCHOR, N. (Org.). Guia de qualidade de vida. São Paulo: Manole, 2006. p. 1-10.

BENINCASA, M. E CUSTÓDIO, E. M. Avaliação da qualidade de vida em adolescentes do município de São Paulo. Boletim de Psicologia, São Paulo, vol. 62, no 134, p. 31-42, 2011.

CAMPANACCI, M. Giant cell tumor and chondrosarcomas: grading, treatment and results (studies of 209 and 131 cases). Recent Results in Cancer Research, Berlim, v. 54, p. 257-261, 1976.

CICONELLI, R. M.; FERRAZ, M. B.; SANTOS, W.; MEINÃO, I.; QUARESMA, M. R. Tradução para a língua portuguesa e validação do questionário genérico de avaliação de qualidade de vida SF-36 (Brasil SF-36). Revista Brasileira de Reumatologia, São Paulo, v. 39, n. 3, p. 143-150, 1997.

COSTA, R.; SILVA, K. R.; MENDONÇA, R. C.; NISHIOKA, S.; SIQUEIRA, S.; TAMAKI, W. T.; CREVELARI, E. S.; MOREIRA, L. F. P.; FILHO, M. M. Incidência de Choques e Qualidade de Vida em Jovens com Cardioversor-Desfibrilador Implantável. Arquivo Brasileiro de Cardiologia, São Paulo, v. 88, n.3, p. 258-264, 2007.

Critério de Classificação Econômica Brasil. ABEP - Associação Brasileira de Empresas de Pesquisa - Dados com base no Levantamento Sócio Econômico 2010 - IBOPE. Disponível em: <HTTP:// www.abep.org>. Acesso em: 18/02/2011 (http://www.abep.org/novo/Content.aspx?ContentID=301). 
DAIGELER, A.; LEHNHARDT, M.; KHADRA, A.; HAUSER, J.; STEINSTRAESSER, L.; LANGER, S.; GOERTZ, O.; STEINAU, H. Proximal major limb amputations - a retrospective analysis of 45 oncological cases. World Journal of Surgical Oncology, London, v. 7, n. 15, p. 07-15, 2009.

DAVIDGE, K.; BELL, R.; FERGUSON, P.; TURCOTTE, R.; WUNDER, J.; DAVIS, A. M. Patient expectations for surgical outcome in extremity soft tissue sarcoma. Journal of Surgical Oncology, New York, v.100, n. 5, p. 375-381, 2009.

DAVIS, A. M.; WRIGHT J. G.; WILLIAMS, J. I.; BOMBARDIER, C.; GRIFFIN, A.; BELL, R. S. Development of a measure of physical function for patients with bone and soft tissue. Quality of Life Research, Oxford, v. 5, n. 5, p. 508-516,1996.

DRUMOND, J. M. N. Eficacia do sistema de estadiamento de Enneking no tratamento dos tumores ósseos benignos e lesões ósseas pseudotumorais. Revista Brasileira de Ortopedia, São Paulo, v. 45, n. 1, p. 46-52, 2010.

EISER, C.; DARLINGTON, A. S.; STRIDE, E. C. B.; GRIMER, R. Quality of life implications as a consequence of surgery: limb salvage, primary and secondary amputation. Sarcoma, Abingdon, vol. 5, n. 4, p. 189-196, 2001.

FAYERS, P. M.; MACHIN, D. Quality of life-the assessment, analysis and interpretation of patient-reported outcomes. 2nd ed. Chichester: England Jonh Wiley \& Sons, 2007.

FERNANDES, L.; CRESCENTINI, M.C.V.; POLETTO, P.;R.; GOTFRYD, A.O.; YI, L.C. Qualidade de vida e funcionalidade em adolescentes com escoliose idiopática: estudo piloto. Fisioter. Mov., Curitiba, v. 25, n. 1, p. 73-81, 2012.

GINSBERG, J. P.; RAI, S. N.; CARLSON, C. A.; MEADOWS, A. T.; HINDS, P. S.; SPEARING, E. M.; ZHANG, L.; CALLAWAY, L.; NEEL, M. D.; RAO, B. N.; MARCHESE, V. G. Comparative analysis of functional outcomes in adolescents and young adults with lower-extremity bone sarcoma. Pediatric Blood \& Cancer, Hoboken, v. 49, p. 964-969, 2007.

HINDS, P. S.; GATTUSO, J. S.; BILLUPS, C. A.; WEST, N. K.; WU, J.; RIVERA, C.; QUINTANA, J.; VILLARROEL, M.; DAW, N. C. Aggressive Treatment of nonmetastatic osteosarcoma improves health-related quality of life in children and adolescents. European Journal of Cancer, Oxford, v. 45, n. 11, p. 4-20, 2009.

HINGURANAGE, A. Z.; BERND, L.; EWERBECK, V.; SABO, D. Equal quality of life after limb-sparing or ablative surgery for lower extremity sarcomas. British Journal of Cancer, London , v. 91, p. 1012-1014, 2004. 
JESUS-GARCIA, R. Tumores ósseos e sarcomas dos tecidos moles. Einstein, São Paulo, v. 6, p. S102-S119, 2008. Suplemento 1.

JESUS-GARCIA, R. Tumores ósseos: uma abordagem ortopédica ao estudo dos tumores ósseos. São Paulo: UNIFESP, 1996.

KOOPMAN, H. M.; KOETSIER, J. A.; TAMINIAU, A. H. M.; HIJNEN, K. E.; BRESTERS, D.; EGELER, R. M. Health-related quality of life and coping strategies of children after treatment of a malignant bone tumor: a 5-year follow-up study. Pediatric Blood \& Cancer, Hoboken, v. 45, p. 694-699, 2005.

MALEK, F.; SOMERSON, J. S.; MITCHEL, S.; WILLIAMS, R. P. Does limb-salvage surgery offer patients better quality of life and functional capacity than amputation? Clinical Orthopaedics and Related Research, Philadelphia , v. 470, n. 7, p. 20002006, 2012.

MANCINI, M. C. Classificação Internacional de Funcionalidade, Incapacidade e Saúde (CIF): caracterização e aplicações. CONGRESSO BRASILEIRO DE TERAPIA OCUPACIONAL, 10., 2007, Goiânia. Anais... Goiânia: 2007. p. 20-26.

MARCHESE, V. G.; SPEARING, E.; CALLAWAY, L.; ZHANG, L.; HINDS, P. S.; CARLSON, C. A.; NEEL, M. D.; RAO, B. N.; GINSBERG, J. Relationships among range of motion, functional mobility and quality of life in children an adolescents after limb-sparing surgery for lower- extremity sarcoma. Pediatric Physical Therapy, Baltimore, v. 18, n. 4, p. 238-244, 2006.

MORAES, V. Y.; GRACITELLI, G. C.; REZENDE, F. C.; PECCIN, M. S.; VIOLA, D. C.; GARCIA FILHO, R. J. Complicações das endopróteses não convencionais em pacientes portadores de tumores ósseos do joelho: revisão sistemática. Acta Ortopédica Brasileira, São Paulo, v. 19, n. 1, p. 49-51, 2011. Disponível em: <http://www.scielo.br/aob>. Acesso em: 18/12/2011 (http://www.scielo.br/pdf/aob/ v19n1/11.pdf)

NAGARAJAN, R.; CLOHISY, D. R.; NEGLIA, J. P.; YASUI, Y.; MITBY, P. A.; SKLAR, C.; FINKLESTEIN, J. Z.; GREENBERG, M.; REAMAN, G. H.; ZELTZER, L.; ROBISON, L. L. Function and quality-of-life of survivors of pelvic and lower extremity osteosarcoma and Ewing's sarcoma: the Childhood Cancer Survivor Study. British Journal of Cancer, Londres, v. 91, p. 1858-1865, 2004.

NAGARAJAN, R.; NEGLIA, J. P.; CLOHISY, D. R.; ROBISON, L. L. Limb salvage and amputation in survivors of pediatric lower-extremity bone tumors: what are the long-term implications? Journal of Clinical Oncology, New York, v. 20, n. 22, p. 4493-4501, 2002. 
ORGANIZAÇÃO MUNDIAL DA SAÚDE (OMS). CIF - Classificação Internacional de Funcionalidade, Incapacidade e Saúde. Centro Colaborador da para a Família de Classificação Internacionais. São Paulo: EDUSP, 2003.

PATRICK, D. L.; ERICKSON, P. Health status and health policy. Nova York: Oxford University Press, 1993.

PONTES, A. C. F.; CORRENTE, J. E. Comparações múltiplas não paramétricas para o delineamento com um fator de classificação simples. Rev. Mat. Estat., São Paulo,v. 19, p. 179-197, 2001.

ROBERT, K; HECK, J. R. General principles of amputations. In: CANALE, T.; BEATY, J. H. Campbell's operative orthopaedics. New York: Elsevier, 1998. Cap. 9. v. 1.

ROBERT, R. S.; OTTAVIANI, G.; HUH, W.; PALLA, S.; JAFFE, N. Psychosocial and functional outcomes in long-term survivors of osteosarcoma: a comparison of limbsalvage surgery and amputation. Pediatric Blood \& Cancer, Hoboken, v. 54, p. 990999, 2010.

ROSA, A. C. F.; MACHADO, M. M.; GRASSO, L. E. F.; ALBERTOTTI, F.; SATO, E.; FIGUEIREDO, M. A. J.; ALBERTOTTI, C. J.; CERRI, G. G. Sarcoma sinovial fibroso do pé - relato de caso. Radiologia Brasileira, São Paulo, v. 35, n. 1, p. 51-54, 2002.

ROUGRAFF, B. T.; SIMON, M. A.; KNEISL, J. S.; GREENBERG, D. B.; MANKIN, H. $\mathrm{J}$. Limb salvage compared with amputation for osteosarcoma of the distal end of the femur. A long-term oncological, functional, and quality-of-life study. Journal of Bone \& Joint Surgery American Volume, Boston, v. 76, n. 5, p. 649-656, 1994.

SARAIVA, D. Tradução e validação do questionário Toronto Extremity Salvage Escore (TESS) em adolescentes e adultos jovens com diagnóstico de osteossarcoma de extremidade inferior. 2007. 101 f. Dissertação (Mestrado) Fundação Antônio Prudente, São Paulo, 2007.

SARAIVA, D.; CAMARGO, B.; DAVIS, A. M. Cultural adaptation, translation and validation of a function outcome questionarie (TESS) to Portuguese with application to patients with lower exttemity osteossarcoma. Pediatric Blood \& Cancer, Hoboken , v. 50, p. 1039-1042, 2008.

SCHREIBER, D.; BELL, R. S.; WUNDER, J. S.; O'SULLIVAN, B.; TURCOTTE, R.; MASRI, B. A.; DAVIS, A. M. Evaluating function and health related quality of life in patients treated for exttemity soft tissue sarcoma. Quality of Life Research, Oxford, v. 15, p. 1439-1446, 2006. 
SEIDL, E. M. F.; ZANNON, C. M. L. C. Qualidade de vida e saúde: aspectos conceituais e metodológicos Cadernos de Saúde Pública, Rio de Janeiro, v. 20, n. 2, p. 580-588, 2004.

SKALICZKI, G.; ANTAL, I.; KISS, J.; SZALA, Y. K.; SKALICZKI, J.; SZENDRÖI, M. Functional outcome and life quality after endoprosthetic reconstruction following malignant tumours around the Knee. International Orthopaedics (SICOT), Berlin , v. 29, p. 174-178, 2005.

SOCIEDADE BRASILEIRA DE CANCEROLOGIA (SBC). Cancer Ósseo. 2012. Disponível em: <www.sbcancer.org.br/final/arquivos/osseos.doc>. Acesso em: 15 jul. 2010.

TANG, M. H.; PAN, D. J. W.; CASTLE, D. J.; CHOONG, P. F. M. A systematic review of the recent quality of life studies in adult extremity sarcoma survivors. Sarcoma, Abingdon, v. 2012, p. 15, 2012.

THIJSSENS, K. M. J.; HOEKSTRA-WEEBERS, J. E. H. M.; VAN GINKEL, R. J.; HOEKSTRA, H. J. Quality of life hyperthermic isolated limb perfusion for locally advanced extremity soft tissue sarcoma. Annals of Surgical Oncology, New York, v. 13, n. 6, p. 864-871, 2006.

TUNN, P. U.; POMRAENKE, D.; GOERLING, U.; HOHENBERGER, P. Functional outcome after endoprosthetic limb-salvage therapy of primary bone tumours-a comparative analysis using the MSTS escore, the TESS and the RNL index. International Orthopaedics (SICOT), Berlim, v. 32, p. 619-625, 2008.

VILAGUT, G.; FERRER, M.; RAJMIL, L.; REBOLLO, P.; PERMANYER-MIRALDA, G.; QUINTANA, J.M.; SANTED, R.; VALDERAS, J.M.; RIBERA, A.; DOMINGOSALVANY, A. \& ALONSO, J. El Cuestionario de Salud SF-36 español: Una década de experiencia y nuevos desarrollos. Gaceta Sanitaria, Barcelona, v.19, n. 2, p. 135$50,2005$.

WARE JR., J. E. SF36 health survey update. In: MARUISH, M. E. The use of psychological testing for treatment planning and outcome assessment. 3rd ed. Lincoln, Taylor and Francis, 2004. p. 693-718. v. 3.

ZELTZER, L. K.; RECKLITIS, C.; BUCHBINDER, D.; ZEBRACK, B.; CASILLAS, J.; TSAO, J. C. I.; LU, Q.; KRULL, K. Psychological status in childhood cancer survivors: a report from the childhood cancer survivor study. Journal of Clinical Oncology, New York, v. 27, p. 2396-2404, 2009. 


\title{
ANEXOS
}

\section{ANEXO 1. TERMO DE CONSENTIMENTO LIVRE E ESCLARECIDO}

\author{
Título da Pesquisa: Qualidade de vida de pacientes submetidos à ressecção de \\ tumores musculoesqueléticos \\ Pesquisadora responsável: Gisele Brides Prieto \\ Orientadora: Profa. Dra. Marysia Mara Rodrigues do Prado De Carlo, docente do Curso de \\ Terapia Ocupacional da FMRP-USP
}

\section{ESCLARECIMENTOS AO SUJEITO DA PESQUISA}

Meu nome é Gisele Brides Prieto. Sou Terapeuta Ocupacional do Hospital das Clínicas da Faculdade de Medicina de Ribeirão Preto - USP. Estou desenvolvendo um projeto de pesquisa cujo título é "OUALIDADE DE VIDA DE PACIENTES SUBMETIDOS À RESSECCÃO DE TUMORES MUSCULOESQUELÉTICOS sob a orientação da Profa. Dra. Marysia Mara Rodrigues do Prado De Carlo e gostaria de convidá-lo(a) a participar deste trabalho.

Esta pesquisa que tem como objetivo estudar a qualidade de vida e a capacidade para realização de atividades na sua vida diária de pessoas que foram submetidas a cirurgias para retirada de tumor de membro inferior.

Caso deseje participar será realizada uma entrevista, em que serão feitas algumas perguntas a respeito de sua vida, utilizando três questionários. O tempo utilizado para a aplicação dos questionários será de aproximadamente 20 minutos, sendo que suas respostas serão anotadas nos questionários. Serão também utilizadas informações contidas no seu prontuário clínico, como dados de sua cirurgia e tratamentos realizados. Ao participar desse processo você poderá contribuir para melhor compreensão da qualidade vida de pessoas submetidas a cirurgias para retirada de tumores de membro inferior, não tendo, porém, benefícios diretos pela sua participação na pesquisa.

Para isso você deve estar ciente de que:

1. Sua participação é voluntária e sua recusa não implicará em prejuízos de qualquer tipo ao seu atendimento ou de qualquer familiar;

2. As informações contidas na entrevista poderão ser utilizadas para fins didáticos e em eventos ou trabalhos científicos, mas não serão expostas de forma que o (a) identifique e sua identidade será sempre preservada; você tem a opção de não declarar seu nome na entrevista e garantimos que as informações prestadas serão confidenciais;

3. Caso você aceite participar, será realizada uma entrevista; cujo procedimento é simples, rápido e dispensa qualquer conhecimento especial.

4. Não existe nenhum risco previsto ou eventual à sua saúde em participar deste estudo;

5. Você é livre para desistir, a qualquer momento, de participar deste trabalho, sem nenhum dano e prejuízo ao seu tratamento.

6. Será excluído do processo se recusar a assinar o Termo de Consentimento Livre e Esclarecido e/ou deixar de pertencer ao grupo do estudo.

7. Os pesquisadores não se responsabilizam por quaisquer indenizações ou reparações financeiras, pois não há possibilidade de que ocorram prejuízos estritamente decorrentes da participação neste estudo. Caso sua participação na pesquisa gere algum tipo de desconforto, poderão ser adotadas medidas terapêuticas para minimizá-lo, como acolhimento ou controle de dor e/ou encaminhamento para serviços de referência, como atendimento psicológico.

8. Os resultados da pesquisa serão tornados públicos, sejam eles favoráveis ou não. 
Tendo recebido as informações sobre o projeto de pesquisa "QUALIDADE DE VIDA DE PACIENTES SUBMETIDOS À RESSECČ̃̃O DE TUMORES MUSCULOESQUELÉTICOS" sob a responsabilidade da pesquisadora Gisele Brides Prieto, eu, $\mathrm{n}^{\circ}$ aceito participar deste estudo, ciente de que minha participação e voluntária e estou livre para, em qualquer momento, desistir de colaborar com a pesquisa, sem nenhuma espécie de prejuízo.

Declaro que, após convenientemente esclarecido pelo pesquisador e ter entendido o que me foi explicado, consinto em participar do presente Protocolo de Pesquisa. Recebi uma cópia deste termo e tive a possibilidade de lê-lo, com o qual concordo.

$$
\text { Ribeirão Preto, }
$$
de de

\section{I - DADOS SOBRE A PESQUISA CIENTÍFICA}

1. TÍTULO DO PROTOCOLO DE PESQUISA Qualidade de vida de pacientes submetidos à resseccão de tumores musculoesqueléticos

Pesquisadora responsável: Gisele Brides Prieto

INSCRIÇÃO CONSELHO REGIONAL: CREFITO3 Nº 3 8808/TO.

Orientadora: Profa. Dra. Marysia Mara Rodrigues do Prado De Carlo - Curso de Terapia

Ocupacional da FMRP-USP

II. INFORMAÇÕES DE NOMES E TELEFONES DOS RESPONSÁVEIS PELO ACOMPANHAMENTO DA PESQUISA, PARA CONTATO.

Gisele Brides Prieto - Fone: (16) 3602-2901(HCFMRP-USP)

Profa. Dra. Marysia Mara Rodrigues do Prado De Carlo - Tel: 3602-2901 (HCFMRP-USP) 


\title{
ANEXO 2 - TERMO DE CONSENTIMENTO LIVRE E ESCLARECIDO MENORES DE IDADE
}

\author{
Título da Pesquisa: Qualidade de vida de pacientes submetidos à ressecção de \\ tumores musculoesqueléticos \\ Pesquisadora responsável: Gisele Brides Prieto \\ Orientadora: Profa. Dra. Marysia Mara Rodrigues do Prado De Carlo, docente do Curso de \\ Terapia Ocupacional da FMRP-USP
}

\section{ESCLARECIMENTOS AOS RESPONSÁVEIS PELOS SUJEITOS DE PESQUISA QUE FOREM MENORES DE IDADE}

Meu nome é Gisele Brides Prieto. Sou Terapeuta Ocupacional do Hospital das Clínicas da Faculdade de Medicina de Ribeirão Preto - USP. Estou desenvolvendo um projeto de pesquisa cujo título é "QUALIDADE DE VIDA DE PACIENTES SUBMETIDOS À RESSECCÃO DE TUMORES MUSCULOESQUELÉTICOS sob a orientação da Profa. Dra. Marysia Mara Rodrigues do Prado De Carlo e gostaria da sua autorização para que seu/sua filha(o) participe deste estudo.

Esta pesquisa que tem como objetivo estudar a qualidade de vida e a capacidade para realização de atividades na sua vida diária de pessoas que foram submetidas a cirurgias para retirada de tumor de membro inferior.

Caso deseje participar será realizada uma entrevista, em que serão feitas algumas perguntas a respeito de sua vida, utilizando três questionários. O tempo utilizado para a aplicação dos questionários será de aproximadamente 20 minutos, sendo que suas respostas serão anotadas nos questionários. Serão também utilizadas informações contidas no seu prontuário clínico, como dados de sua cirurgia e tratamentos realizados. Ao participar desse processo você poderá contribuir para melhor compreensão da qualidade vida de pessoas submetidas a cirurgias para retirada de tumores de membro inferior, não tendo, porém, benefícios diretos pela sua participação na pesquisa.

Para isso você deve estar ciente de que:

1. Sua participação é voluntária e sua recusa não implicará em prejuízos de qualquer tipo ao seu atendimento ou de qualquer familiar;

2. As informações contidas na entrevista poderão ser utilizadas para fins didáticos e em eventos ou trabalhos científicos, mas não serão expostas de forma que o (a) identifique e sua identidade será sempre preservada; você tem a opção de não declarar seu nome na entrevista e garantimos que as informações prestadas serão confidenciais;

3. Caso você aceite participar, será realizada uma entrevista; cujo procedimento é simples, rápido e dispensa qualquer conhecimento especial.

4. Não existe nenhum risco previsto ou eventual à sua saúde em participar deste estudo;

5. Você é livre para desistir, a qualquer momento, de participar deste trabalho, sem nenhum dano e prejuízo ao seu tratamento.

6. Será excluído do processo se recusar a assinar o Termo de Consentimento Livre e Esclarecido e/ou deixar de pertencer ao grupo do estudo.

7. Os pesquisadores não se responsabilizam por quaisquer indenizações ou reparações financeiras, pois não há possibilidade de que ocorram prejuízos estritamente decorrentes da participação neste estudo. Caso sua participação na pesquisa gere algum tipo de desconforto, poderão ser adotadas medidas terapêuticas para minimizá-lo, como acolhimento ou controle de dor e/ou encaminhamento para serviços de referência, como atendimento psicológico.

8. Os resultados da pesquisa serão tornados públicos, sejam eles favoráveis ou não. 
Tendo recebido as informações sobre o projeto de pesquisa "QUALIDADE DE VIDA DE PACIENTES SUBMETIDOS À RESSECCÃO DE TUMORES MUSCULOESQUELÉTICOS" sob a responsabilidade da pesquisadora Gisele Brides Prieto, eu,

$\mathrm{n}^{\circ} \quad$ responsável pelo(a) _ ' -aceito participar deste estudo, ciente de que minha participação é voluntária e estou livre para, em qualquer momento, desistir de colaborar com a pesquisa, sem nenhuma espécie de prejuízo.

Declaro que, após convenientemente esclarecido pelo pesquisador e ter entendido o que me foi explicado, consinto em participar do presente Protocolo de Pesquisa. Recebi uma cópia deste termo e tive a possibilidade de lê-lo, com o qual concordo.

Ribeirão Preto, de de

\section{I - DADOS SOBRE A PESQUISA CIENTÍFICA}

1. TÍTULO DO PROTOCOLO DE PESQUISA Qualidade de vida de pacientes submetidos à resseccão de tumores musculoesqueléticos

Pesquisadora responsável: Gisele Brides Prieto

INSCRIÇÃO CONSELHO REGIONAL: CREFITO3 Nº 3 8808/TO.

Orientadora: Profa. Dra. Marysia Mara Rodrigues do Prado De Carlo - Curso de Terapia

Ocupacional da FMRP-USP

II. INFORMAÇÕES DE NOMES E TELEFONES DOS RESPONSÁVEIS PELO ACOMPANHAMENTO DA PESQUISA, PARA CONTATO.

Gisele Brides Prieto - Fone: (16) 3602-2901(HCFMRP-USP)

Profa. Dra. Marysia Mara Rodrigues do Prado De Carlo - Tel: 3602-2901 (HCFMRP-USP) 


\title{
ANEXO 3 - TERMO DE CONSENTIMENTO LIVRE E ESCLARECIDO (GRUPO-SAUDÁVEL)
}

\author{
Título da Pesquisa: Qualidade de vida de pacientes submetidos à ressecção de \\ tumores musculoesqueléticos \\ Pesquisadora responsável: Gisele Brides Prieto \\ Orientadora: Profa. Dra. Marysia Mara Rodrigues do Prado De Carlo, docente do Curso de \\ Terapia Ocupacional da FMRP-USP
}

\section{ESCLARECIMENTOS AO SUJEITO DA PESQUISA}

Meu nome é Gisele Brides Prieto. Sou Terapeuta Ocupacional do Hospital das Clínicas da Faculdade de Medicina de Ribeirão Preto - USP. Estou desenvolvendo um projeto de pesquisa cujo título é "QUALIDADE DE VIDA DE PACIENTES SUBMETIDOS À RESSECCÃO DE TUMORES MUSCULOESQUELÉTICOS sob a orientação da Profa. Dra. Marysia Mara Rodrigues do Prado De Carlo e gostaria de convidá-lo(a) a participar deste trabalho.

O (a) Senhor (a) está sendo convidado a participar desta pesquisa como membro do grupo-saudável do estudo (composto por sujeitos que não têm câncer). Esta pesquisa que tem como objetivo estudar a qualidade de vida e a capacidade para realização de atividades na sua vida diária de pessoas que foram submetidas a cirurgias para retirada de tumor de membro inferior.

Caso deseje participar será realizada uma entrevista, em que serão feitas algumas perguntas a respeito de sua vida, utilizando três questionários. O tempo utilizado para a aplicação dos questionários será de aproximadamente 20 minutos, sendo que suas respostas serão anotadas nos questionários. Ao participar desse processo você poderá contribuir para maior compreensão da qualidade vida de pessoas submetidas a cirurgias para retirada de tumores de membro inferior. Para isso você deve estar ciente de que:

1. Sua participação é voluntária e sua recusa não implicará em prejuízos de qualquer tipo;

2. As informações contidas na entrevista poderão ser utilizadas para fins didáticos e em eventos ou trabalhos científicos, mas não serão expostas de forma que o (a) identifique e sua identidade será sempre preservada; você tem a opção de não declarar seu nome na entrevista e garantimos que as informações prestadas serão confidenciais;

3. Caso você aceite participar, será realizada uma entrevista; cujo procedimento é simples, rápido e dispensa qualquer conhecimento especial.

4. Não existe nenhum risco previsto ou eventual à sua saúde em participar deste estudo;

5. Você é livre para desistir, a qualquer momento, de participar deste trabalho, sem nenhum dano e prejuízo ao seu tratamento.

6. Os pesquisadores não se responsabilizam por quaisquer indenizações ou reparações financeiras, pois não há possibilidade de que ocorram prejuízos estritamente decorrentes da participação neste estudo. Caso sua participação na pesquisa gere algum tipo de desconforto, poderão ser adotadas medidas terapêuticas para minimizá-lo, como acolhimento ou controle de dor e/ou encaminhamento para serviços de referência, como atendimento psicológico.

7. Os resultados da pesquisa serão tornados públicos, sejam eles favoráveis ou não.

Tendo recebido as informações sobre o projeto de pesquisa "QUALIDADE DE VIDA DE PACIENTES SUBMETIDOS À RESSECCÃO DE TUMORES MUSCULOESQUELÉTICOS" sob a responsabilidade da pesquisadora Gisele Brides Prieto, eu, RG $n^{\circ} \quad$ aceito participar deste estudo, ciente de que minha participação é voluntária e estou livre para, em qualquer momento, desistir de colaborar com a pesquisa, sem nenhuma espécie de prejuízo. 
Declaro que, após convenientemente esclarecido pelo pesquisador e ter entendido o que me foi explicado, consinto em participar do presente Protocolo de Pesquisa. Recebi uma cópia deste termo e tive a possibilidade de lê-lo, com o qual concordo.

Ribeirão Preto, de de

\section{I - DADOS SOBRE A PESQUISA CIENTÍFICA}

1. TÍTULO DO PROTOCOLO DE PESQUISA Qualidade de vida de pacientes submetidos à resseccão de tumores musculoesqueléticos

Pesquisadora responsável: Gisele Brides Prieto

INSCRIÇÃO CONSELHO REGIONAL: CREFITO3 Nº 3 8808/TO.

Orientadora: Profa. Dra. Marysia Mara Rodrigues do Prado De Carlo - Curso de Terapia Ocupacional da FMRP-USP

II. INFORMAÇÕES DE NOMES E TELEFONES DOS RESPONSÁVEIS PELO ACOMPANHAMENTO DA PESQUISA, PARA CONTATO.

Gisele Brides Prieto - Fone: (16) 3602-2901 (HCFMRP-USP)

Profa. Dra. Marysia Mara Rodrigues do Prado De Carlo - Tel: 3602-2901 (HCFMRP-USP) 


\section{ANEXO 4.TESS - MEMBRO INFERIOR}

\section{Toronto extremity salvage escore}

Nome ou iniciais: telefone:

$\mathrm{RH}$ : Data de nascimento: Idade no momento da cirurgia: Sexo: 1 __ masculino 2 feminino

Data do preenchimento do questionário: Data da cirurgia:

1 __ pré-operatório

$2 \_6$ semanas de pós-operatório

$3 \_3$ meses de pós-operatório

$4 \_6$ meses de pós-operatório

$5 \_12$ meses de pós-operatório

Local:

1 Osso lado da lesão: 1 direito

2

$6 \quad 2$ anos de pós-operatório

$7 \_3$ anos de pós-operatório

$8 \quad 4$ anos de pós-operatório

$9 \_5$ anos de pós-operatório

\section{Região:}

1 proximal (ex. proximal de cotovelo, proximal de joelho) distal (ex. distal de cotovelo, distal de joelho)

\section{Local anatômico:}

1 cintura escapular/ ombro

2 __ distal braço/ cotovelo/ proximal de antebraço

3 distal de antebraço/ punho/ mão

4 pélvis/ quadril

5 __ distal de coxa/ joelho/ proximal de perna

$6 \ldots$ distal de perna/ tornozelo/ pé

\section{Diagnóstico patológico:}

1 __ Benigno

2 __ Benigno agressivo (fibromatose)

3 ___ Maligno

4 _ Metástase

Tipo histológico:

\section{Tratamento:}

1 __ Somente cirurgia

2 __ Cirurgia + Radioterapia

3 _ Cirurgia + Quimioterapia

$4 \_$Cirurgia + Radioterapia + Quimioterapia

\section{Procedimento de reconstrução:}

1 Excisão

2 __ Excisão e enxerto de tecido

3 _ Curetagem e enxerto ósseo

$4 \quad$ Enxerto volumoso

5 Prótese

6 __ Prótese autóloga

7 Artrodese

8 __ Tikoff-Linberg

\section{Comorbidade:}

Por favor, responda às seguintes questões.

1A) Por favor, assinale seu tipo de ocupação atual:

1 __ Emprego em tempo integral

2 __ Emprego de meio período 

Inválido

1B) Se você está empregado, por favor descreva suas atividades no seu trabalho atual (ex.trabalho sentado, dirigindo):

DEFINA:

1 ativo

2 sedentário

1C) Se você está aposentado, desempregado ou inválido, por favor descreva suas atividades passadas: DEFINA:

1 ativo

2 __ sedentário

1D) Se você for um estudante, por favor descreva sua área de estudo:

DEFINA:

1 ativo

2 ___ sedentário

1E) Se você não está trabalhando, você recebe assistência financeira como seguro, auxílio-doença ou pensão?

1 Sim

2 ___ Não

2) Brevemente descreva suas atividades de lazer ou recreação (ex. esportes, jardinagem, leitura). DEFINA:

1 ativo

2 ___ sedentário

3A) Medicação para dor:

1 nenhuma

2 __ anti-inflamatório não hormonal ex. cataflam

3 __ analgésico ex. tylenol, novalgina

$4 \quad$ analgésico narcótico ex. morfina

3B) Frequência da medicação para dor:

1 __ não se aplica

$5 \quad 3 \mathrm{X}$ ao dia

2 intermitente

$6 \quad 4 X$ vezes ao dia

$3 \quad 1 X$ ao dia

7 _ mais do que $4 \mathrm{X}$ ao dia

4 __ $2 X$ ao dia

4) Descreva a ajuda necessária para se mover ou andar:

1 __ Sem ajuda

$5 \quad$ Andador

2 __ 1 bengala ou muleta

$6 \quad$ Cadeira de rodas

3 __ 2 bengalas

$7 \quad$ Cadeira de rodas motorizada

4 __ 2 muletas

5) Lista de fatores que limitam a sua habilidade para efetuar suas atividades do dia a dia:

1 dor

2 __ rigidez

3 _ fadiga

4 _ fraqueza

As seguintes questões são sobre as atividades comumente executadas no dia a dia. Assinale cada item (como o exemplo abaixo) ao lado da melhor descrição da sua habilidade em executar cada
5 diminuição no movimento

6 _ outros

7 nenhum 
tarefa durante a última semana. Algumas atividades serão extremamente fáceis para você executar, outras serão extremamente difíceis ou impossíveis.

EXEMPLO:

Andar de bicicleta é:

1 __ impossivel de fazer

4 __ pouca dificuldade

2 __ dificuldade extrema

5 _ sem dificuldade

3 __ dificuldade moderada

99 __Este item não se aplica a mim.

Você deverá escolher a resposta "impossível de fazer", se a atividade é algo que você normalmente faz dentro das atividades diárias, mas agora está impossibilitado devido a limitações físicas como fraqueza, rigidez ou dor. Se você não executa a atividade como parte do seu estilo de vida normal, você deve escolher a resposta "99" para indicar que o item não se aplica. Assinale todos os itens assegurando-se de que você escolheu a descrição que com maior exatidão descreve suas habilidades na última semana.

As seguintes questões perguntam sobre sua habilidade de executar atividades comuns do dia a dia. Considerando o nível de dificuldade que você tem ao executar a atividade devido a um problema atual que você está tendo com a sua perna, responda às questões que melhor descrevem sua habilidade para executar as atividades na última semana.

1) Colocar as calças é:

1 __impossivel de fazer

2 __ dificuldade extrema

3 __ dificuldade moderada

4 _ pouca dificuldade

5 _ sem dificuldade

99 __ Este item não se aplica a mim.

2) Colocar os sapatos é:

1 __ impossível de fazer

2 __ dificuldade extrema

3 __ dificuldade moderada

4 _ pouca dificuldade

5 _ sem dificuldade

99 __ Este item não se aplica a mim.

3) Colocar as meias ou meia-calças é:

1 impossível de fazer

2 _ dificuldade extrema

3 __ dificuldade moderada

4 _ pouca dificuldade

5 _ sem dificuldade

99 __Este item não se aplica a mim.

4) Tomar banho no chuveiro é:

1 _ impossível de fazer

2 __ dificuldade extrema

3 _ dificuldade moderada

4 _ pouca dificuldade

5 _ sem dificuldade

99 __Este item não se aplica a mim.

5) Trabalhos domésticos leves como arrumar e tirar pó são:
1 impossível de fazer
4 _ pouca dificuldade
2 _ dificuldade extrema
5 _ sem dificuldade
3 __ dificuldade moderada
99 __Este item não se aplica a mim.

6) Jardinagem ou trabalho no quintal são:

1 __ impossível de fazer

2 __ dificuldade extrema

3 __ dificuldade moderada

4 _ pouca dificuldade

5 _ sem dificuldade

99 __ Este item não se aplica a mim.

7) Preparar refeições é: 
1 impossível de fazer

2 __ dificuldade extrema

3 ___ dificuldade moderada

8) Sair para fazer compras é:
1 impossível de fazer
2 dificuldade extrema
3 __ dificuldade moderada
4 p pouca dificuldade
5 __ sem dificuldade
99 Este item não se aplica a mim.
$4 \quad$ pouca dificuldade
5 sem dificuldade
99 Este item não se aplica a mim.

9) Trabalhos domésticos pesados como passar o aspirador de pó e mudar a mobília são:

1 impossível de fazer

2 ___ dificuldade extrema

3 ___ dificuldade moderada

10) Entrar e sair da banheira é

1 __ impossível de fazer

2 dificuldade extrema

3 dificuldade moderada

11) Levantar da cama é:

1 __ impossível de fazer

2 dificuldade extrema

3 ___ dificuldade moderada

12) Levantar da cadeira é:

1 __ impossível de fazer

2 __ dificuldade extrema

3 dificuldade moderada

13) Ajoelhar é:

1 __ impossível de fazer

2 dificuldade extrema

3 __ dificuldade moderada

14) Abaixar para pegar algo no chão é:

1 __ impossível de fazer

2 __ dificuldade extrema

3 ___ dificuldade moderada

15) Subir escadas é:

1 __ impossível de fazer

2 _ dificuldade extrema

3 dificuldade moderada

16) Descer escadas é:

1 __ impossível de fazer
4 pouca dificuldade

5 s_sem dificuldade

99 Este item não se aplica a mim.

4 __ pouca dificuldade

5 __ sem dificuldade

99 Este item não se aplica a mim.

4 __ pouca dificuldade

5 sem dificuldade

99 ___Este item não se aplica a mim.

4 _ pouca dificuldade

5 __ sem dificuldade

99 Este item não se aplica a mim.

4 _ pouca dificuldade

5 sem dificuldade

99 ___Este item não se aplica a mim.

4 _ pouca dificuldade

$5 \_$_ sem dificuldade

99 ___Este item não se aplica a mim.

4 __ pouca dificuldade

5 _sem dificuldade

99 Este item não se aplica a mim.

4 _ pouca dificuldade 
2 dificuldade extrema

3 __ dificuldade moderada

\section{7) Dirigir é:}

$1 \_$impossível de fazer

2 dificuldade extrema

3 __ dificuldade moderada

18) Andar em casa é:

1 __ impossível de fazer

2 dificuldade extrema

3 __ dificuldade moderada

19) Andar fora de casa é:

1 __ impossível de fazer

2 __dificuldade extrema

3 dificuldade moderada

20) Sentar é:

1 __ impossível de fazer

2 __dificuldade extrema

3 __ dificuldade moderada

21) Subir ou descrer ladeiras ou rampas é:

1 __ impossível de fazer

2 _ dificuldade extrema

3 ___ dificuldade moderada

22) Ficar em pé é:

1 __ impossível de fazer

2 dificuldade extrema

3 dificuldade moderada

23) Levantar-se da posição ajoelhada é:

1 __ impossível de fazer

2 dificuldade extrema

3 dificuldade moderada

24) Entrar e sair do carro são:

1 __ impossível de fazer

2 __ dificuldade extrema

3 dificuldade moderada

25) Participar de atividades sexuais é:

1 __ impossível de fazer
$5 \_$sem dificuldade

99 Este item não se aplica a mim.

4 _ pouca dificuldade

5 sem dificuldade

99 Este item não se aplica a mim.

4 _ pouca dificuldade

5 __ sem dificuldade

99 ___Este item não se aplica a mim.

4 _ pouca dificuldade

5 __ sem dificuldade

99 Este item não se aplica a mim.

4 _ pouca dificuldade

5 sem dificuldade

99 Este item não se aplica a mim.

4 pouca dificuldade

5 __ sem dificuldade

99 ___ Este item não se aplica a mim.

4 _ pouca dificuldade

5 sem dificuldade

99 Este item não se aplica a mim.

4 _ pouca dificuldade

5 sem dificuldade

99 Este item não se aplica a mim.

4 _ pouca dificuldade

5 __ sem dificuldade

99 Este item não se aplica a mim.

4 __ pouca dificuldade 
2 dificuldade extrema

3 ___ dificuldade moderada
$5 \_$sem dificuldade

99 Este item não se aplica a mim.

26) Completar as tarefas de rotina no trabalho (trabalho inclui tanto o trabalho fora de casa quanto dentro de casa) é:

1 __ impossível de fazer

2 __ dificuldade extrema

3 __ dificuldade moderada
4 pouca dificuldade

5 __ sem dificuldade

99 Este item não se aplica a mim.

27) Trabalhar um número de horas habitual é:

1 __ impossível de fazer

4 _ pouca dificuldade

2 dificuldade extrema

5 sem dificuldade

3 _ dificuldade moderada

99 Este item não se aplica a mim.

28) Participar das atividades de lazer de costume

é:

1 impossível de fazer

4 _ pouca dificuldade

2 ___ dificuldade extrema

5 sem dificuldade

3 dificuldade moderada

99 Este item não se aplica a mim.

29) Relacionar-se com amigos e família é:

1 __ impossível de fazer

4 __ pouca dificuldade

2 dificuldade extrema

5 _ sem dificuldade

3 dificuldade moderada

99 Este item não se aplica a mim.

30) Participar das minhas atividades esportivas de costume é:

1 impossível de fazer

4 pouca dificuldade

2 __ dificuldade extrema

5 sem dificuldade

3 ___ dificuldade moderada

99 Este item não se aplica a mim.

1) Considerando todas as atividades das quais eu participo no dia a dia, eu classificaria a habilidade em executar estas atividades durante a semana passada como:

1 __ impossível de fazer

2 dificuldade extrema

3 ___ dificuldade moderada

2) Eu me classificaria como sendo:

1 _ completamente inválido

2 severamente inválido

3 __ moderadamente inválido
4 pouca dificuldade

5 __sem dificuldade

99 ___Este item não se aplica a mim.

$4 \quad$ levemente inválido

5 _ nem um pouco inválido

Por favor, fazer qualquer comentário adicional sobre as dificuldades vivenciadas por você? Por favor, certifique-se de que você respondeu a todas as perguntas. Obrigada por responder às perguntas. 


\title{
ANEXO 5. MEDICAL OUTCOMES STUDYS 36 - ITEN SHORT FORM HEALTH SURVEY - SF-36
}

\author{
Versão Brasileira do Questionário de Qualidade de Vida -SF-36
}

1- Em geral você diria que sua saúde é:

\begin{tabular}{|c|c|c|c|c|}
\hline Excelente & Muito Boa & Boa & Ruim & Muito Ruim \\
\hline 1 & 2 & 3 & 4 & 5 \\
\hline
\end{tabular}

2- Comparada há um ano atrás, como você classificaria sua idade em geral, agora?

\begin{tabular}{|c|c|c|c|c|}
\hline Muito Melhor & Um Pouco Melhor & Quase a Mesma & Um Pouco Pior & Muito Pior \\
\hline 1 & 2 & 3 & 4 & 5 \\
\hline
\end{tabular}

3- Os seguintes itens são sobre atividades que você poderia fazer atualmente durante um dia comum. Devido à sua saúde, você teria dificuldade para fazer estas atividades? Neste caso, quando?

\begin{tabular}{|l|c|c|c|}
\hline \multicolumn{1}{|c|}{ Atividades } & $\begin{array}{c}\text { Sim, } \\
\text { dificulta } \\
\text { muito }\end{array}$ & $\begin{array}{c}\text { Sim, } \\
\text { dificulta } \\
\text { um pouco }\end{array}$ & $\begin{array}{c}\text { Não, não } \\
\text { dificulta de } \\
\text { modo algum }\end{array}$ \\
\hline $\begin{array}{l}\text { a) Atividades rigorosas, que exigem muito esforço, } \\
\text { tais como correr, levantar objetos pesados, } \\
\text { participar em esportes árduos. }\end{array}$ & 1 & 2 & 3 \\
\hline $\begin{array}{l}\text { b) Atividades moderadas, tais como mover uma } \\
\text { mesa, passar aspirador de pó, jogar bola, varrer a } \\
\text { casa. }\end{array}$ & 1 & 2 & 3 \\
\hline c) Levantar ou carregar mantimentos & 1 & 2 & 3 \\
\hline d) Subir vários lances de escada & 1 & 2 & 3 \\
\hline e) Subir um lance de escada & 1 & 2 & 3 \\
\hline f) Curvar-se, ajoelhar-se ou dobrar-se & 1 & 2 & 3 \\
\hline g) Andar mais de 1 quilômetro & 1 & 2 & 3 \\
\hline h) Andar vários quarteirões & 1 & 2 & 3 \\
\hline i) Andar um quarteirão & & 2 & 3 \\
\hline j) Tomar banho ou vestir-se & & 2 & 3 \\
\hline
\end{tabular}

4- Durante as últimas quatro semanas, você teve algum dos seguintes problemas com seu trabalho ou com alguma atividade regular, como consequência de sua saúde física?

\begin{tabular}{|c|c|c|}
\hline & Sim & Não \\
\hline $\begin{array}{l}\text { a) Você diminui a quantidade de tempo que se dedicava ao seu } \\
\text { trabalho ou a outras atividades? }\end{array}$ & 1 & 2 \\
\hline b) Realizou menos tarefas do que você gostaria? & 1 & 2 \\
\hline $\begin{array}{l}\text { c) Esteve limitado no seu tipo de trabalho ou a outras } \\
\text { atividades. }\end{array}$ & 1 & 2 \\
\hline
\end{tabular}


d) Teve dificuldade de fazer seu trabalho ou outras atividades

(p. ex. necessitou de um esforço extra).

5- Durante as últimas quatro semanas, você teve algum dos seguintes problemas com seu trabalho ou outra atividade regular diária, como consequência de algum problema emocional (como se sentir deprimido ou ansioso)?

\begin{tabular}{|c|c|c|}
\hline & Sim & Não \\
\hline $\begin{array}{l}\text { a) Você diminui a quantidade de tempo que se dedicava ao seu } \\
\text { trabalho ou a outras atividades? }\end{array}$ & 1 & 2 \\
\hline b) Realizou menos tarefas do que você gostaria? & 1 & 2 \\
\hline $\begin{array}{l}\text { c) Não realizou ou fez qualquer das atividades com tanto } \\
\text { cuidado como geralmente faz. }\end{array}$ & 1 & 2 \\
\hline
\end{tabular}

6- Durante as últimas quatro semanas, de que maneira sua saúde física ou problemas emocionais interferiram nas suas atividades sociais normais, em relação à família, aos amigos ou em grupo?

\begin{tabular}{|c|c|c|c|c|}
\hline De forma nenhuma & Ligeiramente & Moderadamente & Bastante & Extremamente \\
\hline 1 & 2 & 3 & 4 & 5 \\
\hline
\end{tabular}

7- Quanta dor no corpo você teve durante as últimas quatro semanas?

\begin{tabular}{|c|c|c|c|c|c|}
\hline Nenhuma & Muito leve & Leve & Moderada & Grave & Muito grave \\
\hline 1 & 2 & 3 & 4 & 5 & 6 \\
\hline
\end{tabular}

8- Durante as últimas quatro semanas, quanto a dor interferiu com seu trabalho normal (incluindo o trabalho dentro de casa)?

\begin{tabular}{|c|c|c|c|c|}
\hline $\begin{array}{c}\text { De maneira } \\
\text { alguma }\end{array}$ & Um pouco & $\begin{array}{c}\text { Moderadament } \\
\mathrm{e}\end{array}$ & Bastante & Extremamente \\
\hline 1 & 2 & 3 & 4 & 5 \\
\hline
\end{tabular}

9- Estas questões são sobre como você se sente e como tudo tem acontecido com você durante as últimas quatro semanas. Para cada questão, por favor dê uma resposta que mais se aproxime de maneira como você se sente, em relação às últimas quatro semanas.

\begin{tabular}{|l|c|c|c|c|c|c|}
\hline & $\begin{array}{c}\text { Todo } \\
\text { Tempo }\end{array}$ & $\begin{array}{c}\text { A maior } \\
\text { parte do } \\
\text { tempo }\end{array}$ & $\begin{array}{c}\text { Uma boa } \\
\text { parte do } \\
\text { tempo }\end{array}$ & $\begin{array}{c}\text { Alguma } \\
\text { parte do } \\
\text { tempo }\end{array}$ & $\begin{array}{c}\text { Uma } \\
\text { pequena } \\
\text { parte do } \\
\text { tempo }\end{array}$ & Nunca \\
\hline $\begin{array}{l}\text { a) Quanto tempo você tem se sentido } \\
\text { cheio de vigor, de vontade, de força? }\end{array}$ & 1 & 2 & 3 & 4 & 5 & 6 \\
\hline $\begin{array}{l}\text { b) Quanto tempo você tem se sentido } \\
\text { uma pessoa muito nervosa? }\end{array}$ & 1 & 2 & 3 & 4 & 5 & 6 \\
\hline $\begin{array}{l}\text { c) Quanto tempo você tem se sentido } \\
\text { tão deprimido que nada pode animá- } \\
\text { lo? }\end{array}$ & 1 & 2 & 3 & 4 & 5 & 6 \\
\hline $\begin{array}{l}\text { d) Quanto tempo você tem se sentido } \\
\text { calmo ou tranquilo? }\end{array}$ & 1 & 2 & 3 & 4 & 5 & 6 \\
\hline
\end{tabular}




\begin{tabular}{|l|c|c|c|c|c|c|}
\hline $\begin{array}{l}\text { e) Quanto tempo você tem se sentido } \\
\text { com muita energia? }\end{array}$ & 1 & 2 & 3 & 4 & 5 & 6 \\
\hline $\begin{array}{l}\text { f) Quanto tempo você tem se sentido } \\
\text { desanimado ou abatido? }\end{array}$ & 1 & 2 & 3 & 4 & 5 & 6 \\
\hline $\begin{array}{l}\text { g) Quanto tempo você tem se sentido } \\
\text { esgotado? }\end{array}$ & 1 & 2 & 3 & 4 & 5 & 6 \\
\hline $\begin{array}{l}\text { h) Quanto tempo você tem se sentido } \\
\text { uma pessoa feliz? }\end{array}$ & 1 & 2 & 3 & 4 & 5 & 6 \\
\hline $\begin{array}{l}\text { i) Quanto tempo você tem se sentido } \\
\text { cansado? }\end{array}$ & 1 & 2 & 3 & 4 & 5 & 6 \\
\hline
\end{tabular}

10- Durante as últimas quatro semanas, quanto de seu tempo a sua saúde física ou problemas emocionais interferiram com as suas atividades sociais (como visitar amigos, parentes, etc.)?

\begin{tabular}{|c|c|c|c|c|}
\hline $\begin{array}{c}\text { Todo } \\
\text { Tempo }\end{array}$ & $\begin{array}{c}\text { A maior parte } \\
\text { do tempo }\end{array}$ & $\begin{array}{c}\text { Alguma parte do } \\
\text { tempo }\end{array}$ & $\begin{array}{c}\text { Uma } \\
\text { pequena } \\
\text { parte do } \\
\text { tempo }\end{array}$ & $\begin{array}{c}\text { Nenhuma } \\
\text { parte do } \\
\text { tempo }\end{array}$ \\
\hline 1 & 2 & 3 & 4 & 5 \\
\hline
\end{tabular}

11- O quanto verdadeiro ou falso é cada uma das afirmações para você?

\begin{tabular}{|l|c|c|c|c|c|}
\hline & $\begin{array}{c}\text { Definitivamente } \\
\text { verdadeiro }\end{array}$ & $\begin{array}{c}\text { A maioria } \\
\text { das vezes } \\
\text { verdadeiro }\end{array}$ & Não sei & $\begin{array}{c}\text { A maioria } \\
\text { das vezes } \\
\text { falso }\end{array}$ & $\begin{array}{c}\text { Definitiva- } \\
\text { mente falso }\end{array}$ \\
\hline $\begin{array}{l}\text { a) Eu costumo obedecer } \\
\text { um pouco mais facilmente } \\
\text { que as outras pessoas }\end{array}$ & 1 & 2 & 3 & 4 & 5 \\
\hline $\begin{array}{l}\text { b) Eu sou tão saudável } \\
\text { quanto qualquer pessoa } \\
\text { que eu conheço }\end{array}$ & 1 & 2 & 3 & 4 & 5 \\
\hline $\begin{array}{l}\text { c) Eu acho que a minha } \\
\text { saúde vai piorar }\end{array}$ & 1 & 2 & 3 & 4 & 5 \\
\hline d) Minha saúde é excelente & 1 & 2 & 3 & 4 & 5 \\
\hline
\end{tabular}




\section{ANEXO 6. QUESTIONÁRIO SOCIODEMOGRÁFICO}

O Critério de Classificação Econômica Brasil, enfatiza sua função de estimar o poder de compra das pessoas e famílias urbanas, abandonando a pretensão de classificar a população em termos de "classes sociais". A divisão de mercado definida abaixo é de classes econômicas.

\section{SISTEMA DE PONTOS}

Posse de itens

\begin{tabular}{|c|c|c|c|c|c|}
\hline & & Qu: & ade & ten & \\
\hline & $\mathbf{0}$ & 1 & 2 & 3 & 4 ou + \\
\hline Televisão em cores & 0 & 1 & 2 & 3 & 4 \\
\hline Rádio & 0 & 1 & 2 & 3 & 4 \\
\hline Banheiro & 0 & 4 & 5 & 6 & 7 \\
\hline Automóvel & 0 & 4 & 7 & 9 & 9 \\
\hline Empregada mensalista & 0 & 3 & 4 & 4 & 4 \\
\hline Máquina de lavar & 0 & 2 & 2 & 2 & 2 \\
\hline Videocassete e/ou DVD & 0 & 2 & 2 & 2 & 2 \\
\hline Geladeira & 0 & 4 & 4 & 4 & 4 \\
\hline Freezer (aparelho independente ou parte da geladeira duplex) & 0 & 2 & 2 & 2 & 2 \\
\hline
\end{tabular}

Grau de Instrução do chefe de família

Analfabeto / Primário incompleto
Primário completo / Ginasial incompleto
Ginasial completo / Colegial incompleto
Colegial completo / Superior incompleto
Superior completo

\section{RENDA FAMILIAR POR CLASSES}

\begin{tabular}{|c|c|c|}
\hline \multirow{2}{*}{ Classe } & Pontos & $\begin{array}{c}\text { Renda média familiar } \\
\text { (Valor Bruto em R\$̣) }\end{array}$ \\
A1 & 42 a 46 & 2008 \\
\hline A2 & 35 a 41 & 14.366 \\
B1 & 29 a 34 & 8.099 \\
B2 & 23 a 28 & 4.558 \\
C1 & 18 a 22 & 2.327 \\
C2 & 14 a 17 & 1.391 \\
D & 8 a 13 & 933 \\
E & 0 a 7 & 618 \\
\hline
\end{tabular}




\section{ANEXO 7. APROVAÇÃO DO COMITÊ DE ÉTICA EM PESQUISA}

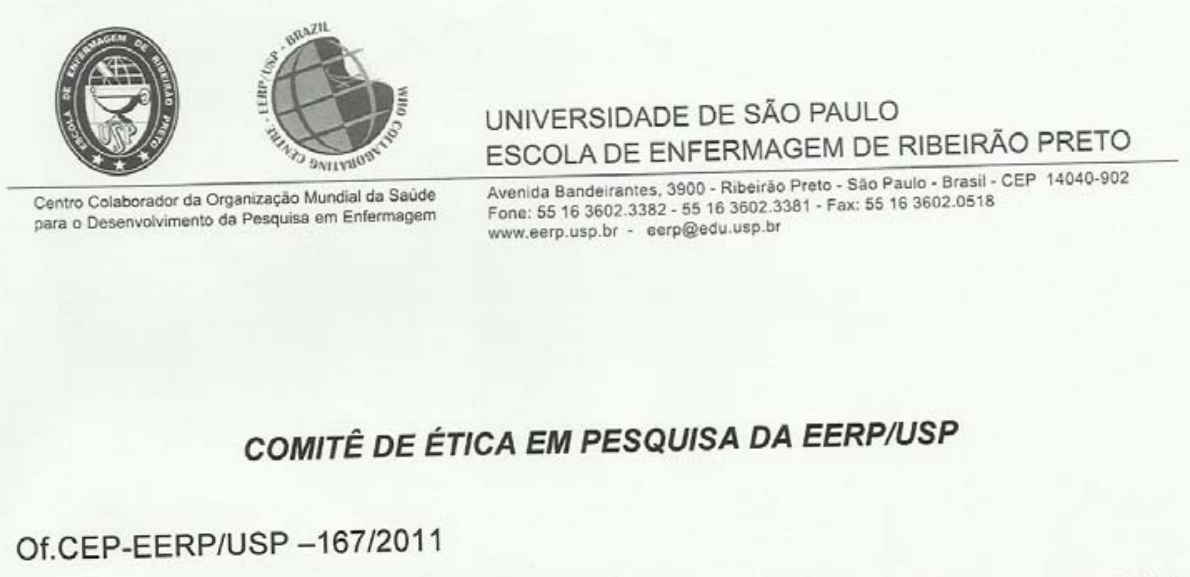

Ribeirão Preto, 26 de maio de 2011.

Prezada Senhora,

Comunicamos que o projeto de pesquisa, abaixo especificado, foi analisado e considerado APROVADO AD REFERENDUM pelo Comitê de Ética em Pesquisa da Escola de Enfermagem de Ribeirão Preto da Universidade de São Paulo, em 26 de maio de 2011.

Protocolo:

$n^{\circ} 1263 / 2011$

Projeto:

Qualidade de Vida de Pacientes submetidos à Ressecção de Tumores Musculoesqueléticos.

Pesquisador: Marysia M.R. Prado de Carlo Gisele Brides Prieto

Em atendimento à Resolução 196/96, deverá ser encaminhado ao CEP o relatório final da pesquisa e a publicação de seus resultados, para acompanhamento, bem como comunicada qualquer intercorrência ou a sua interrupção.

Atenciosamente,

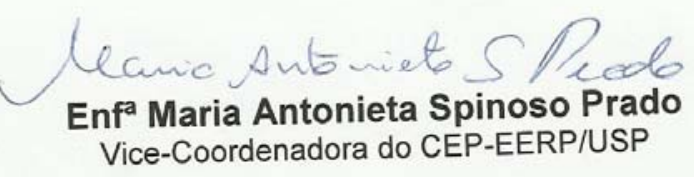

IIma. Sra.

Profa. Dr ${ }^{\mathrm{a}}$. Marysia M.R. Prado de Carlo

Departamento de Enfermagem Materno-Infantil e Saúde Pública

Escola de Enfermagem de Ribeirão Preto-USP 
Universidade de São Paulo

Escola de Enfermagem de Ribeirão Preto

Comitê de Ética em Pesquisa

Protocolo $n^{\circ}: 1263 / 201$

Entrada: 01/02/2011

Pesquisadores: Marysia M.R. Prado de Carlo e Gisele Brides Prieto

\section{Parecer}

Pela análise do material concluímos que os pesquisadores promoveram as adequaçöes solicitadas pelo CEP-EERP-USP o que pode ser comprovado pela documentação anexada ao Projeto (folhas 56 a 96).

Pelo exposto, o Comitê de Ética em Pesquisa da Escola de Enfermagem de Ribeirão Preto da Universidade de São Paulo considera o projeto Aprovado. 
ANEXO 8. ESCORE SF36

\begin{tabular}{|c|c|c|c|c|c|c|c|c|c|}
\hline Sujeito & Grupos & $\begin{array}{l}\text { Capacidade } \\
\text { funcional }\end{array}$ & $\begin{array}{l}\text { Aspecto } \\
\text { físico }\end{array}$ & Dor & $\begin{array}{c}\text { Estado geral de } \\
\text { saúde }\end{array}$ & Vitalidade & $\begin{array}{l}\text { Aspecto } \\
\text { social }\end{array}$ & $\begin{array}{c}\text { Aspecto } \\
\text { emocional }\end{array}$ & $\begin{array}{l}\text { Saúde } \\
\text { mental }\end{array}$ \\
\hline 01 & 1 & 45 & - & - & 57 & 55 & 25 & - & 56 \\
\hline 02 & 1 & 85 & 75 & 61 & 100 & 75 & 100 & 100 & 92 \\
\hline 03 & 1 & 100 & 100 & 51 & 82 & 90 & 100 & 100 & 80 \\
\hline 04 & 1 & 90 & 100 & 52 & 100 & 75 & 100 & 33,3 & 76 \\
\hline 05 & 1 & 80 & 75 & 100 & 92 & 65 & 100 & 100 & 76 \\
\hline 06 & 1 & 25 & - & 52 & 87 & 25 & - & - & 48 \\
\hline 07 & 1 & 100 & 100 & 84 & 87 & 85 & 62,5 & 100 & 92 \\
\hline 08 & 1 & 60 & 100 & 41 & 52 & 70 & 62,5 & - & 80 \\
\hline 09 & 1 & 10 & 25 & 51 & 72 & 45 & 62,5 & 33,3 & 76 \\
\hline 10 & 1 & 90 & 100 & 100 & 62 & 80 & 100 & 100 & 84 \\
\hline 11 & 1 & 95 & 100 & 100 & 97 & 90 & 75 & 33,3 & 76 \\
\hline 12 & 1 & 65 & 100 & 100 & 82 & 75 & 100 & 100 & 92 \\
\hline 13 & 2 & 75 & 100 & 100 & 67 & 50 & 37,5 & 66,7 & 76 \\
\hline 14 & 2 & 45 & 25 & 22 & 47 & 60 & 62,5 & 100 & 80 \\
\hline 15 & 2 & 95 & 100 & 100 & 100 & 100 & 100 & 100 & 96 \\
\hline 16 & 2 & 30 & 25 & 100 & 87 & 65 & - & 100 & 64 \\
\hline 17 & 2 & 60 & 100 & 72 & 82 & 75 & 100 & 100 & 72 \\
\hline 18 & 2 & 100 & 100 & 100 & 100 & 80 & 100 & 100 & 76 \\
\hline 19 & 2 & 40 & 100 & 51 & 82 & 60 & 62,5 & 100 & 68 \\
\hline 20 & 2 & 55 & 75 & 31 & 62 & 65 & 62,5 & 100 & 52 \\
\hline 21 & 2 & 45 & - & 41 & 62 & 80 & 50 & 33,3 & 80 \\
\hline 22 & 2 & 50 & 25 & 100 & 87 & 70 & 50 & 100 & 68 \\
\hline 23 & 2 & 60 & 100 & 100 & 82 & 70 & 75 & - & 44 \\
\hline 24 & 2 & 25 & - & 62 & 35 & 65 & 87,5 & 33,3 & 56 \\
\hline 25 & 2 & 60 & 100 & 74 & 57 & 65 & 87,5 & 100 & 68 \\
\hline 26 & 2 & 60 & 100 & 72 & 67 & 70 & 75 & 100 & 76 \\
\hline 27 & 2 & 10 & - & - & 55 & 10 & 25 & - & 16 \\
\hline 28 & 2 & 25 & - & 22 & 87 & 50 & 100 & - & 100 \\
\hline 29 & 3 & 95 & 100 & 62 & 67 & 40 & 75 & - & 64 \\
\hline 30 & 3 & 90 & 100 & 51 & 82 & 60 & 100 & 100 & 56 \\
\hline
\end{tabular}




\section{ESCORE SF36 (CONT)}

\begin{tabular}{|c|c|c|c|c|c|c|c|c|c|}
\hline Sujeito & Grupos & $\begin{array}{c}\text { Capacidade } \\
\text { funcional }\end{array}$ & $\begin{array}{l}\text { Aspecto } \\
\text { físico }\end{array}$ & Dor & $\begin{array}{c}\text { Estado geral de } \\
\text { saúde }\end{array}$ & Vitalidade & $\begin{array}{l}\text { Aspecto } \\
\text { social }\end{array}$ & $\begin{array}{c}\text { Aspecto } \\
\text { emocional }\end{array}$ & $\begin{array}{l}\text { Saúde } \\
\text { mental }\end{array}$ \\
\hline 31 & 3 & 90 & 100 & 41 & 62 & 30 & 87,5 & 100 & 32 \\
\hline 32 & 3 & 100 & 100 & 72 & 72 & 70 & 100 & 100 & 80 \\
\hline 33 & 3 & 95 & 100 & 74 & 67 & 50 & 100 & 100 & 68 \\
\hline 34 & 3 & 85 & 100 & 100 & 87 & 15 & 75 & 66,7 & 40 \\
\hline 35 & 3 & 95 & 100 & 100 & 100 & 80 & 100 & 100 & 72 \\
\hline 36 & 3 & 25 & 25 & 51 & 50 & 5 & 25 & - & 44 \\
\hline 37 & 3 & 40 & 75 & 41 & 20 & 35 & 100 & 100 & 52 \\
\hline 38 & 3 & 95 & 100 & 72 & 100 & 75 & 100 & 100 & 84 \\
\hline 39 & 3 & 100 & 100 & 72 & 77 & 50 & 100 & 100 & 80 \\
\hline 40 & 3 & 95 & 100 & 100 & 72 & 70 & 100 & 100 & 100 \\
\hline 41 & 3 & 90 & 100 & 100 & 77 & 65 & 100 & 100 & 76 \\
\hline 42 & 3 & 45 & 75 & 42 & 57 & 25 & 12,5 & - & 12 \\
\hline 43 & 3 & 100 & 100 & 84 & 92 & 75 & 75 & 100 & 96 \\
\hline 44 & 3 & 95 & 100 & 72 & 100 & 80 & 100 & 100 & 84 \\
\hline 45 & 3 & 100 & 100 & 100 & 92 & 40 & 50 & - & 40 \\
\hline 46 & 3 & 90 & 100 & 62 & 72 & 55 & 100 & 100 & 48 \\
\hline 47 & 3 & 85 & 100 & 61 & 77 & 70 & 100 & 100 & 80 \\
\hline 48 & 3 & 100 & 100 & 100 & 77 & 60 & 87,5 & 66,7 & 64 \\
\hline 49 & 3 & 95 & 100 & 62 & 77 & 60 & 87,5 & 100 & 64 \\
\hline 50 & 3 & 100 & 100 & 84 & 100 & 80 & 100 & 100 & 92 \\
\hline 51 & 3 & 95 & 100 & 84 & 100 & 70 & 100 & 100 & 92 \\
\hline 52 & 3 & 100 & 100 & 100 & 87 & 85 & 100 & 100 & 88 \\
\hline 53 & 3 & 100 & 100 & 100 & 82 & 55 & 100 & 100 & 72 \\
\hline 54 & 3 & 95 & - & 51 & 32 & 65 & 75 & - & 64 \\
\hline 55 & 3 & 90 & 25 & 22 & 42 & 65 & 50 & 66,7 & 68 \\
\hline 56 & 3 & 90 & 100 & 100 & 57 & 65 & 100 & 100 & 80 \\
\hline
\end{tabular}




\section{ANEXO 9. DOMÍNIOS TESS}

\begin{tabular}{|c|c|c|c|c|c|c|c|c|c|c|c|c|c|c|c|c|c|c|c|c|c|c|c|c|c|c|c|c|c|c|}
\hline $\begin{array}{l}\text { o } \\
\frac{E}{\bar{L}} \\
\bar{\zeta} \\
\text { ๘ }\end{array}$ & 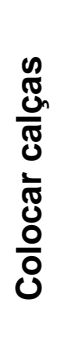 & 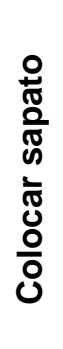 & 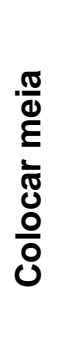 & 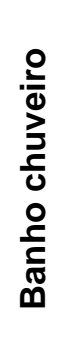 & 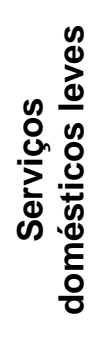 & 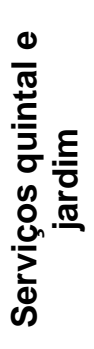 & 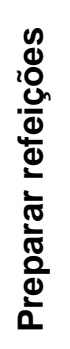 & 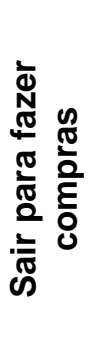 & 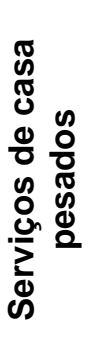 & 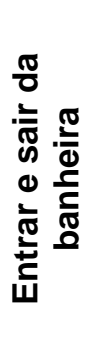 & 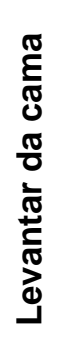 & 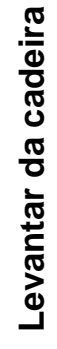 & 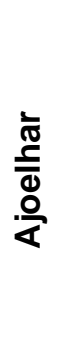 & $\begin{array}{l}\frac{1}{\pi} \\
\frac{x}{\pi} \\
\frac{0}{\alpha}\end{array}$ & 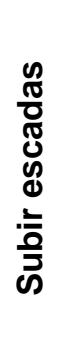 & 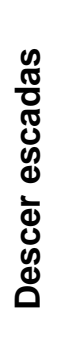 & 产 & 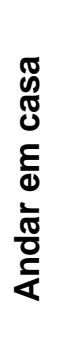 & 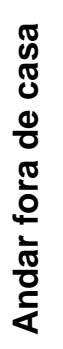 & ڤัँ & 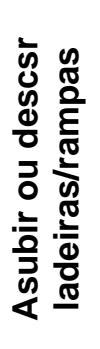 & 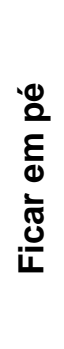 & 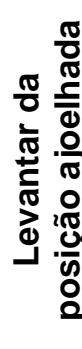 & 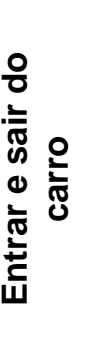 & 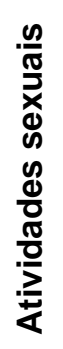 & 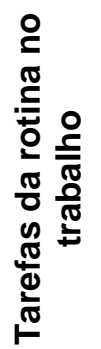 & 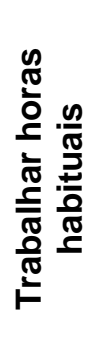 & 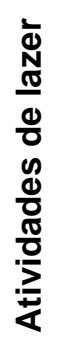 & 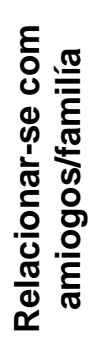 & 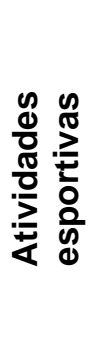 \\
\hline 01 & 4 & 3 & 3 & 4 & 2 & & 4 & 3 & 2 & & 5 & 3 & 2 & 3 & 2 & 2 & & 3 & 3 & 5 & 1 & 4 & 3 & 4 & 5 & 3 & & 4 & 4 & \\
\hline 02 & & 5 & 5 & 5 & & & & 5 & & & 3 & 5 & 3 & 5 & 5 & 4 & 5 & 5 & 5 & 5 & 5 & 5 & 3 & 5 & 5 & & & 5 & 5 & \\
\hline 03 & 5 & 5 & 5 & 5 & 5 & 5 & 5 & 5 & 5 & & 5 & 5 & 5 & 5 & 5 & 5 & & 5 & 5 & 5 & 5 & 4 & 5 & 5 & 5 & 5 & 5 & 5 & 5 & \\
\hline 04 & 5 & 5 & 5 & 5 & 5 & 5 & 5 & 5 & 5 & & 5 & 5 & 5 & 5 & 5 & 5 & 5 & 5 & 5 & 5 & 5 & 5 & 5 & 5 & 5 & 5 & 5 & 5 & 5 & 5 \\
\hline 05 & 5 & 5 & 5 & 5 & 5 & 5 & 5 & 5 & 5 & & 5 & 5 & 4 & 4 & 4 & 4 & 5 & 5 & 5 & 5 & 4 & 5 & 5 & 5 & 5 & 5 & 5 & 5 & 5 & 5 \\
\hline 06 & 3 & 4 & 2 & 4 & 4 & 5 & 5 & 1 & 1 & & 5 & 4 & 1 & 1 & 2 & 3 & & 3 & 2 & 2 & 1 & 4 & 1 & 3 & 1 & 3 & & 2 & 1 & \\
\hline 07 & 5 & 5 & 5 & 5 & 5 & 5 & 5 & 5 & 5 & & 5 & 5 & 5 & 5 & 5 & 5 & & 5 & 5 & 5 & 5 & 5 & 5 & 5 & & 5 & 5 & 5 & 5 & \\
\hline 08 & 5 & 5 & 5 & 5 & & & & 5 & & & 5 & 5 & 5 & 5 & 5 & 5 & 5 & 5 & 5 & 5 & 4 & 5 & 5 & 5 & 5 & 5 & & 5 & 5 & 5 \\
\hline 09 & 3 & 4 & 4 & 4 & 4 & 4 & 4 & 1 & 4 & & 4 & 4 & 1 & 4 & 1 & 2 & & 4 & 4 & 4 & 1 & 4 & 1 & 4 & 5 & 4 & 1 & 4 & 4 & \\
\hline 10 & 5 & 5 & 5 & 5 & 5 & 5 & 5 & 5 & 4 & & 5 & 5 & 5 & 5 & 5 & 5 & & 5 & 5 & 5 & 4 & 5 & 5 & 5 & 5 & 5 & 4 & 5 & 5 & \\
\hline 11 & 5 & 5 & 5 & 5 & 5 & 5 & 5 & 5 & 3 & & 5 & 5 & 5 & 5 & 5 & 5 & 5 & 5 & 5 & 5 & 5 & 5 & 4 & 5 & 5 & 5 & 5 & 5 & 5 & 4 \\
\hline 12 & 4 & 5 & & 3 & 5 & 5 & 5 & 5 & 4 & & 5 & 5 & 1 & 5 & 3 & 3 & 5 & 5 & 5 & 5 & 3 & 3 & & 5 & 5 & 5 & & 5 & 5 & \\
\hline 13 & 5 & 4 & 5 & 5 & & & 5 & 5 & & & 5 & 5 & 1 & 4 & 4 & 5 & & 5 & 5 & 5 & 4 & 5 & & 5 & & 5 & & 5 & 5 & \\
\hline 14 & 4 & 4 & 3 & 4 & 4 & 4 & 4 & 4 & 1 & & 4 & 4 & 2 & 3 & 2 & 2 & 3 & 4 & 3 & 4 & 2 & 2 & 2 & 3 & 4 & 4 & & 3 & 5 & \\
\hline 15 & 5 & 5 & 5 & 5 & 5 & 5 & 5 & 5 & 5 & & 5 & 5 & 4 & 5 & 5 & 5 & 5 & 5 & 5 & 5 & 5 & 5 & 5 & 5 & 5 & 5 & 5 & 5 & 5 & 5 \\
\hline
\end{tabular}




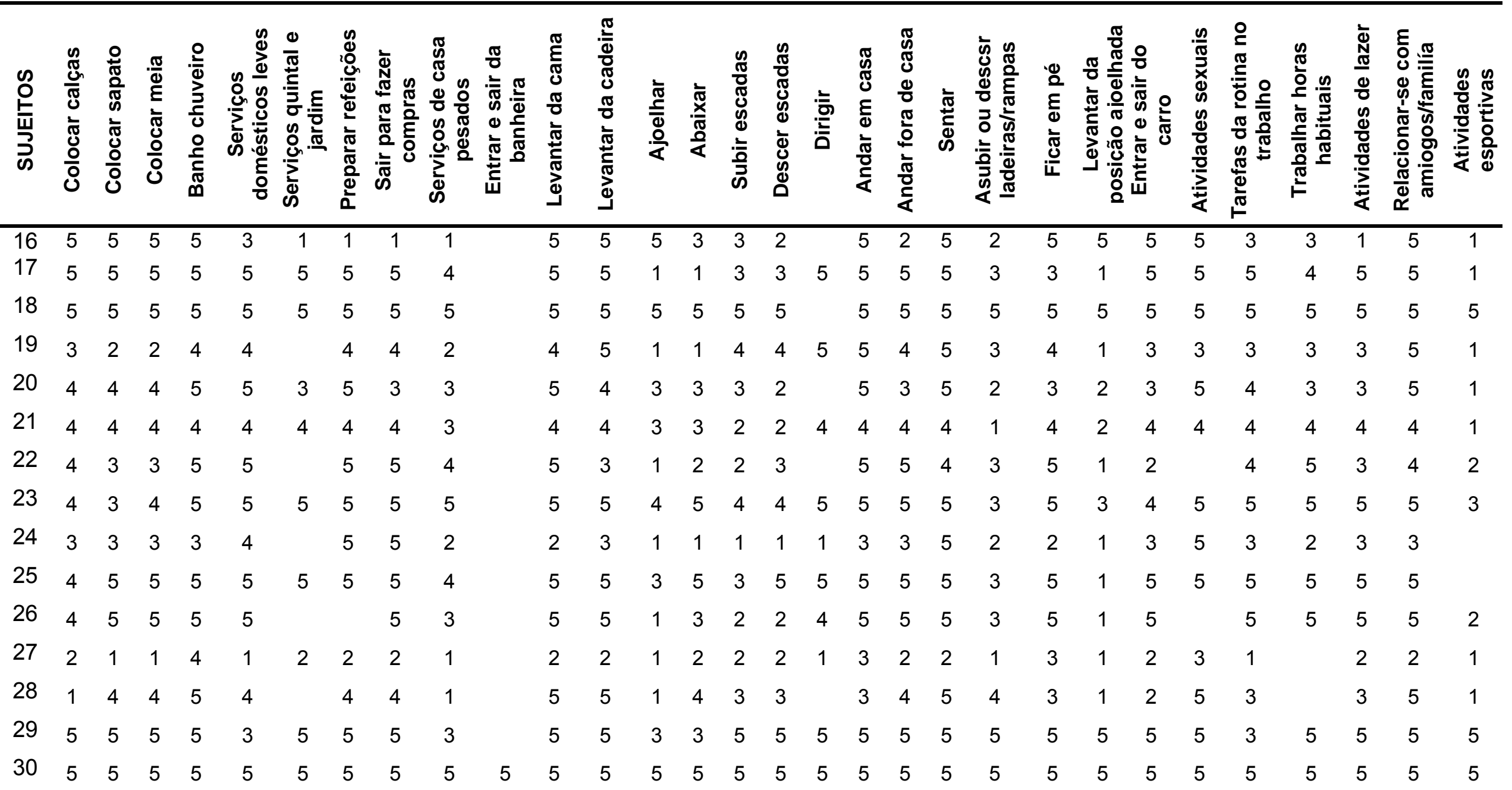




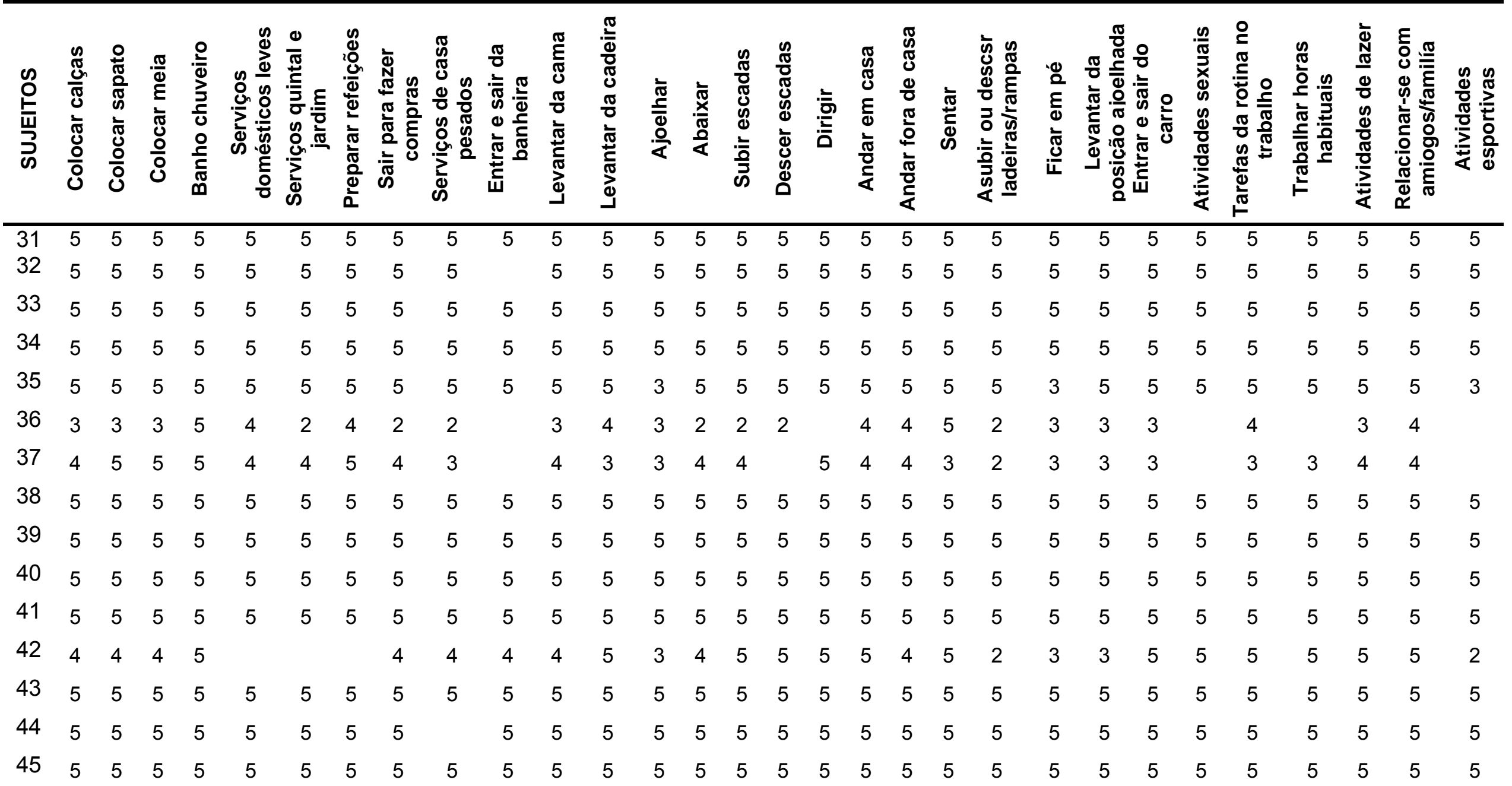




\section{DOMÍNIOS TESS (CONT)}

\begin{tabular}{|c|c|c|c|c|c|c|c|c|c|c|c|c|c|c|c|c|c|c|c|c|c|c|c|c|c|c|c|c|c|c|}
\hline 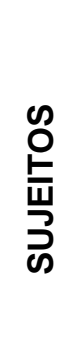 & 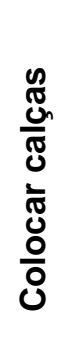 & 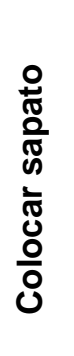 & $\begin{array}{l}\frac{\pi}{\Phi} \\
\stackrel{\sigma}{\Xi} \\
\frac{\pi}{0} \\
\frac{0}{0} \\
0\end{array}$ & 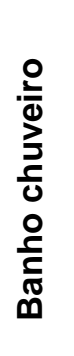 & 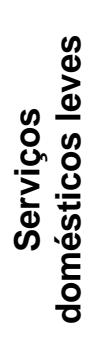 & 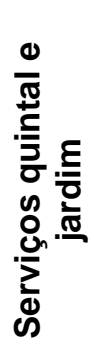 & 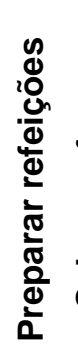 & 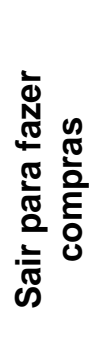 & 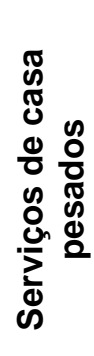 & 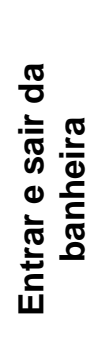 & 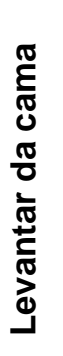 & 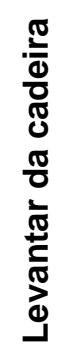 & $\begin{array}{l}\text { ప } \\
\overline{\bar{d}} \\
\frac{0}{\sigma}\end{array}$ & 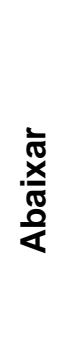 & 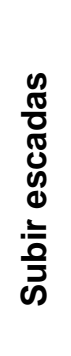 & 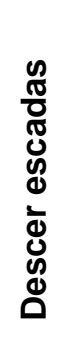 & 言 & 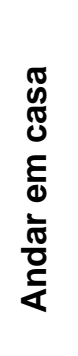 & 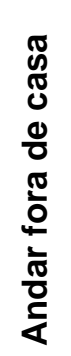 & ஸे & 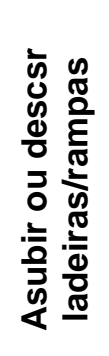 & 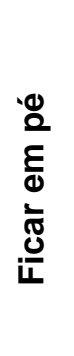 & 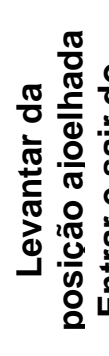 & 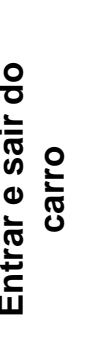 & 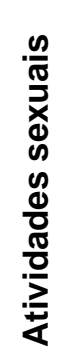 & 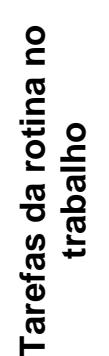 & 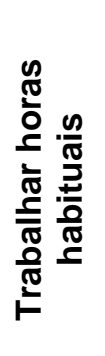 & 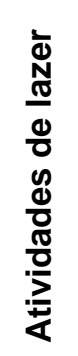 & 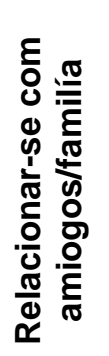 & 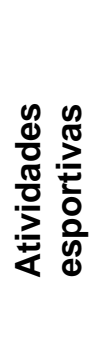 \\
\hline 46 & 5 & 5 & 5 & 5 & 5 & 5 & 5 & 5 & 5 & 5 & 5 & 5 & 5 & 5 & 4 & 5 & 5 & 5 & 5 & 5 & 5 & 5 & 5 & 5 & 5 & 5 & 5 & 5 & 5 & 5 \\
\hline 47 & 5 & 5 & 5 & 5 & 5 & 5 & 5 & 5 & 5 & 5 & 5 & 5 & 5 & 5 & 5 & 5 & 5 & 5 & 5 & 5 & 5 & 5 & 5 & 5 & 5 & 5 & 5 & 5 & 5 & 5 \\
\hline 48 & 5 & 5 & 5 & 5 & 5 & 5 & 5 & 5 & 5 & 5 & 5 & 5 & 5 & 5 & 5 & 5 & 5 & 5 & 5 & 5 & 5 & 5 & 5 & 5 & 5 & 5 & 5 & 5 & 5 & 5 \\
\hline 49 & 5 & 5 & 5 & 5 & 5 & 5 & 5 & 5 & 5 & 5 & 5 & 5 & 5 & 5 & 5 & 5 & 5 & 5 & 5 & 5 & 5 & 5 & 5 & 5 & 5 & 5 & 5 & 5 & 5 & 5 \\
\hline 50 & 5 & 5 & 5 & 5 & 5 & 5 & 5 & 5 & 5 & 5 & 5 & 5 & 5 & 5 & 5 & 5 & 5 & 5 & 5 & 5 & 5 & 5 & 5 & 5 & 5 & 5 & 5 & 5 & 5 & 5 \\
\hline 51 & 5 & 5 & 5 & 5 & 5 & 5 & 5 & 5 & 5 & 5 & 5 & 5 & 5 & 5 & 5 & 5 & 5 & 5 & 5 & 5 & 5 & 5 & 5 & 5 & 5 & 5 & 5 & 5 & 5 & 5 \\
\hline 52 & 5 & 5 & 5 & 5 & 5 & 5 & 5 & 5 & 5 & 5 & 5 & 5 & 5 & 5 & 5 & 5 & 5 & 5 & 5 & 5 & 5 & 5 & 5 & 5 & 5 & 5 & 5 & 5 & 5 & 5 \\
\hline 53 & 5 & 5 & 5 & 5 & 5 & 5 & 5 & 5 & 5 & 5 & 5 & 5 & 5 & 5 & 5 & 5 & 5 & 5 & 5 & 5 & 5 & 5 & 5 & 5 & 5 & 5 & 5 & 5 & 5 & 5 \\
\hline 54 & 5 & 5 & 5 & 5 & 5 & 5 & 5 & 5 & 5 & 5 & 5 & 5 & 5 & 5 & 5 & 5 & 5 & 5 & 5 & 5 & 5 & 5 & 5 & 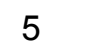 & 5 & 5 & 5 & 5 & 5 & 5 \\
\hline 55 & 5 & 5 & 5 & 5 & 5 & 5 & 5 & 5 & 5 & 5 & 5 & 5 & 5 & 5 & 5 & 5 & 5 & 5 & 5 & 5 & 5 & 5 & 5 & 5 & 5 & 5 & 5 & 5 & 5 & 5 \\
\hline 56 & 5 & 5 & 5 & 5 & 5 & & 5 & 5 & & 5 & 5 & 5 & 5 & 5 & 5 & 5 & & 5 & 5 & 5 & 5 & 5 & 5 & 5 & & 5 & 5 & 5 & 5 & 5 \\
\hline
\end{tabular}


ANEXO 10. ESCORE TESS

\begin{tabular}{|c|c|c|c|c|}
\hline Sujeitos & Grupos & Total answer & Range & Final escore \\
\hline 01 & 1 & 25 & 100 & 56 \\
\hline 02 & 1 & 21 & 84 & 91,67 \\
\hline 03 & 1 & 27 & 108 & 99,07 \\
\hline 04 & 1 & 29 & 116 & 100 \\
\hline 05 & 1 & 29 & 116 & 95,69 \\
\hline 06 & 1 & 26 & 104 & 40,38 \\
\hline 07 & 1 & 26 & 104 & 100 \\
\hline 08 & 1 & 24 & 96 & 98,96 \\
\hline 09 & 1 & 27 & 108 & 56,48 \\
\hline 10 & 1 & 27 & 108 & 97,22 \\
\hline 11 & 1 & 29 & 116 & 96,55 \\
\hline 12 & 1 & 25 & 100 & 84 \\
\hline 13 & 2 & 21 & 84 & 90,48 \\
\hline 14 & 2 & 27 & 108 & 56,48 \\
\hline 15 & 2 & 29 & 116 & 99,14 \\
\hline 16 & 2 & 28 & 112 & 61,61 \\
\hline 17 & 2 & 29 & 116 & 77,59 \\
\hline 18 & 2 & 28 & 112 & 100 \\
\hline 19 & 2 & 28 & 112 & 57,14 \\
\hline 20 & 2 & 28 & 112 & 64,29 \\
\hline 21 & 2 & 29 & 116 & 62,07 \\
\hline 22 & 2 & 26 & 104 & 64,42 \\
\hline 23 & 2 & 29 & 116 & 87,93 \\
\hline 24 & 2 & 27 & 108 & 42,59 \\
\hline 25 & 2 & 28 & 112 & 89,29 \\
\hline 26 & 2 & 26 & 104 & 75,96 \\
\hline 27 & 2 & 28 & 112 & 20,54 \\
\hline 28 & 2 & 26 & 104 & 58,65 \\
\hline 29 & 3 & 29 & 116 & 91,38 \\
\hline 30 & 3 & 30 & 120 & 100 \\
\hline 31 & 3 & 30 & 120 & 100 \\
\hline 32 & 3 & 29 & 116 & 100 \\
\hline 33 & 3 & 30 & 120 & 100 \\
\hline 34 & 3 & 30 & 120 & 100 \\
\hline 35 & 3 & 30 & 120 & 95 \\
\hline 36 & 3 & 25 & 100 & 54 \\
\hline 37 & 3 & 26 & 104 & 69,23 \\
\hline 38 & 3 & 30 & 120 & 100 \\
\hline 39 & 3 & 30 & 120 & 100 \\
\hline
\end{tabular}


ESCORE TESS (Cont)

\begin{tabular}{ccccc}
\hline Sujeitos & grupos & Total answer & Range & Final escore \\
\hline 40 & 3 & 30 & 120 & 100 \\
41 & 3 & 30 & 120 & 100 \\
42 & 3 & 27 & 108 & 80,56 \\
43 & 3 & 30 & 120 & 100 \\
44 & 3 & 29 & 116 & 100 \\
45 & 3 & 30 & 120 & 100 \\
46 & 3 & 30 & 120 & 99,17 \\
47 & 3 & 30 & 120 & 100 \\
48 & 3 & 30 & 120 & 100 \\
49 & 3 & 30 & 120 & 100 \\
50 & 3 & 30 & 120 & 100 \\
51 & 3 & 30 & 120 & 100 \\
52 & 3 & 30 & 120 & 100 \\
53 & 3 & 30 & 120 & 100 \\
54 & 3 & 30 & 120 & 100 \\
55 & 3 & 30 & 120 & 100 \\
56 & 3 & 26 & 104 & 100 \\
\hline
\end{tabular}

